\title{
Sistema JAVA para gerenciamento de esquema CADx em mamografia
}

\author{
Tese apresentada a Escola de \\ Engenharia de São Carlos da \\ Universidade de São Paulo para \\ obtenção de título de Doutor em \\ Ciências, Programa de Engenharia \\ Elétrica
}
Área de concentração:
Processamento de Sinais e
Instrumentação

Orientador: Prof. Dr. Homero

Schiabel

São Carlos

2015

Trata-se da versão corrigida da tese. A versão original se encontra disponível na EESC/USP que aloja o Programa de Pós-Graduação de engenharia Elétrica 
AUTORIZO A REPRODUÇÃO TOTAL OU PARCIAL DESTE TRABALHO, POR QUALQUER MEIO CONVENCIONAL OU ELETRÔNICO, PARA FINS DE ESTUDO E PESQUISA, DESDE QUE CITADA A FONTE.

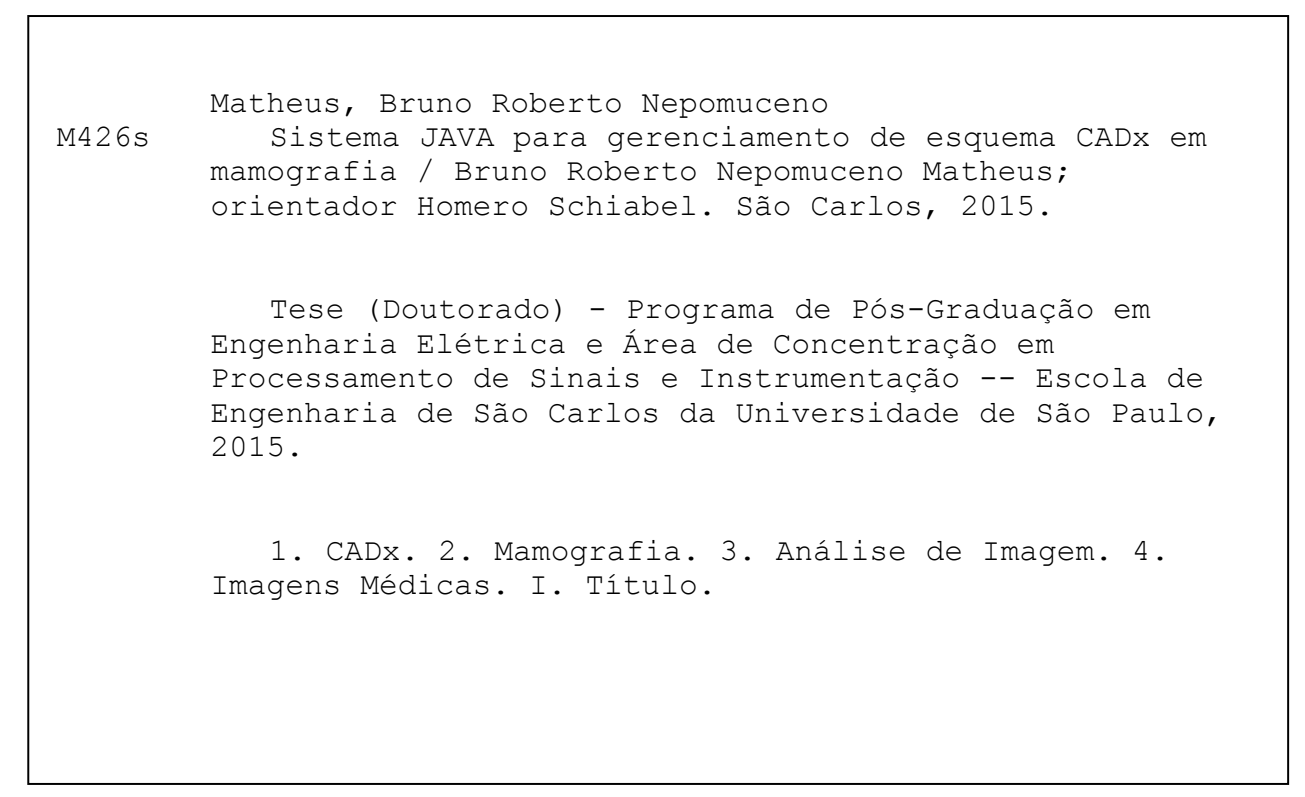


FOLHA DE JULGAMENTO

Candidato: Bacharel BRUNO ROBERTO NEPOMUCENO MATHEUS.

Título da tese: "Sistema JAVA para gerenciamento de esquema CADx em mamografia".

Data da defesa: 17/09/2015

Comissão Julgadora:

Prof. Associado Homero Schiabel (Orientador)

(Escola de Engenharia de São Carlos/EESC)

Prof. Dr. Leonardo Vidal Batista

(Universidade Federal da Paraíba/UFPB)

Prof. Dr. Marco Antônio Gutierrez

(Instituto do Coração/INCOR)

Profa. Dra. Regina Bitelli Medeiros

(Universidade Federal de São Paulo/UNIFESP)

Prof. Associado Antônio Adilton Oliveira Carneiro

(Faculdade de Filosofia, Ciências e Letras de Ribeirão Preto/FFCLRP-USP)
Resultado:

APROVADO

APROVADO

APROVADO

APRDUADO
Priversidade Federal de Sä Paulo/UNIESP)

Coordenador do Programa de Pós-Graduação em Engenharia Elétrica:

Prof. Associado Luis Fernando Costa Alberto

Presidente da Comissão de Pós-Graduação:

Prof. Associado Paulo César Lima Segantine 

À minha amada Gi, por me indicar o caminho, me acalmar e me aguentar.

Aos meus pais, por me fazer quem eu sou, me apoiar e sempre me incentivar.

E ao meu irmão, por me irritar, me guiar e sempre ser meu exemplo, mesmo quando longe.

Eu não teria chegado aqui sem vocês. 



\section{Agradecimentos}

Ao Prof. Dr. Homero Schiabel, pelo auxilio, direção e paciência durante a orientação deste doutorado, culminando uma década de pesquisa juntos.

A Prof. Dra. Simone Elias e Dra. Luciana Verçosa, por tentar me fazer entender como um radiologista enxerga e quão difícil seria reproduzir isso usando um computador.

Aos membros do LAPIMO (atuais e antigos), pelas sugestões e auxilio sempre que precisei.

Ao Departamento de Engenharia Elétrica da Escola de Engenharia de São Carlos, pela oportunidade de realização deste doutorado.

À FAPESP (Fundação de Amparo à Pesquisa do estado de São Paulo), pela concessão da bolsa de doutorado e auxílio financeiro para realização desta pesquisa. 



\section{Resumo}

Matheus, B., Sistema JAVA para gerenciamento de esquema CADx em mamografia. 2015. 147 f. Tese (Doutorado) - Escola de Engenharia de São Carlos, Universidade de São Paulo, São Carlos, 2015.

Estudos mostram que a maior parte dos erros de diagnóstico mamográfico estão ligados a dificuldades de classificação e não de detecção (MEYER, EBERLEIN, et al., 1990; KARSSEMEIJER, 2011; SCHIABEL, 2014). Uma possível solução a este problema é a estruturação de um esquema CADx (Computer-aided Diagnosis), ou seja, um sistema computacional que analisa as informações disponíveis e tenta apresentar um diagnóstico com base nos dados fornecidos pela imagem processada.

Este trabalho tem como intuito apresentar um esquema CADe/Dx completo e funcional para uso por radiologistas. $\mathrm{O}$ software final poderá ser usado em qualquer sistema operacional, ou mesmo via Internet, permitindo que qualquer médico interessado acesse e utilize o sistema como segunda opinião sem restrições. A formação da biblioteca JAVA também visa a permitir que outros desenvolvedores possam fazer uso das ferramentas desenvolvidas em projetos futuros, facilitando ampliações e melhorias no esquema CADx.

Vários módulos de processamento previamente desenvolvidos para o protótipo do esquema CADx-LAPIMO tiveram que ser reconstruídos, e outros elaborados completamente, produzindo novos resultados que são analisados neste trabalho, assim como suas vantagens e limitações. Estes módulos estão divididos em duas partes: o préprocessamento, que inclui a correção baseada na curva característica do digitalizador (técnica BCC), amplamente testada neste trabalho, e o processamento propriamente, incluindo detecção de microcalcificações e detecção e classificação de nódulos.

O programa CADx desenvolvido neste trabalho foi separado em duas versões (cada uma com uma versão online correspondente): um é o esquema CADe/Dx que envolve tanto a detecção como a classificação da estrutura encontrada e o outro é um 
esquema CADx semiautomático, cujas regiões que devem ser classificadas são previamente demarcadas pelo usuário.

Os principais resultados obtidos neste trabalho estão associados ao detector de microcalcificações e ao classificador de nódulos. Para o detector de microcalcificações atingiu-se $89 \%$ de sensibilidade com 1,4 falso-positivo por imagem quando usado em imagens digitais de sistemas FFDM e 99\% de sensibilidade com 5,4 falsos-positivos quando usado em imagens digitalizadas de mamas densas . Já o classificador de nódulos apresentou $72 \%$ de acurácia, usando apenas 4 atributos associados a contorno, densidade e textura, resultando em um sistema robusto e de fácil treinamento.

Palavras-chaves: CADx, Mamografia, Análise de Imagem, Imagens Médicas 


\section{Abstract}

Matheus, B., JAVA system for mammographic CADx managing, 2015. 147 p. Thesis (Doctorate) - Escola de Engenharia de São Carlos, Universidade de São Paulo, São Carlos, 2015.

Studies show that most diagnostic errors are linked to classification difficulties and not detection (MEYER, EBERLEIN, et al., 1990; KARSSEMEIJER, 2011; SCHIABEL, 2014). A possible solution for this problem is the construction of a CAD (Computer aided Diagnosis), a computational system that analyses the available information e tries to present a diagnosis based on the data offered by the processed image.

This thesis presents a complete and functional mammographic CADe/Dx scheme for radiologist use. The software is designed to function in any operational system, or even online, allowing any interested radiologist to access the software as a second opinion. The formation of a JAVA library also allows any future developers can use all tools developed for this system, easing future improvements in the CADx scheme.

Several modules of the scheme previously developed for the CADx-LAPIMO prototype had to be rebuilt or completely developed, generating new results that are analyzed in here, as are their advantages and limitations. Those modules are divided in two parts, the preprocessing, that includes the scanner's characteristic curve based correction, detailed tested in this thesis and the processing itself, including detection of microcalcifications, and detections and classification of masses.

The CADx scheme developed here was separated in two versions (each one with a corresponding online version): one is a $\mathrm{CADe} / \mathrm{Dx}$ scheme that involves both detection and classification of the found structures and the other is a CADx semi-automatic scheme, where the classified regions are previously marked by the user.

The main results obtained in this thesis are associated with the microcalcifications detector and the mass classification. The microcalcifications detector obtained a $89 \%$ 
sensibility with 1,4 false-positives per image when used in digital FFDM systems and $99 \%$ sensibility with 5,4 false-positives per image in digitalized images of dense breasts. The mass classification module presented a $72 \%$ accuracy, using only 4 attributes associated to contour, density and texture, resulting in a robust system and of easy training.

Key-words: CADx, Mammography, Image Analysis, Medical Images 


\section{Lista de Siglas}

BancoWeb: Base de imagens do Laboratório LAPIMO/EESC-USP

BCC: Baseada na Curva Característica

BI-RADS: Breast Imaging-Reporting and Data System (Sistema de laudo e informação de imagens de mama)

CAD: Computer Aided Diagnostics (Diagnóstico Auxiliado por Computador) (obsoleto)

CADe: Computer Aided Detection (Detecção Auxiliada por Computador)

CADx: Computer Aided Diagnosis (Diagnóstico Auxiliado por Computador)

CR: Computed Radiography (Radiologia computadorizada)

DDSM: Digital Database for Screening Mammography

DICOM: Digital Imaging and Communications in Medicine

ECM: Exame Clínico de Mama

EICAMM: Enhanced ICA Mixture Model (ICAMM Melhorado)

FAPESP: Fundação de Amparo à Pesquisa do Estado de São Paulo

FDA: Food and Drug Administration

FFDM: Full field digital mammography (Mamografia digital de campo completo)

FROC: Free-response Receiver Operating Characteristic (Característica de Operação do Receptor com Resposta Livre)

ICA: Independent Component Analysis (Análise de Componentes Independentes)

ICAMM: ICA Mixture Model (Modelo de Mistura ICA)

INBreast: Banco de imagens do Breast Centre em Porto, Portugal 
JVM: Java Virtual Machine (Máquina Virtual JAVA)

LAPIMO: Laboratório de Análise e Processamento de Imagens Médicas e Odontologicas

LJPEG: Lossless Joint Photographic Experts Group

PACS: Picture Archiving and Communication System

QCT: Quantitative Computed Tomography

RI: Região de Interesse

ROC: Receiver Operating Characteristic (Característica de Operação do Receptor)

SVM: Support Vector Machines

TIFF: Tagged Image File Format

WORA: Write Once, Run Anywhere (Escreva uma vez, rode em qualquer lugar) 


\section{Sumário}

Capítulo 1 Introdução

1.1 Câncer de mama 15

1.2 Detecção e diagnóstico de câncer de mama 15

1.3 CADe/Dx 17

1.4 Objetivos 18

1.5 Disposição do trabalho 19

Capítulo 2 CAD mamográfico 21

2.1 Desenvolvimento de esquemas CAD mamográficos 21

2.2 Consequências do uso de esquemas CAD na análise mamográfica 23

2.3 Avaliação de CAD 24

2.4 Curvas ROC 26

Capítulo 3 Formatos de imagens, bases de dados e linguagem 29

3.1 Formatos de imagem 29

3.2 Bases de imagens 31

3.2.1 BancoWeb/LAPIMO (MATHEUS e SCHIABEL, 2011) 31

3.2.2 DDSM (HEATH, BOWYER, et al., 2001) 32

3.2.3 INBreast (MOREIRA, AMARAL, et al., 2012) 32

3.3 JAVA ${ }^{\circledR}$ 33

3.3.1 Image $J^{\circledR}$ (RASBAND, 2011; COLLINS, 2007) 35

Capítulo 4 Métodos para CAD desenvolvidos no LAPIMO 37

4.1 Correção BCC (GOES, 2010) 37

4.2 Segmentação de mama por (MENECHELLI, 2013) 40

4.3 Segmentação do músculo peitoral (MENECHELLI, 2013) 41

4.4 Classificação de densidade (MENECHELLI, 2013) 43

4.5 Detector de Assimetrias locais (SCHIABEL e MENECHELLI, 2013) 45

4.6 Detecção de nódulos (BARBOSA FILHO, 2012) 47

4.7 Segmentador e Classificador de Nódulos (RIBEIRO, 2013) 49

4.7.1 Segmentação EICAMM 50

4.7.2 Classificação de Nódulos 50

4.8 Transformação área-ponto (NISHIKAWA, GIGER, et al., 1993) 53 
4.9 Detector de nódulos no músculo peitoral

Capítulo 5 Materiais e métodos: CADe/Dx Completo

5.1 CADX LAPIMO

5.2 Engenharia de Software

5.3 Modelo Final 59

5.3.1 Abertura da imagem

5.3.2 Pré-processamento

5.3.3 Processamento

5.3.5 Limitações do sistema

Capítulo 6 Materiais e Métodos: CADx Guiado 81

6.1 Esquema CADx Guiado: Versão Simplificada com ênfase na interpretação dos sinais

6.2 Pré-processamento __ 82

6.3 Interface 83

6.4 Segmentação _ 84

6.5 Classificação _ 85

6.6 Apresentação dos resultados___ 86

6.7 Avaliação do CADx Guiado___ 88

Capítulo 7 Resultados e Discussão______________________

7.1 Correção BCC (GOES, 2010) ___ 90

7.1.1 Influencia na Detecção de Nódulos___ 99

7.2 Detector de calcificações (MATHEUS, FERRO NETO e SCHIABEL, 2013)

7.3 Segmentação de nódulos 106

7.4 Classificação de nódulos 109

7.4.1 Efeito da classificação de contornos na opinião de radiologistas experientes _ 109

7.4.2 Efeito da classificação geral na opinião de radiologistas experientes _ 112

7.4.3 Avaliação e validação do método de classificação final 114

7.4.4 Avaliação do método de segmentação de nódulos sob a óptica da classificação 122

7.5 Comparação do módulo classificador com a literatura 123

7.6 Tempo de Processamento 127

7.7 CADx Guiado 129

7.8 CADx Web 131

Capítulo 8 Conclusão 133

8.1 Desenvolvimentos futuros 137 


\section{Capítulo 1 Introdução}

\subsection{Câncer de mama}

Segundo estatísticas do INCA (INSTITUTO NACIONAL DO CÂNCER, 2014) o câncer de mama é o segundo câncer mais comum no mundo. Em mulheres ele corresponde a $22 \%$ dos casos diagnosticados de câncer a cada ano, o que corresponde, em 2014, a 57.120 novos casos apenas no Brasil.

Se corretamente diagnosticado e tratado em seus estágios iniciais o prognóstico é relativamente bom. Infelizmente a taxa de mortalidade ainda é alta, muito provavelmente porque a doença é frequentemente diagnosticada em seus estágios mais avançados. $\mathrm{Na}$ população mundial a taxa de sobrevivência após 5 anos é de 61\% (INSTITUTO NACIONAL DO CÂNCER, 2014).

Normalmente o câncer de mama é encontrado em mulheres com mais de 35 anos, apesar de raros casos acontecerem antes. A probabilidade aumenta rapidamente com o aumento da idade. Assim como várias outras formas de câncer, não existem métodos de prevenção para o câncer de mama, apenas rastreio com vistas a detecção precoce. Por conta disso é recomendado que todas as mulheres acima de 35 anos realizem exames periódicos de mama.

\subsection{Detecção e diagnóstico de câncer de mama}

O rastreio do câncer de mama pode ser feito, de modo eficaz, por dois métodos: o exame clínico de mama (ECM) e a mamografia. Outras técnicas podem ser usadas para detecção e diagnóstico, incluindo ultrassom, tomografia e ressonância magnética, mas seu uso em larga escala é impraticável por custos ou difículdades técnicas.

O ECM exige apenas um médico ou enfermeira treinados, podendo detectar tumores de até $1,0 \mathrm{~cm}$, se superficial. As limitações deste método em geral resultam em 
detecções tardias. Por isso, a mamografia é considerada, até o momento, o melhor método para detecção precoce e diagnóstico de câncer de mama, sendo, quando propriamente realizada, capaz de detectar em fases iniciais lesões menores que um milímetro.

O exame mamográfico, ao contrário do ECM, exige um equipamento apropriado, o mamógrafo, que é um aparelho de raios X com o campo mais restrito e uma maior sensibilidade para detecção de objetos pequenos. Como este exame tem foco na detecção e avaliação de lesões extremamente pequenas, é muito importante que todo o processo de aquisição da imagem seja feito com grande cuidado e atenção. Isto inclui manutenção e calibração dos mamógrafos e qualificação de técnicos especializados para realização do exame.

Cada exame mamográfico é composto geralmente por 4 imagens (uma crâniocaudal e uma médio-lateral, para cada mama). Isto quer dizer que cada exame realizado exige que o radiologista avalie, ao menos, 4 imagens.

Estudos indicam que entre 10 e 15\% das mamografias são erroneamente avaliadas, podendo resultar em biópsias desnecessárias, ou até mesmo, atrasar o tratamento do câncer (PEIXOTO, CANELLA e AZEVEDO, 2007). O ultrassom é frequentemente utilizado para confirmação no caso de uma detecção positiva no exame mamográfico. Normalmente seu uso consegue esclarecer dúvidas e reduz consideravelmente o risco de biópsias desnecessárias, mas a imagem proveniente do ultrassom de mama é ruidosa e de difícil interpretação sem o exame mamográfico como guia para o radiologista. Por conta disso o ultrassom, apesar de ser um exame que não envolve radiação ionizante ou outros riscos, não pode ser usado como exame de rastreio.

Já sistemas mais avançados, como tomografia e ressonância magnética, têm custos muito altos para uso como rastreio em larga escala. Recentemente, um sistema intermediário entre a tomografia e a mamografia foi desenvolvido, chamado tomossíntese, que permite a visualização das estruturas da mama em 3D. No entanto, ainda é um equipamento de alto custo e não é usado em larga escala, em particular no Brasil onde tais equipamentos ainda não estão disponíveis. 


\subsection{CADe/Dx}

Estudos mostram que a maior parte dos erros de diagnóstico mamográfico estão ligados a dificuldades de classificação e não de detecção (MEYER, EBERLEIN, et al., 1990; KARSSEMEIJER, 2011; SCHIABEL, 2014). O uso de uma segunda opinião parece aliviar parcialmente esse problema.

Além disso, testes demonstram que o uso de uma segunda opinião não só reduz os erros, mas também melhora consideravelmente os resultados da análise mamográfica (GEORGIAN-SMITH, MOORE e HALPERN, 2007), tanto em termos de sensibilidade quanto especificidade. No entanto, a falta de profissionais treinados impede esta opção de ser utilizada em muitos dos hospitais e clínicas, além de aumentar o tempo total de análise por imagem.

Uma possível solução a este problema é a estruturação de um esquema CAD (Computer-aided Detection), que corresponde a um programa de auxílio ao diagnóstico, ou seja, um sistema computacional que analisa as informações disponíveis e tenta apresentar um diagnóstico com base nos dados fornecidos pela imagem processada. No caso da mamografia, usualmente o sistema analisa as imagens resultantes do exame e fornece marcações com regiões de interesse para o médico, informando quais achados são prováveis em cada região (BRZAKOVIC, LUO e BRZAKOVIC, 1990; GIGER, CHAN e BOONE, 2008).

Os esquemas CAD atuais ainda não se equiparam a um radiologista experiente, mas estudos mostram que um bom esquema CAD no lugar da segunda opinião gera resultados muito próximos a um segundo profissional (GEORGIAN-SMITH, MOORE e HALPERN, 2007).

Atualmente vem-se tornando comum o uso dos termos CADe (Computer aided detection - Detecção auxiliada por computador) e CADx (Computer aided diagnosis Diagnóstico auxiliado por computador) para diferenciar duas formas de lidar com CAD:

- Esquemas CADe auxiliam o radiologista na detecção de estruturas de interesse, chamando a atenção do especialista para regiões que podem conter alguma característica indicativa de câncer. Estes 
esquemas não estabelecem classificação das estruturas encontradas, no máximo dividindo as regiões entre calcificações, nódulos e áreas de densidade anormal.

- $\quad$ Esquemas CADx são uma junção dos esquemas CADe com um sistema de classificação de achados, tentando indicar o risco de que a estrutura detectada seja um câncer. A classificação varia com o tipo de estrutura detectada, podendo ser uma classificação de nódulos (avaliando contorno, textura, formato, etc.), calcificações (avaliando formato, tipo de agrupamento, etc.), entre outros. Idealmente, um esquema CADx seria capaz de detectar todos os achados possíveis de uma mamografia e classificá-los de modo a gerar uma avaliação completa do caso.

A FDA (Food and Drug Administration, EUA) até o momento autorizou apenas o uso de sistemas CADe em auxílio ao diagnóstico clínico. Por conta disso, nenhum sistema CADx ainda foi comercializado para uso clínico.

\subsection{Objetivos}

Este trabalho é o resultado do desenvolvimento cumulativo de mais de uma década de pesquisa do LAPIMO (http://lapimo.sel.eesc.usp.br/) com o intuito de desenvolver um esquema CADelDx para exame mamográficos.

Ao longo dos anos, vários projetos, incluindo mestrados e doutorados, desenvolveram técnicas para melhoramento, detecção e classificação em imagens mamográficas. Cada um destes projetos foi desenvolvido praticamente isolado dos outros, gerando resultados e, ao final, softwares independentes.

Por isso, um objetivo fundamental deste trabalho é unificar os diferentes métodos e softwares em um único esquema CADx coerente, capaz de realizar análises clínicas e auxiliar radiologistas no diagnóstico precoce de câncer de mama.

Além disso, a análise dos códigos já existentes proporciona uma oportunidade rara de atualização e conversão dos códigos para uma linguagem única, no caso JAVA, 
permitindo que futuros projetos possam facilmente fazer uso dos desenvolvimentos anteriores e funcionando como uma biblioteca para a utilização e aplicação do esquema de processamento, o que corresponde a outro objetivo decorrente da proposta acima especificada.

O terceiro objetivo deste trabalho é aproveitar a versatilidade da linguagem JAVA para desenvolver uma versão on-line do esquema CADx, ou seja, uma página na Internet para a qual imagens mamográficas possam ser enviadas para processamento e os resultados transmitidos ao usuário. Uma grande vantagem desta versão é a disponibilidade mundial independente de sistemas operacionais e da capacidade de processamento do computador do usuário.

Em resumo, este trabalho tem como intuito produzir um esquema $\mathrm{CADe} / \mathrm{Dx}$ completo e funcional para uso por radiologistas. O software final poderá ser usado em qualquer sistema operacional, ou mesmo via Internet, permitindo que qualquer médico interessado acesse e utilize o sistema como segunda opinião sem restrições. A formação da biblioteca JAVA também visa a permitir que outros desenvolvedores possam fazer uso das ferramentas desenvolvidas em projetos futuros, facilitando ampliações e melhorias no esquema CADx.

\subsection{Disposição do trabalho}

Além deste capítulo de introdução, este trabalho divide-se em 6 outros capítulos:

Capítulos 2 e 3: apresentam revisões bibliográficas sobre CAD mamográfico e as estruturas computacionais utilizadas.

Capítulo 4: apresenta uma descrição detalhada dos trabalhos desenvolvidos anteriormente no LAPIMO em sua forma original.

Capítulo 5: apresenta a metodologia do trabalho relaciona ao esquema CADe/Dx completo, incluindo a motivação, os detalhes de sua implementação e os limites do sistema. 
Capítulo 6: apresenta a metodologia associada ao esquema CADx Guiado, uma versão simplificada derivada diretamente do CADe/Dx completo, que direciona a análise apenas as regiões selecionadas pelo radiologista.

Capítulo 7: apresenta os resultados do projeto e, quando pertinente, comparações com a literatura.

Capítulo 8: apresenta a conclusão do trabalho e futuros desenvolvimentos. 


\section{Capítulo 2 CAD mamográfico}

\subsection{Desenvolvimento de esquemas CAD mamográficos}

Em mamografia é extremamente importante localizar e diagnosticar estruturas suspeitas precocemente, pois, como as causas do câncer de mama não são ainda compreendidas, a única forma de reduzir as consequências e aumentar a taxa de sobrevivência é o diagnóstico precoce (ANDERSON, YIP, et al., 2008).

No entanto as estruturas indicativas de câncer são muito próximas das estruturas naturais de uma mama saudável, em termos de absorção de raios-X e contraste na imagem mamográfica. Este problema se torna particularmente complexo em estruturas muito pequenas, como microcalcificações, que podem ser menores que $0,5 \mathrm{~mm}$. Ao lidar com estruturas tão pequenas, mesmo uma minuciosa avaliação da imagem pode não ser suficiente para encontrá-las (GIGER, 2004).

Para facilitar a detecção de estruturas, Winsberg (WINSBERG, ELKIN, et al., 1967) utilizou computadores há mais de 40 anos já para processar as densidades ópticas de imagens mamográficas e correlacionar diferenças bruscas com áreas suspeitas, produzindo o primeiro sistema de diagnóstico auxiliado por computador em imagens mamográficas. Apesar de tentativas como a de Winsberg, até o fim da década de 1980 os sistemas inicias de CAD, que tinham como objetivo separar tumores malignos de benignos, sofriam com precisões muito baixas se comparados a observadores humanos experimentes (CHAN, DOI, et al., 1998).

O desenvolvimento durante a década de 1990 de sistemas radiológicos mais modernos e técnicas mais avançadas de processamento de imagens tornaram os esquemas CAD uma ferramenta válida para o radiologista (DAVIES e DANCE, 1990), tanto para a detecção quanto para a classificação de microcalcificações (QIAN, 1995; JIAN, NISHIKAWA e PAPAIOANNOU, 1998; CHENG, CAI, et al., 2003; KALLERGI, 2004), nódulos e tumores (LAI, LI e BISCHOF, 1989; BRZAKOVIC, LUO e BRZAKOVIC, 1990; HADJIISKI, CHAN e SAHINER, 2004). 
Em 1998 o R2 Technology's Image Checker® tornou-se o primeiro esquema CAD mamográfico aprovado pela FDA (U. S. FOOD AND DRUG ADMINISTRATION, 1998). Este sistema foi desenvolvido para localizar os principais sinais indicativos de câncer de mama. Massas são marcadas com asteriscos e aglomerados de microcalcificações com triângulos (SAMPAT, MARKEY e BOVIK, 2005).

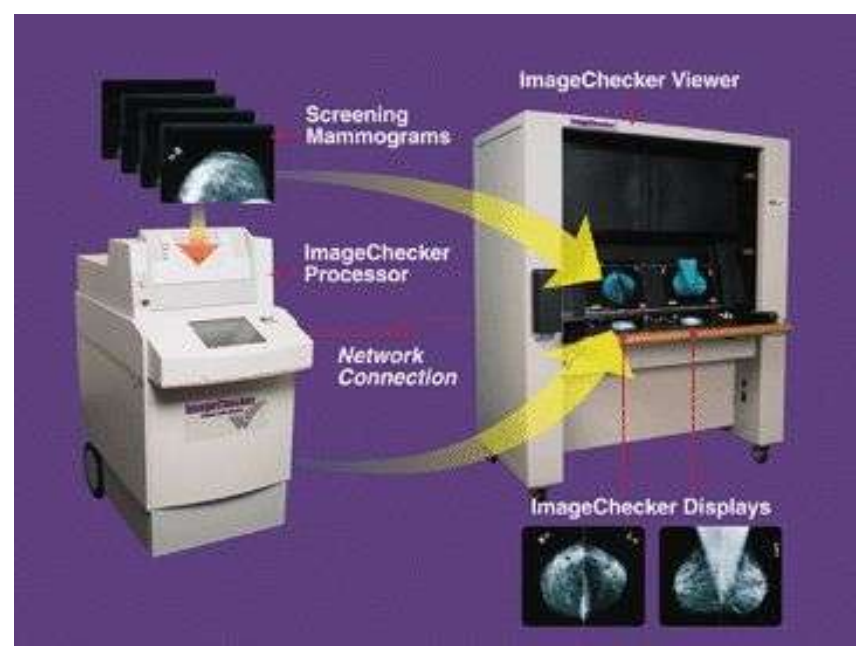

(a)

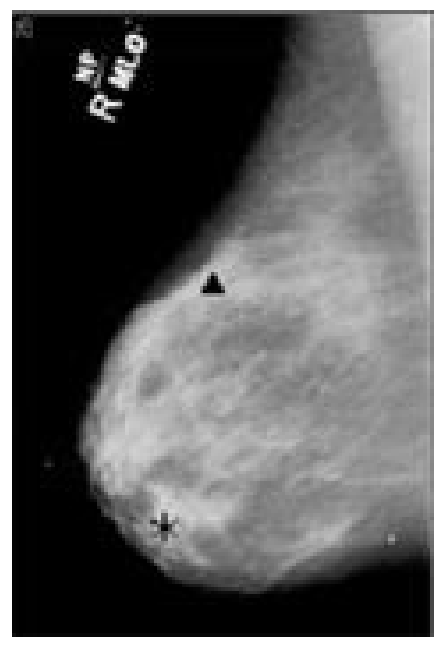

(b)

Figura 1: Sistema R2 ImageChecker®. a) Exemplo do sistema completo para filmes. B) exemplo dos resultados apresentados pelo ImageChecker ${ }^{\circledR}$ 
Em 2002 mais dois esquemas CAD para mamografias foram aprovados pela FDA: MammoReader® da Intelligent System Software Inc. (ISSI) (U. S. FOOD AND DRUGS ADMINISTRATION, 2002) e SecondLook da CADx Medical Systems (U. S. FOOD AND DRUGS ADMINISTRATION, 2002). Ambos mantinham o sistema de marcar a imagem onde microcalcificações e massas foram detectadas, mas utilizando símbolos diferentes de acordo com a padronização utilizada.

Atualmente existem várias empresas com esquemas CADe comerciais desenvolvidos ou em desenvolvimento, incluindo CADVision ${ }^{\circledR}, \operatorname{VuComp}{ }^{\circledR}, \mathrm{iCAD} \AA$, Imagediagnostic ${ }^{\circledR}, \mathrm{M}-\mathrm{Vision} \AA$ e outros.

Desenvolvimentos em CAD mamográficos vêm sendo impulsionados por uma legislação aprovada pelo Congresso dos Estados Unidos em 2001 (HALL, 2007) que oferece complementações financeiras para hospitais e clínicas que façam uso comprovado de esquemas CAD. No entanto, essa legislação não diferencia CADe de CADx, ou seja, para ser beneficiado pela legislação o esquema CAD utilizado não precisa realizar classificações, apenas detecções. Este é um dos principais fatores por que não existem esquemas CADx comercialmente disponíveis.

É importante ressaltar que estes esquemas, assim como outros algoritmos e técnicas não comercias, têm como intuito auxiliar o radiologista em seu trabalho, funcionando como uma segunda opinião (SAMPAT, MARKEY e BOVIK, 2005) e aumentar a eficiência da avaliação dos exames mamográficos, diminuindo a quantidade de erros de diagnóstico (incluindo biópsias desnecessárias) e a quantidade de mortes (VYBORNY, GIGER e NISHIKAWA, 2000; GIGER, 2004). Nenhum esquema CADelDx desenvolvido ou em desenvolvimento tem como objetivo substituir o radiologista, apenas informa-lo e auxilia-lo a tomar as melhores decisões possíveis.

\subsection{Consequências do uso de esquemas CAD na análise mamográfica}

Inicialmente, esquemas $\mathrm{CAD}$ foram desenvolvidos com o intuito de reduzir a quantidade de biópsias desnecessárias, mas se mostraram muito mais eficazes para reduzir a taxa de falsos-negativos. A maioria dos estudos na área mostra um impacto 
positivo na sensibilidade do radiologista com auxílio de um esquema CAD, associado a um aumento na taxa de retorno dos pacientes para obtenção de novas imagens ou biópsia (BYWOOD, NEWTON, et al., 2004; MORTON, WHALEY, et al., 2006).

De fato, um problema recorrente em esquemas CADe, é a quantidade de falsospositivos demarcados pelos sistemas (KARSSEMEIJER, 2011), um fato que pode estar diretamente ligado ao aumento das taxas de retorno dos pacientes. Além disso, o excesso de falsos-positivos pode provocar desconfiança no radiologista, levando o mesmo a ignorar as marcações do sistema. Uma análise em um hospital, realizada por Eliot L. Siegel e descrita em palestra no congresso SPIE 2014 (Re-thinking CAD for the next generation), mostrou que apenas $2 \%$ dos médicos confiavam em esquemas CADe - dos demais, $49 \%$ não confiavam e outros $49 \%$ talvez.

Esta desconfiança, somada a estudos que indicam que as maiores dificuldades do radiologista estão na classificação e não na detecção (MEYER, EBERLEIN, et al., 1990; KARSSEMEIJER, 2011), está levando a uma mudança no enfoque dos esquemas CAD. Esse enfoque vem-se desassociando das ideias CADe e caminhando para o CADx, em que o esquema não só realiza detecções, mas, principalmente, analisa e fornece informações auxiliares à interpretação do radiologista.

Estes esquemas, incluindo um dos considerados nesta tese, frequentemente trabalham em regiões de interesse selecionadas pelo radiologista, servindo como uma segunda opinião localizada em caso de dúvida.

\subsection{Avaliação de CAD}

Para avaliar técnicas de esquemas CAD, o trabalho de (VYBORNY, GIGER e NISHIKAWA, 2000) recomenda utilizar três fatores:

- Sensibilidade (S): porcentagem de detecções positivas corretamente localizadas (verdadeiros-positivos), ou seja, o número de verdadeiros-positivos (VP) dividido pela soma do número de casos verdadeiros-positivos (VP) mais falsos-negativos (FN), conforme especificado na equação 1 . 


$$
S=\frac{V P}{V P+F N}
$$

- Especificidade (E): porcentagem de detecções negativas corretas (verdadeirosnegativos), ou seja, o número de verdadeiros-negativos (VN) dividido pela soma do número de casos verdadeiros-negativos (VN) mais falsos-positivos (FP), conforme especificado na equação 2 .

$$
E=\frac{V N}{V N+F P}
$$

Eq. 2

- Natureza da base de dados: conjunto de imagens utilizado para a análise estatística do sistema. Este fator inclui características físicas da imagem (resolução espacial, nível de contraste, tamanho da imagem, etc.) e informação contida na imagem (densidade da mama, tipos de achado, etc.). Testes indicam que este fator pode causar grandes diferenças nos fatores acima e no resultado final (SCHIABEL, NUNES, et al., 2000). No caso de esquemas CAD comerciais, as características físicas das imagens podem ser conhecidas, mas o conteúdo não é publicamente revelado.

Esta avaliação do comportamento dos esquemas de processamento pode ser feita selecionando-se um conjunto de imagens com laudos conhecidos e contando a quantidade de verdadeiros-positivos e de falsos-positivos resultantes do sistema. É importante lembrar que estas duas características devem ser avaliadas juntas, ou seja, não adianta um sistema ter sensibilidade de $100 \%$, mas apresentar muitas detecções falsas em imagens de casos não suspeitos.

Assim, um CAD, ao ser calibrado (durante a construção do programa ou pelo usuário final, quando possível), exige que seja feita uma escolha do nível de sensibilidade em relação à especificidade que mais vale a pena para o objetivo do programa. 


\subsection{Curvas ROC}

Neste mesmo tipo de análise, normalmente são utilizadas as curvas ROC (Receiver Operating Characteristic) (CHAN, SAHINER, et al., 1999; HADJIISKI, CHAN e SAHINER, 2004; NUNES, SCHIABEL e BENNATI, 2002). O método relativo a sua construção foi desenvolvido originalmente para avaliar detecção de sinais de radar e na psicologia sensorial, pois é um método que leva em conta o aspecto subjetivo envolvido em um determinado evento. Na prática, a curva ROC é uma curva relacional entre a taxa de verdadeiros-positivos (Sensibilidade) e a taxa de falsos-positivos (1 Especificidade) para um determinado evento. No caso da análise de CAD mamográfico, a curva ROC permite efetivamente identificar a redução necessária da especificidade para aumentar a sensibilidade do programa.

O exemplo mostrado na (Figura 2) ilustra curvas ROC comparando 3 casos: médico sem auxílio, médico com auxílio de um esquema CAD e o esquema CAD sozinho. De acordo com os autores do estudo (VYBORNY, GIGER e NISHIKAWA, 2000), o esquema CAD individualmente só apresenta resultados melhores do que o conjunto médico $+\mathrm{CAD}$ porque os radiologistas selecionados não tinham experiência prévia com CAD e tiveram dificuldade em adaptar seu treinamento ao uso do sistema.

Estudos posteriores (LUO, QIAN e ROMILLY, 2005) indicam que o treinamento no uso dos esquemas CAD amplia consideravelmente a qualidade dos resultados. Testes realizados durante o desenvolvimento do presente trabalho (SCHIABEL, MATHEUS, et al., 2012; MATHEUS e SCHIABEL, 2013) confirmam que existe a possibilidade de melhora na qualidade de avaliação do radiologista.

Tendo em mãos a curva ROC de um programa é recomendado que o mesmo seja calibrado para o ponto em que a sensibilidade seja a maior possível para uma ocorrência baixa de falsos-positivos. Além disso, a área sob a curva ROC pode ser utilizada como um índice para avaliação de um esquema $\mathrm{CAD}$, pois quanto maior for a área embaixo da curva melhor é a taxa de acertos do método avaliado, até o máximo ideal de 1 (onde o sistema apresenta sensibilidade de $100 \%$ e nenhum falso-positivo).

Com as informações da curva ROC, a comparação de esquemas CAD parece simples. No entanto, estas curvas, apesar de importantes, ignoram o terceiro fator que 
Vyborny (VYBORNY, GIGER e NISHIKAWA, 2000) requerem para avaliação: a natureza da base de dados. Este último elemento será discutido nos próximos capítulos.

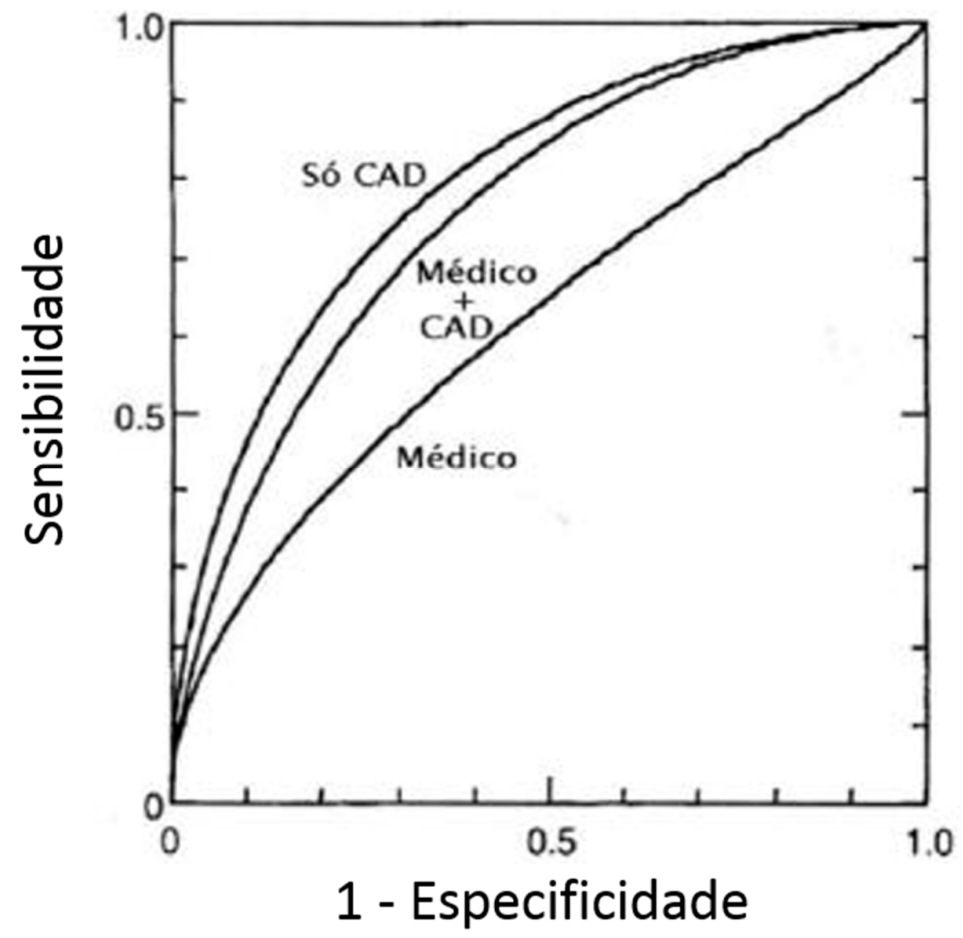

Figura 2: Desempenho de um esquema CAD para detectar e classificar microcalcificações comparados ao desempenho dos radiologistas sem auxilio (VYBORNY, GIGER e NISHIKAWA,

2000)

No caso de esquemas de deteç̧ão, em que vários achados podem existir em uma dada imagem, se torna difícil calcular a taxa de verdadeiro-negativos (VN) e, portanto, a especificidade. Neste caso a curva ROC pode ser alterada para considerar a sensibilidade versus taxa de falso positivos por imagem, resultando em uma curva FROC (Freeresponse Receiver Operating Characteris).

A curva FROC tem propriedade similares a curva ROC, mas pode ser mais facilmente construída para esquemas de detecção. 



\section{Capítulo 3 Formatos de imagens, bases de dados e linguagem}

Neste capítulo será feita uma revisão das estruturas computacionais mais gerais pertinentes a esta tese. Primeiramente serão descritos os formatos mais comuns de imagens médicas digitais e suas principais características. Em seguida, serão descritas bases de imagens mamográficas que foram utilizadas nesta tese. Por último, será feita uma rápida descrição da linguagem escolhida para o desenvolvimento do software, incluindo os motivos da sua escolha para este projeto.

\subsection{Formatos de imagem}

Os variados tipos de imagens médicas exigem diferentes níveis de qualidade e precisão para seu uso diagnóstico. No caso de exames mamográficos, em particular, a imagem precisa apresentar uma alta resolução espacial e uma alta resolução de contraste, características que têm diferentes consequências do ponto de vista prático.

Microcalcificações são calcificações com menos de $0,5 \mathrm{~mm}$, tendo sido encontradas com tamanhos de $24 \mu \mathrm{m}$ (IMAMURA, EHARA, et al., 2008), por conta disso a resolução espacial da imagem precisa ser suficientemente boa para visualização de detalhes tão pequenos. Do ponto de vista computacional, uma resolução espacial melhor significa que objetos menores e pequenos detalhes serão mais visíveis, porem isso implica em imagens contendo mais pixels e, por consequência, maior espaço de memória ocupado por imagem.

Já no caso da resolução de contraste (ou profundidade), testes recomendam que a imagem deveria no mínimo 9 ou 10 bits de resolução (SIEGEL, KRUPINSKI, et al., 2006), frequentemente variando entre 12 e 16 bits. Do ponto de vista computacional, as 
consequências são mais profundas, pois exigem uma alteração estrutural em como imagens normalmente são armazenadas e apresentadas ao usuário.

Imagens comuns têm 8 bits de resolução (ou seja, representariam as estruturas em 256 tonalidades distintas) e todas as partes de um sistema computacional são construídas com base nisso, incluídos os formatos de armazenamento e até o método de apresentação de imagens em um monitor convencional.

Por conta da diferença entre imagens comuns e imagens com alta resolução de constraste, formatos convencionais (BMP, PNG, JPEG, GIF, etc.) não podem ser usados para imagens mamográficas de qualidade, pois, além de não serem capazes de comportar a necessária resolução de contraste, vários destes formatos correspondem a resultado de técnicas de compactação com perdas, ou seja, o espaço de memória da imagem é menor, já que pequenos detalhes são perdidos na compactação. Por conta disso, dois formatos são os mais frequentemente vistos em bases de imagens mamográficas: TIFF (.TIF ou .TIFF) e LJPEG (.LJEPG).

\section{O formato TIFF (Tagged Image File Format) (ADOBE DEVELOPERS} ASSOCIATION, 1992), armazena a imagem em duas partes: um cabeçalho informativo e a imagem propriamente. No cabeçalho, é possível definir uma série de características da imagem, incluindo as resoluções espacial e de contraste. As especificações TIFF permitem que a resolução de contraste varie de acordo com os objetivos da imagem, incluindo as resoluções entre 10 e 16 bits necessárias para exames mamográficos. A especificação também permite o uso de compactação com e sem perdas, porém, para garantir a qualidade da imagem, normalmente nenhuma compactação com perdas é usada em imagens mamográficas.

Já o formato LJPEG (Lossless Joint Photographic Experts Group) (HAMILTON, 1992) é muito mais restrito em sua definição do que o formato TIFF, mas ainda assim permite que a resolução de contraste seja selecionada. LJPEG é baseado no JPEG tradicional, mas é importante destacar que este formato utiliza uma compressão sem perdas (lossless), diferente do formato JPEG usual que produz perdas em sua compactação. 
O frequentemente chamado de "formato de imagem" DICOM (Digital Imaging and Communications in Medicine) (NATIONAL ELECTRICAL MANUFACTURERS ASSOCIATION, 2009), na verdade, não é um formato de imagem como TIFF ou LJEPG, e sim um método de empacotamento de informação que inclui uma imagem médica. Especificamente, este procedimento armazena uma imagem médica no formato TIFF ou LJPEG descritos acima e um conjunto de informações sobre o equipamento utilizado na aquisição da mesma. Portanto, qualquer sistema capaz de manipular imagens TIFF e LJPEG será capaz de manipular imagens em padrão DICOM, contanto que sejam capazes de extrair a imagem do arquivo DCM. O DICOM é frequentemente utilizado por hospitais nacionais e internacionais em seus PACS (Picture Archiving and Communication System).

\subsection{Bases de imagens}

A obtenção de imagens mamográficas de qualidade para desenvolvimento e teste de esquemas $\mathrm{CAD}$ pode ser um grande obstáculo para desenvolvedores que não são diretamente associados a hospitais e clínicas. Além disso, para testes comparativos de métodos, é importante que as imagens provenham de uma fonte similar.

Uma solução para estes problemas é a formação de bases públicas de imagens mamográficas. Todos os testes realizados neste projeto usaram apenas fontes públicas, especificamente as bases descritas abaixo.

\subsubsection{BancoWeb/LAPIMO (MATHEUS e SCHIABEL, 2011)}

Desenvolvido pelo grupo do LAPIMO - EESC/USP, esta base contém por volta de 6000 imagens e seus respectivos laudos. As imagens estão no formato TIFF e foram obtidas por digitalização com resoluções espaciais de $150 \mu \mathrm{m}$ ou $75 \mu \mathrm{m}$ e 12 bits de resolução de contraste a partir de filmes mamográficos.

As imagens podem ser localizadas através de um sistema de busca por características descritas no laudo, do paciente ou dos equipamentos de mamografia ou 
digitalização. Uma vez localizada a imagem de interesse, ela pode ser obtida individualmente, ou todas pertencentes ao mesmo exame ou ao mesmo paciente.

$\mathrm{O}$ acesso à base BancoWeb/LAPIMO é livre pelo endereço http://lapimo.sel.eesc.usp.br/bancoweb/, mas exige um cadastro e autorização dos administradores antes do acesso ser liberado. A versão web contém por volta de 1700 das imagens do banco off-line.

\subsubsection{DDSM (HEATH, BOWYER, et al., 2001)}

Desenvolvida pela University of South Florida, a base DDSM é a maior base pública de imagens mamográficas, consistindo de mais de 10.000 imagens com laudos detalhados, contendo as coordenadas das bordas dos achados em um arquivo de texto associado a cada imagem individual. As imagens são provenientes de filmes digitalizados, com resoluções espaciais entre $40 \mu \mathrm{m}$ e $50 \mu \mathrm{m}$ e resoluções de contraste de 12 ou 16 bits.

As imagens são separadas em quatro tipos: normal, câncer, benigno e benigno sem retorno. Cada tipo de imagem é subdividido em volumes, cada volume contendo entre 20 e 117 exames provenientes do mesmo aparelho mamográfico e digitalizador. A DDSM não oferece nenhum sistema de busca textual ou por características.

As imagens são livremente disponíveis para download, mas o formato delas é uma versão não-padrão do LJPEG que não pode ser utilizada diretamente mesmo em softwares tradicionais da área como MATLAB ${ }^{\circ}$ (MATHWORKS, 2014) e ImageJ (RASBAND, 2011; COLLINS, 2007). Por conta disso, utilizar as imagens da base exige alterações no cabeçalho e no formato de armazenamento. Para os testes descritos neste trabalho, as imagens da base DDSM foram convertidas para TIFF.

3.2.3 INBreast (MOREIRA, AMARAL, et al., 2012) 
A base INBreast foi compilada pelo Centro de Mama no Centro Hospitalar de S. João, associado à Universidade do Porto, contendo 115 exames (410 imagens). Apesar da quantidade restrita, a base contém apenas imagens digitais diretas (FFDM), no momento, sendo uma das únicas bases públicas no mundo a oferecer tais imagens.

Ao contrário das bases descritas anteriormente, a INBreast não tem um site estruturado onde as imagens ficam disponíveis. Para acessá-la é necessário entrar em contato com o Breast Research Group do Porto, Portugal (http://medicalresearch.inescporto.pt/breastresearch/) e pedir acesso. O acesso consiste do link para baixar conjuntos das imagens compactadas em RAR e um usuário e senha para poder ter acesso ao site.

Uma vez descompactados, os arquivos contêm as imagens em .DCM e um arquivo .XML com informações de cada uma, incluindo os contornos de cada achado feitos por especialistas. Para facilitar a localização de achados específicos, existe um arquivo .XLS fornecendo dados gerais de todas as imagens da base.

\subsection{JAVA®}

Para o desenvolvimento deste projeto um dos objetivos é integrar os diferentes módulos de processamento da imagem mamográfica já desenvolvidos a fim de produzir um esquema versátil para ser utilizado em diferentes sistemas operacionais. Daí a necessidade de escolher uma linguagem de programação capaz de viabilizar essa meta. A linguagem de programação JAVA (ORACLE, 2014) foi selecionada para este projeto por conta de duas características principais: modularização e ubiquidade.

JAVA foi desenvolvida em 1991 pela Sun Microsystems para servir como linguagem de programação para sistemas embarcados, em particular um controle multimídia chamado Device *7 (BYOUS, 2003). De acordo com (STROUSTRUP, 1997), a nova linguagem tinha o intuito de corrigir problemas de $\mathrm{C} / \mathrm{C}++$ com uma linguagem que fosse puramente orientada a objeto. 
Com o fracasso do projeto Device *7, a linguagem JAVA foi reorientada para programação voltada à web, em particular com uma parceria em 1995 com o Netscape ${ }^{\circ}$. O resultado foi uma linguagem de programação plena, com a capacidade de ser utilizada via browser. Atualmente, JAVA é uma linguagem utilizada mundialmente em desenvolvimento de variados softwares, incluindo sistemas operacionais e jogos.

Como JAVA é orientada a objeto, a linguagem naturalmente é modular, ou seja, as diferentes classes e objetos podem ser reutilizados sem necessidade de reescrever o código. No caso desta pesquisa, JAVA permite que os diferentes módulos, uma vez convertidos ou desenvolvidos em JAVA, possam ser utilizados em diferentes configurações, permitindo seu uso como biblioteca durante o projeto e para usos futuros.

Uma das principais características de JAVA é sua ubiquidade. Seguindo a filosofia WORA (Write Once, Run Anywhere - Escreva uma vez, rode em qualquer lugar) a linguagem foi desenvolvida para ser rodada utilizando um emulador chamado JVM (Java Virtual Machine - Máquina Virtual JAVA), o qual, uma vez instalado em um computador, permite que códigos JAVA sejam rodados, independentemente do sistema operacional do computador. A consequência desta característica é que, apesar do esquema CADx descrito neste trabalho ter sido desenvolvido em um sistema operacional Windows, o software resultante (e todos os seus módulos) podem ser utilizados em sistemas Unix, MAC, FreeBSD, etc. sem alterações. Atualmente, quase todo sistema operacional tem suporte para JAVA, incluindo sistemas móveis como Android e iPhone.

A linguagem JAVA tem raízes óbvias em $\mathrm{C}++$, mantendo a estrutura e tipos básicos de $\mathrm{C}++$, mas restringindo a orientação a objeto apenas. Em outras palavras, JAVA elimina elementos de $\mathrm{C}$ que $\mathrm{C}++$ ainda mantém para garantir compatibilidade.

Assim, por conta de sua modularidade e ubiquidade, JAVA foi escolhida para ser a linguagem de desenvolvimento deste projeto. Com isso é garantido que, uma vez pronto, o programa pode funcionar em sua versão biblioteca e para servidores com alterações mínimas.

Neste trabalho foi usada a versão 7 de JAVA. 


\subsubsection{ImageJ $®($ RASBAND, 2011; COLLINS, 2007)}

Outra vantagem do uso de JAVA para desenvolvimento é a possibilidade de utilizar a biblioteca ImageJ para abrir e manipular imagens. Essa biblioteca permite a abertura de todos os formatos de imagens comumente utilizados em processamento de imagens médicas, incluído a extração e abertura de imagem em DICOM.

ImageJ foi criado em 1997 por Wayne Rasband, que, após 10 anos de desenvolvimento do programa para MacIntosh NIH (National Institutes of Health) Image, decidiu iniciar um novo programa usando JAVA (COLLINS, 2007). Este programa foi nomeado ImageJ e é independente de sistema operacional, exigindo apenas a JVM para seu uso.

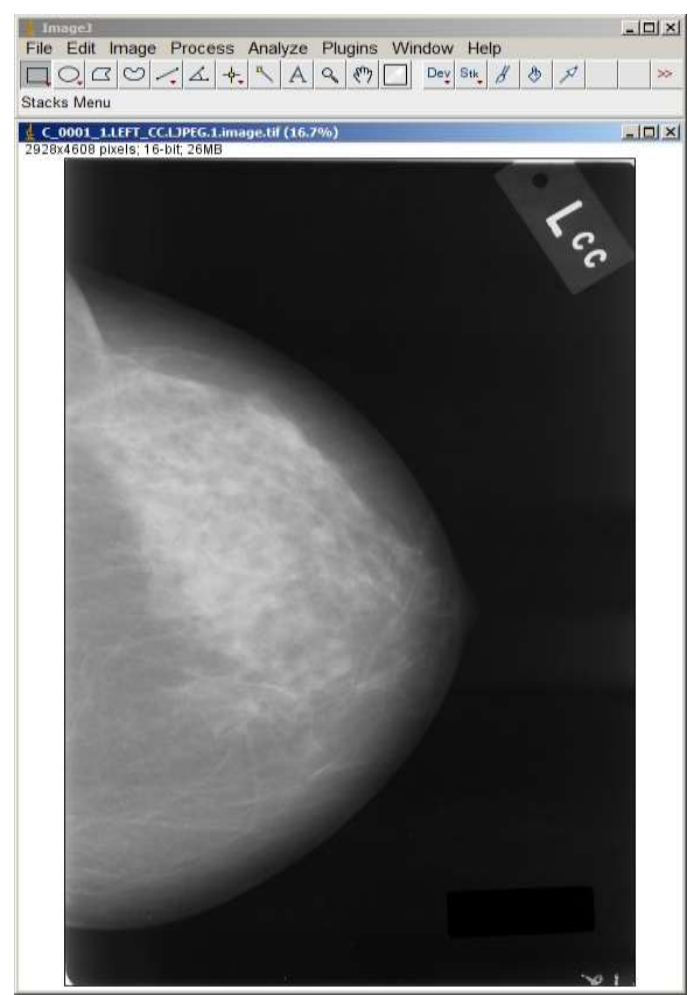

Figura 3: Programa ImageJ com uma imagem de mama aberta 
O ImageJ consiste de duas partes paralelas, porém distintas: o programa e a biblioteca. O programa é um executável JAVA que permite abrir e visualizar imagens (Figura 3), além de fornecer uma série de ferramentas para análise e processamento de imagens. Já a biblioteca consiste de código apenas, que pode ser acessado e utilizado por desenvolvedores JAVA para realizar tarefas que se expandem além do programa ImageJ.

Na biblioteca ImageJ, uma vez abertas, as imagens podem ser manipuladas como matrizes. As duas classes principais da biblioteca ImageJ são ImageProcessor e ImagePlus.

Na classe ImageProcessor ficam os dados da imagem propriamente, assim como cabeçalhos e informações úteis. A classe ImagePlus contém um atributo ImageProcessor e uma série de métodos de interface para facilitar a manipulação e apresentação da imagem ao usuário.

Neste trabalho a versão 1.48 do ImageJ foi utilizada. 


\section{Capítulo 4 Métodos para CAD desenvolvidos no LAPIMO}

Neste capítulo serão apresentadas técnicas CAD desenvolvidas anteriormente para detecção e classificação de estruturas em imagens de mama. Estas técnicas são o ponto de partida desta tese e foram utilizadas na estruturação do esquema CADe/Dx completo.

Com exceção da Transformada Área-Ponto descrita na seção 4.8 todas as técnicas descritas neste capítulo foram desenvolvidas por pesquisadores do grupo do LAPIMO ao longo de mais de 15 anos de pesquisa em imagens mamográficas.

Em alguns casos foi necessária a conversão do código existente para JAVA, em outros, apenas a alteração do código já em JAVA para adaptá-lo aos requerimentos do esquema CADx. Aqui também são explicitadas as alterações necessárias para cada método.

\subsection{Correção BCC (GOES, 2010)}

Este módulo foi desenvolvido com o intuito de padronizar as imagens obtidas através de sistemas filme + digitalizador, de modo que as imagens resultantes independam do equipamento de digitalização.

Este método exige o levantamento da curva característica do digitalizador utilizado, o que pode ser feito usando um filme sensibilizado por um sensitômetro, de modo que seja possível criar uma tabela que relaciona a densidade óptica no filme e o nível de cinza de saída mostrado pelo digitalizador. A partir desta tabela, usando uma aproximação polinomial de terceiro grau, é possível obter uma aproximação muito boa 
da curva característica real do equipamento. Usando essa curva característica, é possível transformar a imagem em níveis de cinza em uma imagem de densidades ópticas.

Essa imagem pode ser retornada para uma imagem em níveis de cinza usando a curva característica apresentada por um filme de alto padrão, tornando as relações de contraste da imagem final mais próximas do que se visualiza em um filme de boa qualidade. No caso, foi usado como referência da Correção BCC o filme KODAK MinSR (KODAK, 2004).

Nos testes descritos em (GOES, 2010) foram utilizados 21 níveis de sensibilização para caracterizar os digitalizadores pertinentes, e na base DDSM (HEATH, BOWYER, et al., 2001) os digitalizadores são descritos em seu site (ROSE, TURI, et al., 2003) por 22 níveis de sensibilização. Testes com a Correção BCC (MATHEUS, VERÇOSA, et al., 2014), nos casos em que não seja possível obter a curva característica, mostraram bons resultados ao assumir uma curva característica ideal, ou seja, uma reta conectando a densidade óptica máxima do filme (normalmente 4,0) ao nível de cinza 0 e a densidade óptica mínima (assumido 0) com o valor máximo de nível de cinza para a profundidade de contraste da imagem digitalizada (255 para 8 bits, 4095 para 12 bits, etc.). Na Figura 4 temos um exemplo das curvas características de alguns aparelhos.

Como pode ser visto na região de interesse (RI) exemplificada na Figura 5, o uso deste método tende a ampliar o contraste nas regiões centrais da imagem ao custo de reduzi-lo nos valores extremos. Isso é benéfico para imagens mamográficas, pois as regiões de importância para a análise (tanto visual quanto computacional) estão nesta região de valores centrais, em particular massas. No extremo inferior, valores perto do preto, está apenas o fundo da imagem que não tem importância para análise e, no extremo superior, valores perto do branco, só são encontradas calcificações, para as quais pequenas diferenças de contraste não alteram o diagnóstico.

Testes de processamento em imagens corrigidas mostraram uma redução entre $70 \%$ e $90 \%$ (dependendo do digitalizador) na taxa de falsos positivos para detecção de microcalcificações, além de uma melhora (menos significativa) na sensibilidade. Quando utilizado em conjunto ao método de segmentação descrito em (GOES, SCHIABEL e 
SOUSA, 2013) obtemos resultados visualmente superiores, conforme mostrados na

Figura 5.

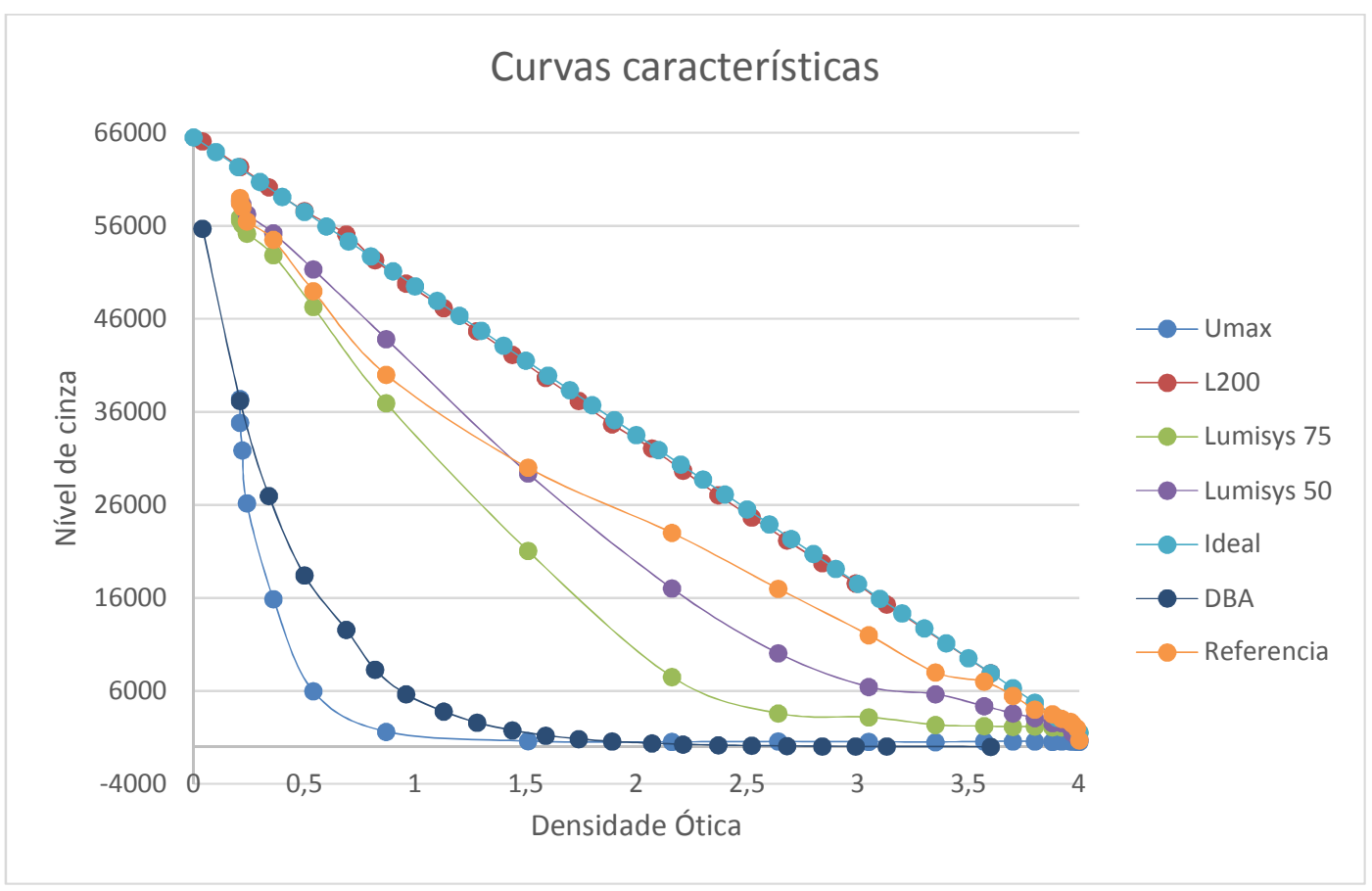

Figura 4: Curva característica relacionando nível de cinza com densidade ótica. Comparação entre digitalizadores e filme referência da Correção BCC.

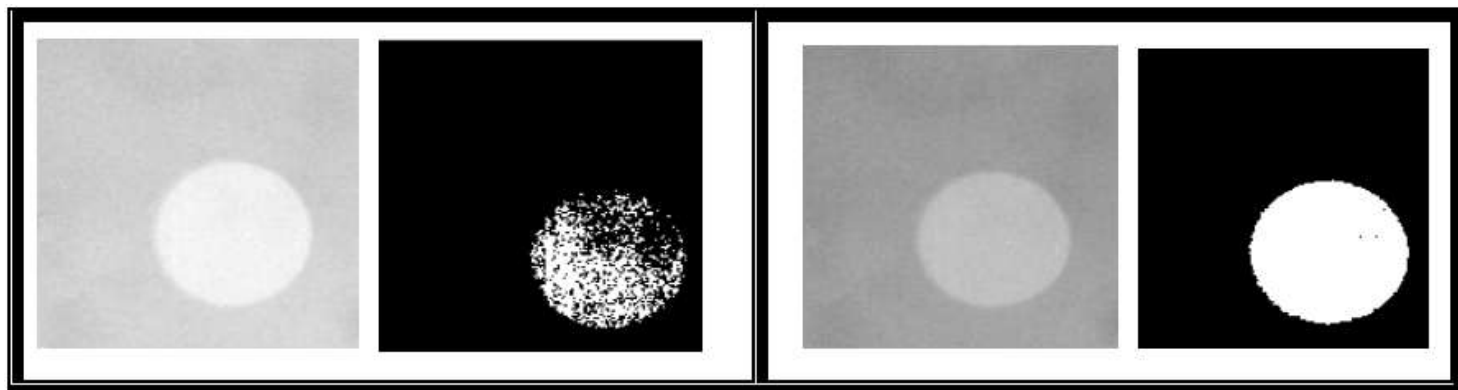

(a)

(b)

(c)

(d)

Figura 5: RIs de imagens de simulador digitalizadas no scanner Vidar Diagnost Pro: (a) original,

(b) segmentada original, (c) corrigida pelo método de correção da digitalização, (d) segmentação de

(c). (GOES, 2010) 


\subsection{Segmentação de mama (MENECHELLI, 2013)}

No método de segmentação de mama desenvolvido por (MENECHELLI, 2013), a mama é segmentada para separar o tecido mamário propriamente do fundo da imagem. $\mathrm{O}$ intuito é reduzir a área de manipulação removendo as regiões desnecessárias para o processamento (Figura 6), como o fundo e as tags de identificação.

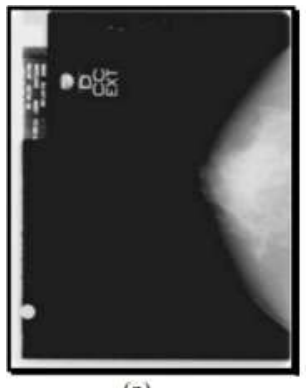

(a)

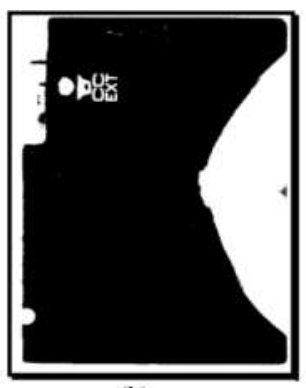

(b)

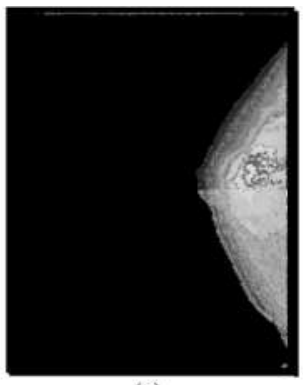

(c)

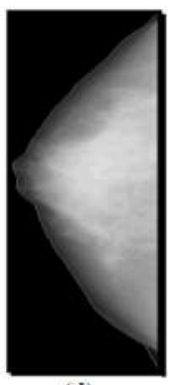

(d)

Figura 6: Exemplo de segmentação de mama (MENECHELLI, 2013). (a) Imagem original, (b) imagem (a) após limiarização, (c) imagem (a) com a mama delimitada e fundo removido, (d) imagem final para processamento.

O método consiste nos seguintes passos:

a) Alargamento de contraste logarítmico (GONZALES e WOODS, 2008; FERRARI, RANGAYYAN, et al., 2004);

b) Limiar de segmentação global de Pun (PUN, 1981);

c) Remoção das linhas com mais de $90 \%$ de pixels brancos (regiões brancas no topo e base da imagem) para evitar erros no passo g;

d) Avaliação do lado da mama (esquerda ou direita) (ELTOUKHY, FAYE e SAMIR, 2010) através do centro de massa; 
e) Seleção da região da mama usando crescimento de região (GONZALES e WOODS, 2008) a partir do conhecimento do lado da mama (passo d). O ponto inicial é o centro de massa.

f) Multiplicação da imagem binária segmentada pela imagem original, obtendo uma imagem que é apenas o tecido mamário contra um fundo totalmente preto.

g) Remoção das colunas e linhas que não contêm tecido mamário, ou seja, sem nenhuma parte branca.

\subsection{Segmentação do músculo peitoral (MENECHELLI, 2013)}

Nas imagens mamárias obtidas na posição Médio-Lateral Oblíqua (MLO), parte do músculo peitoral é visível como uma região de alta densidade. Para o radiologista, essa seção da imagem tem valor diagnóstico, permitindo uma avaliação dos linfonodos ou presença de massas nas regiões axilares. Entretanto, para esquemas CAD a alta densidade da musculatura pode confundir o sistema e resultar em falsos positivos ou falsos negativos, além de alterar a classificação de densidade e, por consequência, afetar o detector de assimetrias.

Para evitar tais erros, como parte do módulo de pré-processamento, a região do músculo peitoral é segmentada e separada da imagem, sendo enviada para um módulo da seção de processamento chamado "Módulo Peitoral" (seção 5.3.3d, Capítulo 5). A imagem com o músculo peitoral e o fundo removidos é utilizada pelo "Módulo Assimetrias" (5.3.3a, Capítulo 5) e pelo "Módulo Nódulos” (5.3.3b, Capítulo 5). 

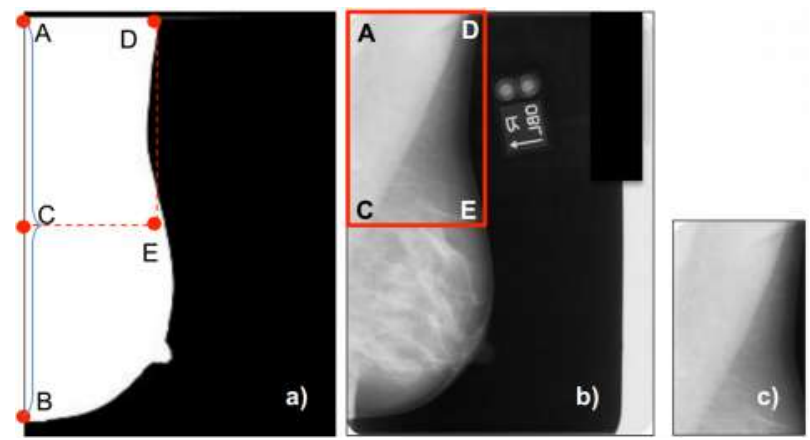

Figura 7: Demarcação da região de interesse para segmentação do musculo peitoral. A) Imagem

binária com RI demarcada, b) RI na imagem original e c) RI isolada. (MENECHELLI, 2013)

Esta segmentação utiliza a imagem após a Correção BCC (seção 4.1) e segmentada no passo anterior (seção 4.2). Para discriminar a região do músculo peitoral, os pontos C e D são selecionados, conforme demonstrado na Figura 7. O ponto C se encontra na primeira coluna, na linha localizada na metade da extensão da mama, medida na primeira coluna (extensão A até B na Figura 7). O ponto D se encontra na primeira linha, na borda de transição tecido/fundo.

Os pontos A e E mostrados na Figura 7 apenas completam o retângulo ACED, formando a região de interesse. Dentro desta é calculado o limiar de Otsu (OTSU, 1979) e esse limiar resultante é utilizado para segmentar a imagem como um todo, conforme demonstrado na Figura 8.

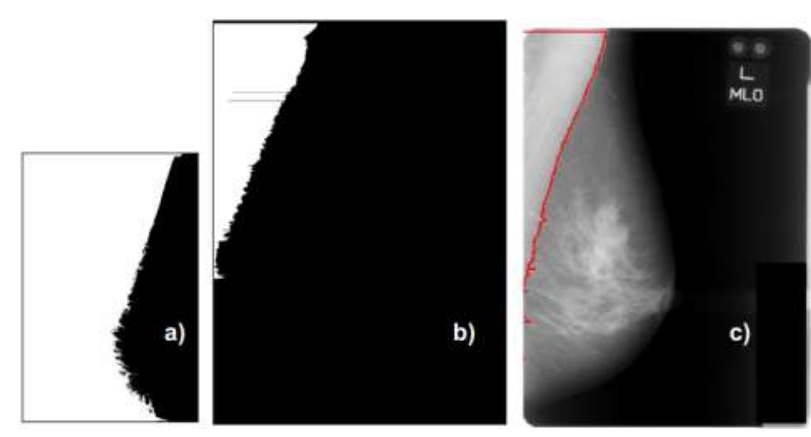

Figura 8: Segmentação do musculo peitoral após seleção da RI. A) RI segmentada usando o limiar de Otsu (OTSU, 1979), b) Imagem completada segmentada pelo mesmo limiar obtido em a, c) 
demarcação da borda segmentada do musculo peitoral sobre a imagem original. (MENECHELLI, 2013)

Para reduzir o ruído da borda segmentada, uma abertura morfológica é realizada com um elemento estruturante na forma de um disco com 25 pixels de diâmetro.

\subsection{Classificação de densidade (MENECHELLI, 2013)}

De acordo com o Atlas BI-RADS (AMERICAN COLLEGE OF RADIOLOGY, 2003), as mamas devem ser classificadas com base em densidades em uma de quatro classes:

i) Classe 1: Mama quase ou totalmente lipossubstituída

ii) Classe 2: Mama com tecido fibrograndular esparso

iii) Classe 3: Mama heterogeneamente densa

iv) Classe 4: Mama extremamente densa

Apesar do sistema BI-RADS estabelecer as classes, elas são claramente subjetivas, especialmente no caso de imagens limítrofes - em particular, imagens no limite superior da classe 2 ou no limite inferior da classe 3. Como consequência, uma mesma imagem pode ser classificada por dois especialistas como pertencentes a diferentes classes de densidades.

Para reduzir a subjetividade, um método de classificação de densidade quantitativo foi proposto por (MENECHELLI, 2013). O método consiste em dividir a imagem em quadrados iguais de 256 x 256 pixels de modo que apenas aqueles com mais de $95 \%$ dos pixels pertencentes ao tecido mamário sejam levados em conta nos passos seguintes. 
Cada quadrado é separadamente classificado pelos atributos autocorrelação e variância (HARALICK, SHANMUGAM e DISTEIN, 1973) usando uma rede neural MLP. A rede selecionada tem 7 neurônios em uma camada única e foi treinada usando backpropagation e função de ativação logística (MENECHELLI, 2013). O treinamento foi feito com 940 RIs selecionadas de um conjunto de 1950 por um especialista como sendo características de sua respectiva classe. A rede retorna um valor inteiro entre 1 e 4, correspondente à classe BI-RADS.

Uma vez classificados todos os quadrados, a mama é considerada parte da classe da maioria dos seus quadrados. Testes usando 400 imagens (100 de cada classe) obtidas na base BancoWeb (MATHEUS e SCHIABEL, 2011) geraram um resultado médio de $83,25 \%$ de sensibilidade e $29,19 \%$ de taxa de falsos-positivos.

Análise dos resultados (Tabela 1) mostrou que o principal motivo para a queda da sensibilidade está na classe 3 , que o sistema tende a confundir com as classes vizinhas.

Tabela 1: Resultados da classificação de densidade da mama

\begin{tabular}{|c|c|c|c|c|}
\hline Classe & VP (\%) & VN (\%) & FP (\%) & FN (\%) \\
\hline 1 & 80.00 & 74.75 & 25.25 & 20.00 \\
\hline 2 & 99.00 & 68.25 & 31.75 & 1.00 \\
\hline 3 & 58.00 & 73.50 & 26.50 & 42.00 \\
\hline 4 & 96.00 & 66.75 & 33.25 & 4.00 \\
\hline Média & $\mathbf{8 3 . 2 5}$ & $\mathbf{7 0 . 8 1}$ & $\mathbf{2 9 . 1 9}$ & $\mathbf{1 6 . 7 5}$ \\
\hline
\end{tabular}

Especialistas da área reportam que, para efeito de diagnóstico, o mais importante é classificar a mama como densa ou lipossubstituída, ao ponto que frequentemente essa é toda a informação fornecida nos laudos médicos. Baseado nesse conceito, os resultados foram reanalisados utilizando apenas duas classes: Lipossubstituída (abrangendo classes 1 e 2) e Densa (abrangendo classes 3 e 4). A rede neural não foi alterada, apenas os resultados foram reavaliados nessa nova perspectiva. 
Considerando apenas as duas classes, a sensibilidade do programa foi $92 \%$ com uma taxa de falso positivos de $5 \%$, resultados muito superiores ao esquema com 4 classes (MENECHELLI, 2013).

\subsection{Detector de Assimetrias locais (SCHIABEL e MENECHELLI, 2013)}

Este método tem como intuito demarcar na imagem as regiões em que mama direita e esquerda são suficientemente diferentes para ser um alerta ao radiologista. Primeiramente, a mama é dividida em seus quatro quadrantes e cada quadrante é subdividido em quatro partes iguais. Na Figura 9 temos um exemplo de como uma imagem é dividida.
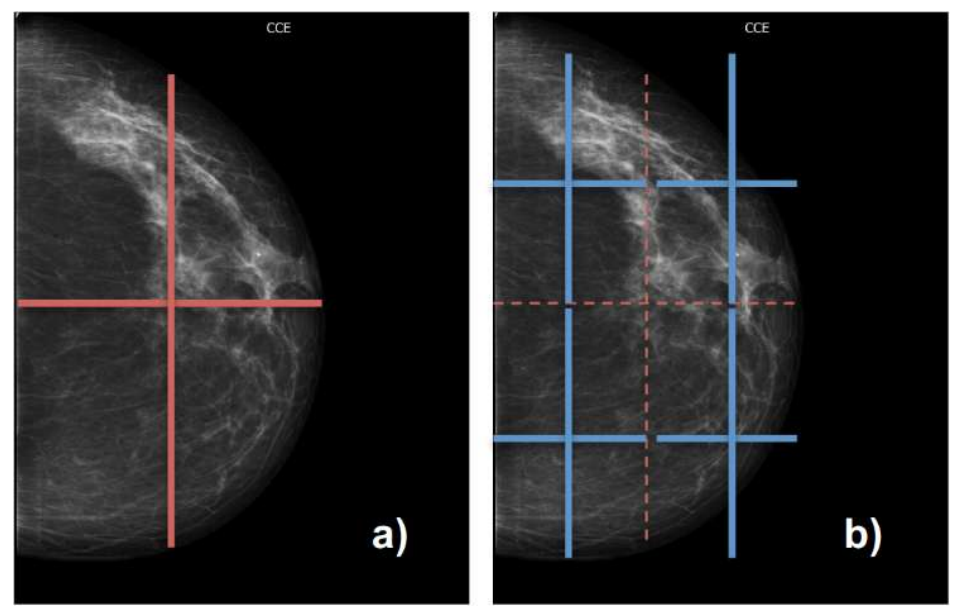

Figura 9: Exemplo de divisão para detecção de assimetrias. a) imagem dividida nos quatro quadrantes e b) imagem subdividida em 16 quadrantes para busca de assimetrias.

Cada um destes 16 retângulos é separadamente avaliado e seus atributos de autocorrelação e variância calculados, assim como no método de avaliação de densidade global (4.4), porém, ao contrário do método anterior, nenhuma rede neural é utilizada. 
Para a avaliação, a diferença destes atributos é comparada entre as RIs e seus pares correspondentes da outra mama na mesma orientação. Na Figura 10 temos um exemplo desta correspondência entre as imagens.

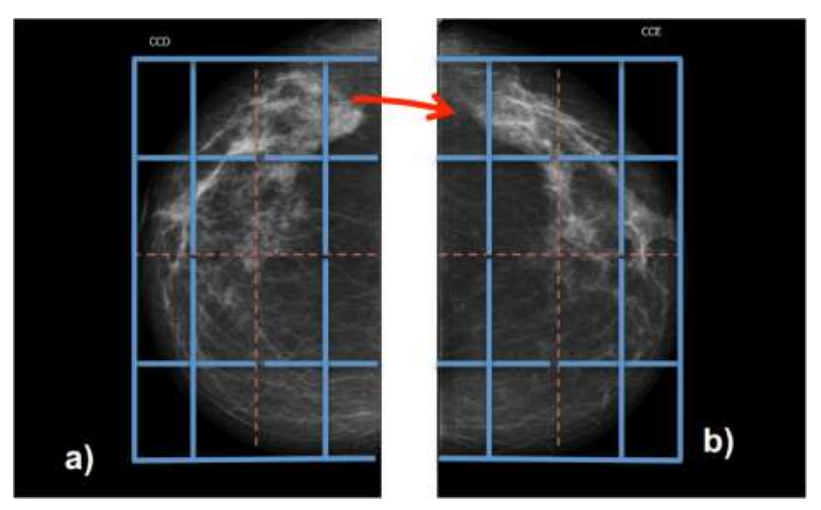

Figura 10: Exemplo de correspondência entre RI direita (a) e esquerda (b) em uma imagem CC

A comparação dos atributos é feita percentualmente usando a seguinte fórmula:

$$
p D_{a, v}=\left[1-\frac{\min \left(D_{a, v}, E_{a, v}\right)}{\max \left(D_{a, v}, E_{a, v}\right)}\right] x 100
$$

Eq. 3

onde $p D_{a}$ é a diferença percentual entre as autocorrelações das RIs correspondentes e $p D_{v}$ é a diferença entre variâncias; $D_{a}$ é a autocorrelação da RI da mama direita e $D_{v}$ é a variância da mama direita, estes dados são calculados similarmente para as imagens de ambas mamas, gerando os valores $E_{a, v}$. O resultado desta equação é um valor entre 0 e $100 \%$, que representa a diferença entre os atributos, sempre considerando o maior valor como $100 \%$.

A média aritmética das diferenças dos dois atributos (Variação Percentual Final VPF) é usada como valor de referência para a detecção. A partir de uma curva ROC foi possível definir que um valor para VPF maior que 35\% indica uma assimetria, resultando em uma sensibilidade de $84 \%$ e taxa de falsos positivos por imagem de 5,1 . 
Com o intuito de reduzir a alta taxa de falsos positivos por imagem, um novo teste foi adicionado ao esquema. Caso a VPF esteja entre $35 \%$ e $60 \%$, os atributos das duas RIs são colocados para classificação usando a rede neural MLP descrita na seção 4.4 com quatro classes; caso os resultados da rede sejam iguais, a região é considerada uma marcação incorreta e não é demarcada. Se o VPF for maior que $60 \%$, a região é diretamente marcada como assimetria (MENECHELLI, 2013).

Os testes deste módulo com a rede obtiveram resultados de $82,8 \%$ de sensibilidade com uma drástica redução na média de falsos positivos por imagem: 0,7 (MENECHELLI, 2013).

\subsection{Detecção de nódulos (BARBOSA FILHO, 2012)}

Este método consiste de duas redes neurais que são utilizadas em sequência. A primeira, chamada de "rede de binarização", é uma rede neural MLP de camada única com 14 neurônios e é usada para obter o limiar de binarização da imagem. A segunda é a "rede do modelo", uma rede neural MLP de camada única com 18 neurônios, que tem como objetivo definir o raio do disco a ser utilizado para localizar nódulos.

A rede de binarização utiliza os seguintes atributos:

a. Descritores de Haralick (distancia d=10) (HARALICK, SHANMUGAM e DISTEIN, 1973):

- Segundo momento angular

- $\quad$ Contraste

- Correlação

- Variância

- $\quad$ Momento da diferença inversa (IDM)

- $\quad$ Soma média

- $\quad$ Entropia

b. Momentos centrais

- $\quad$ Média

- Variância 
- $\quad$ Obliquidade

- $\quad$ Curtose

c. Conjunto dos sete momentos invariantes de $\mathrm{Hu}(\mathrm{HU}, 1962)$

A saída da primeira rede é um valor numérico que é o limiar usado na binarização da imagem, conforme mostrado na Figura 11.
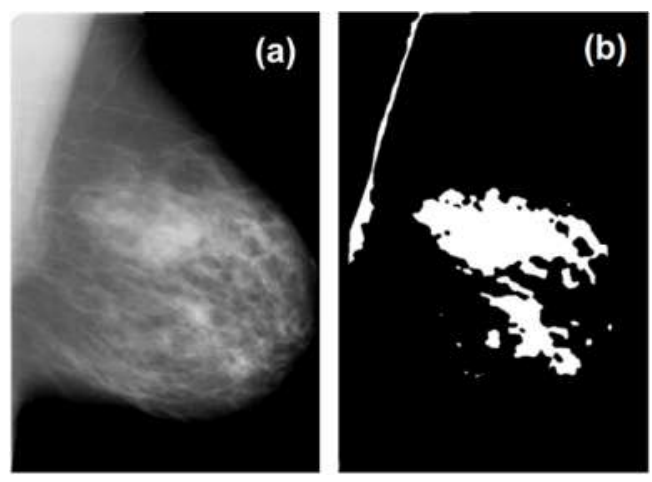

Figura 11: Exemplo de resultado usando limiar da rede de binarização. a) Imagem Original antes do pré-processamento, b) imagem "a" binarizada usando limiar da rede.

A partir da imagem binarizada acima, um novo conjunto de atributos é extraído para a "rede de modelo". Esses atributos são:

- Área da mama,

- $\quad$ Número de pixels segmentados,

- Número de áreas segmentadas,

- Média dos raios dessas áreas,

- Desvio médio destes raios,

- $\quad$ Razão entre a área segmentada e a área da mama.

O resultado desta segunda rede também é um valor numérico, neste caso o raio de um disco que representa o tamanho provável de um nódulo nesta imagem. A escolha de um disco é devido ao provável formato de um nódulo, ao menos em sua estrutura central. 
Este círculo é utilizando como elemento de um filtro casado (BARBOSA FILHO, 2012; GONZALES e WOODS, 2008) para localizar as regiões da imagem que mais se assemelham ao nódulo mais provável. A imagem em níveis de cinza resultante é então binarizada para obter as detecções propriamente. O limiar utilizado é calculado usando a Eq. 4:

$$
L=0.95 \cdot\left(\pi R^{2}\right)
$$

aonde $R$ é o raio obtido pela rede de modelo. Isso significa que se a região ao redor de um dado ponto for $95 \%$ similar ao disco de raio $R$ o ponto será mantido como resultado final. Um exemplo pode ser visto na Figura 12.
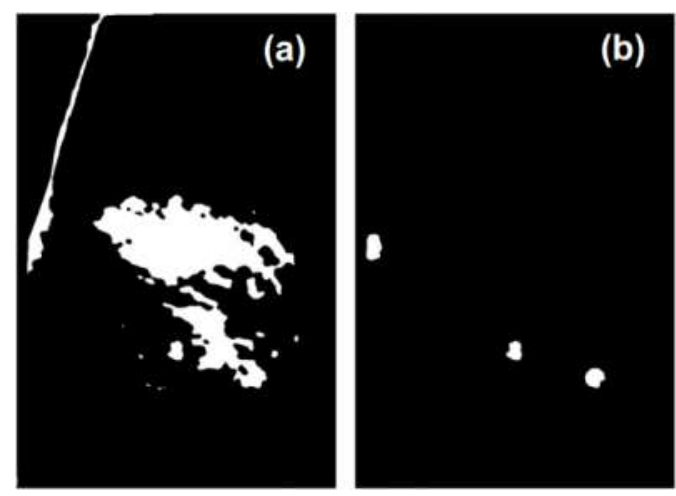

Figura 12: Exemplo do resultado final da deteç̧ão de nódulos. a) Imagem binarizada pela primeira rede (Figura 11), b) Detecção final

Utilizando 120 imagens da base DDSM, este programa teve resultados de $74 \%$ de sensibilidade e 3,5 falsos positivos por imagem. As redes neurais foram avaliadas usando a técnica leave-one-out.

4.7 Segmentador e Classificador de Nódulos (RIBEIRO, 2013) 
O esquema de classificação inicialmente desenvolvido por (RIBEIRO, 2013) é uma adaptação da técnica de classificação por contorno desenvolvida anteriormente (RIBEIRO, 2006). O método consiste em segmentar a imagem utilizando a técnica EICAMM (Enhanced ICA Mixture Model), separando o nódulo e o tecido mamário normal (RIBEIRO, ROMERO, et al., 2013), e, em seguida, calcular uma série de atributos que permitam ao sistema decidir uma classificação.

\subsubsection{Segmentação EICAMM}

A técnica de segmentação EICAMM é uma expansão da técnica ICAMM (ICA Mixture Model) que, por sua vez, é uma optimização da técnica ICA (Independent Component Analysis - Análise de Componentes Independentes). A técnica ICA tenta separar em classes conjuntos estatisticamente independentes, porém misturados, de informações (COMON, 1994; HYVÄRINEN, KARHUNEN e OJA, 2001). Um exemplo típico de uso é a separação de vozes em uma conversa. A expansão conhecida como ICAMM (LEE, LEWICKI e SEJNOWSKI, 2000), tenta superar uma das principais limitações da ICA, que é a suposição de que os dados são independentes. Para suavizar esta restrição, um modelo de misturas (mixture model) é adicionado, permitindo que as classes previstas sejam "misturas", ou seja, tenham elementos que interagem entre si.

Já a técnica EICAMM (RIBEIRO, 2013) tem como principal objetivo ser uma implementação mais rápida e mais robusta da ICAMM. Para obter tais melhorias a EICAMM adiciona o método de Levenberg-Marquardt (MASTERS, 1995), reduzindo a influência de ruídos e acelerando consideravelmente o tempo de convergência do problema.

Quando da adaptação para uso em segmentação de nódulos em imagens mamográficas, partiu-se do princípio que existiriam apenas duas classes: Nódulo e Fundo. A definição clara e a pequena quantidade de classes aceleram o processamento e tendem de modo muito mais forte para convergência (RIBEIRO, ROMERO, et al., 2013).

\subsubsection{Classificação de Nódulos}


Uma vez segmentadas as imagens, foi desenvolvido processo de classificação que começa com a extração dos atributos pertinentes para a decisão (RIBEIRO, 2013). Neste método os atributos são:
i) Variância
ii) Entropia da Diferença
iii) Perímetro
iv) Compacidade
v) Densidade do nódulo

Variância e Entropia da Diferença são atributos diretamente relacionados à textura do nódulo; já Compacidade e Perímetro caracterizam o contorno/forma e Densidade do Nódulo avalia a densidade radiográfica. Essas são as principais características recomendadas para classificação de nódulos pelo Atlas BI-RADS (AMERICAN COLLEGE OF RADIOLOGY, 2003).

O atributo Variância para textura foi definido por Haralick (HARALICK, SHANMUGAM e DISTEIN, 1973), sendo a variação de intensidade ao redor da média. A Variância pode ser calculada seguindo a Eq. 5.

$$
\sigma^{2}=\sum_{i=0}^{G-1}(i-\mu)^{2} p(i)
$$

Eq. 5

aonde $i$ é um dado nível de intensidade, $\mu$ é a média da região e $p(i)$ é a probabilidade de um pixel ser do nível $i$.

Assim como a Variância, o atributo Entropia da Diferença também foi definido por Haralick (HARALICK, SHANMUGAM e DISTEIN, 1973), porém ele foi descrito apenas como uma característica estatística da textura, sem uma correlação visual direta. A Entropia da diferença é calculada usando Eq. 6 e Eq. 7, seguindo as mesmas definições usadas na Eq. 5:

$$
E_{D}=-\sum_{i=0}^{G-1} p_{|x-y|}(i) \log \left[p_{|x-y|}(i)\right]
$$

Eq. 6 


$$
p_{|x-y|}(k)=\sum_{i=0}^{G-1} \sum_{j=0}^{G-1} p(i, j){ }_{k} \begin{gathered}
k=|i-j| \\
k=0,1,2 . . G-2
\end{gathered}
$$

Eq. 7

O Perímetro é calculado diretamente com base na imagem binária segmentada do nódulo obtida na seção anterior. O número de pixels da borda é a melhor aproximação possível do valor real do perímetro do nódulo, considerando as restrições de resolução da imagem digital. Normalmente, quanto maior o perímetro, maior a probabilidade de malignidade do nódulo.

$\mathrm{O}$ atributo Compacidade relaciona o perímetro com a área de uma dada figura bidimensional, avaliando quão compacta a superfície é. A Compacidade é calculada conforme a Eq. 8, tomando por base a mesma imagem binária segmentada utilizada no cálculo do Perímetro.

$$
C=\frac{P}{2 \sqrt{\pi A}}
$$

Eq. 8

onde $P$ é o perímetro da figura e $A$ é a área. O resultado normalmente é comparado a um círculo, onde a compacidade é mínima $(C=1)$. Quanto mais distante de um círculo a figura for, maior será a Compacidade. Como nódulos circunscritos são mais próximos de um círculo do que espiculados, este atributo tende a ser maior em casos malignos e menor em casos benignos.

O atributo Densidade do Nódulo é calculado através da média de intensidades dos pixels segmentados como nódulo. Para isso a imagem binária segmentada do nódulo é multiplicada pela imagem original, resultando em uma imagem em que o nódulo tem os níveis de cinza originais e o fundo é zero. A média dos valores de intensidade dos pontos não zero é a Densidade do Nódulo.

É importante ressaltar que o cálculo de valores de densidade conforme descrito acima não é uma boa avaliação da densidade biológica dos tecidos, sendo melhor 
relacionada à densidade radiológica, ou seja, a taxa de absorção de raios $\mathrm{X}$ dos tecidos. Porém, como os tecidos são conhecidos, é possível correlacionar a densidade biológica com a densidade radiológica, já que tecidos moles tendem a ser mais radiopacos conforme sua maior densidade biológica.

Em seus testes originais (RIBEIRO, 2013), este método apresentou uma taxa média de acerto de 80,5\% usando por volta de 470 imagens provenientes das bases BancoWeb (MATHEUS e SCHIABEL, 2011) e DDSM (HEATH, BOWYER, et al., 2001).

\subsection{Transformação área-ponto (NISHIKAWA, GIGER, et al., 1993)}

A transformação área ponto (NISHIKAWA, GIGER, et al., 1993) trabalha em imagens binárias e consiste em converter cada região positiva (branca) em um único ponto positivo. Esta técnica é usada quando o número de detecções é mais importante do que o tamanho de uma dada detecção. Em uma versão simplificada, o método pode ser descrito de acordo com os seguintes passos abaixo:

i. Varredura da imagem binária em busca de um ponto positivo (Figura 13.b);

ii. Uma vez localizado esse ponto, uma técnica de crescimento de região é utilizada para localizar todos os pontos positivos conectados (Figura 13.c);

iii. A região conectada é substituída por valores negativos exceto por um ponto que é mantido positivo (Figura 13.d);

iv. A varredura, então, continua até outro ponto positivo ser localizado, quando o método retorna ao passo 2 (Figura 13.e);

v. Quando a varredura encontra o fim da imagem o método para (Figura 13.f).

A Figura 13 mostra um exemplo do método seguindo os passos acima.

Existem várias versões deste método, com as principais diferenças sendo a forma de varredura, a definição de vizinhanças nas regiões e a posição final do ponto resultante do processo. Na verdade, o método de varredura faz pouca diferença, alterando apenas a 
ordem na qual as regiões são transformadas, sem efeito no resultado final. A definição de vizinhanças (vizinhos de 4 ou 8 ) tem efeito se o que é considerado uma região conectada inclui conexões na diagonal ou não. Alterações da vizinhança podem acarretar uma menor quantidade de pontos no resultado final. Por último, a posição do ponto resultante da transformada pode ser o ponto inicialmente detectado (como no exemplo da Figura 13), pode ser o centro de massa da região, o último ponto detectado ou qualquer outra variante pertinente ao problema estudado.

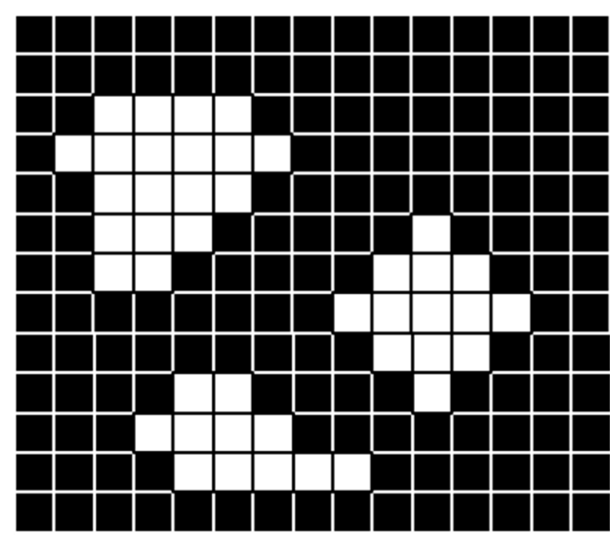

(a)

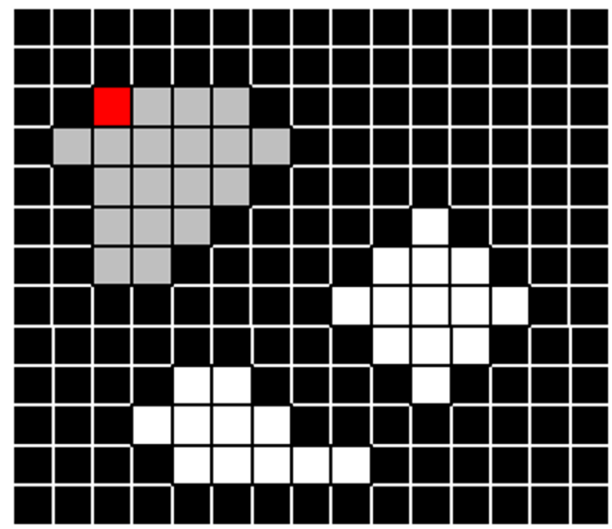

(c)

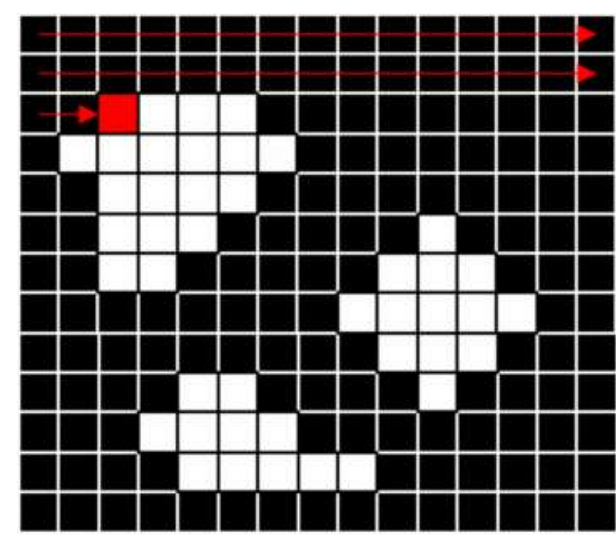

(b)

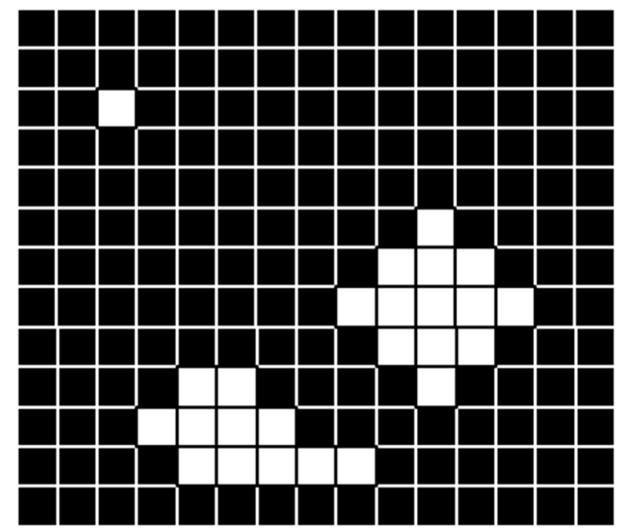

(d) 


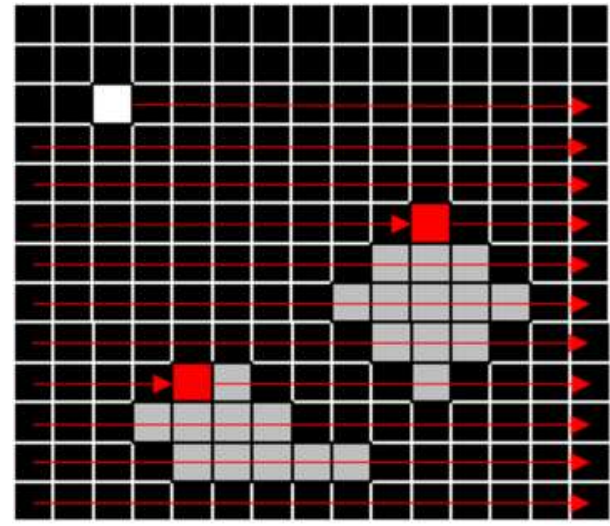

(e)

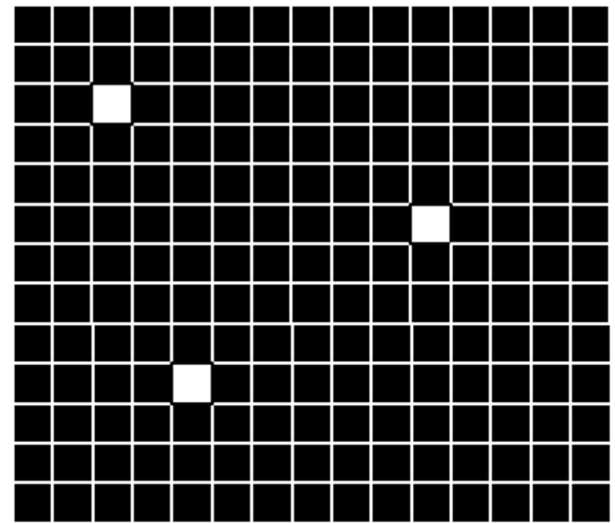

(f)

Figura 13: Exemplo da transformada área ponto. (a) Imagem binária original, (b) Varredura até localizar um ponto positivo, (c) Crescimento de região para localizar pontos positivos conectados, (d) Substituição da região por ponto, (e) Varredura até localização de outros pontos positivos ou fim da imagem, (f) Imagem resultado.

Para efeito desta tese, a transformada área-ponto - aplicada ao processo envolvendo detecção de agrupamentos de microcalcificações na imagem mamográfica sempre utilizará um método de varredura da esquerda para direita e de cima para baixo (conforme o exemplo da Figura 13), com vizinhança de 4 e o ponto demarcado será o centro de massa da região.

\subsection{Detector de nódulos no músculo peitoral}

Normalmente, a região do músculo peitoral não contém nódulos mamários indicativos de câncer, mas linfonodos axilares são visíveis nesta região da mama. Estes linfonodos são importantes para avaliar a extensão do comprometimento, caso câncer seja diagnosticado.

Por conta da homogeneidade da área, detectar nódulos na região do músculo (sejam eles anômalos ou não) e possível simplesmente localizando e demarcando os pontos de máximo regional. Para isso utiliza-se uma classe nativa da biblioteca ImageJ chamada MaximumFinder, obtendo o resultado através do método findMaxima. O método 
findMaxima tem como entrada um parâmetro chamado "Noise tolerance", que define o nível de suavização que será realizado na imagem antes da detecção propriamente.

No trabalho de (MENECHELLI, 2013), a escolha deste parâmetro foi automatizada, associada ao número de achados em cada imagem. Testes realizados mostraram que dificilmente existem mais do que 7 linfonodos por imagem, o que levou ao estabelecimento de um limite de localização de 7 pontos no sistema de processamento desenvolvido. Se forem localizados mais do que isso o método aumenta o valor de "Noise tolerance" até que um resultado com menos de 7 marcações seja encontrado.

Em seus testes originais, o detector apresentou 74,5\% de sensibilidade com 3,5 falsos positivos por imagem. 


\section{Capítulo 5 Materiais e métodos: CADe/Dx Completo}

\subsection{CADx LAPIMO}

$\mathrm{O} \underline{\text { esquema }} \mathrm{CADx}^{1}$ desenvolvido pelo grupo do Laboratório de Análise e Processamento de Imagens Médicas e Odontológicas - LAPIMO (http://lapimo.sel.eesc.usp.br), onde este projeto se desenvolve - foca em pesquisa e desenvolvimento de novas técnicas, sendo composto de diferentes módulos criados por diferentes pesquisadores, muitos dos quais não fazem mais parte do grupo. Com os diferentes módulos do sistema estando quase completos (exceto por algumas seções que serão discutidas posteriormente neste trabalho), tornou-se importante criar um programa $\underline{\mathrm{CADx}}^{1}$ de fácil acesso e que possa ser utilizado com treinamento mínimo pela comunidade médica.

Uma dificuldade deste projeto foi o fato de que cada um dos módulos foi criado e desenvolvido por um pesquisador diferente, trabalhando sozinho, com o intuito de completar um projeto ou obter um conjunto de resultados, ou seja, os códigos fontes foram construídos sem um desenho prévio ou preocupação com a arquitetura de software. Como consequência, os códigos são dificilmente modularizados e esparsamente comentados.

Além disso, diferentes linguagens foram utilizadas para os desenvolvimentos originais, incluindo DELPHI ${ }^{\circledR}$ (ENBARCADERO, 2014), M-code (MATLAB ${ }^{\circledR}$ ) (MATHWORKS, 2014) e JAVA® (ORACLE, 2014).

\footnotetext{
1 Durante este trabalho será utilizado o termo "esquema CADx" referenciando as técnicas, ferramentas e protótipos. Já "programa CADx" será usado para referenciar o objetivo final deste projeto: um programa para uso público com as ferramentas e técnicas desenvolvidas.
} 
O intuito final do programa CADx desenvolvido neste projeto é sempre ser o mais versátil possível; por isso decidiu-se construir o programa na linguagem JAVA®, dada a facilidade de utilização do código em diferentes plataformas e sistemas operacionais. Além disso, a comunidade de programadores em JAVA ${ }^{\circledR}$ oferece extensas e detalhadas bibliotecas em sistemas fair-use (liberadas para uso não comercial) e open-source (liberadas para uso gratuito), incluindo a biblioteca ImageJ® (RASBAND, 2011) utilizada neste projeto.

\subsection{Engenharia de Software}

Ao aplicar técnicas de engenharia de software (ABRAN e MOORE, 2004; PRESSMAN, 2010) no desenvolvimento do esquema CADx, o primeiro passo foi a construção de uma lista de requisitos.

Três fontes principais foram usadas para construir a lista de requisitos: o Atlas BIRADS (AMERICAN COLLEGE OF RADIOLOGY, 2003), radiologistas experientes e a experiência acumulada nas últimas décadas de trabalho pelo LAPIMO.

O Atlas BI-RADS fornece um protocolo distinto para análise e diagnóstico de imagens mamográficas. De acordo com as recomendações do Atlas, a mama deve ser analisada globalmente, localmente, em comparação a outra orientação e em comparação à outra mama. No entanto, apesar do Atlas definir regras para classificar um dado caso como câncer, as características são classificadas a critério do observador especializado. Por exemplo, o Atlas classifica a densidade em 4 tipos e define cada um deles qualitativamente, não quantitativamente, podendo causar conflito entre radiologistas sobre a exata densidade de um dado caso.

Apesar do Atlas BI-RADS fornecer informações importantes, as informações mais cruciais nesse sentido vieram dos radiologistas contatados durante $\mathrm{O}$ desenvolvimento deste projeto. Com o auxílio deles foi possível entender em detalhes o procedimento para avaliação de imagens mamográficas e entender o tipo de informação pertinente e importante para o radiologista e, assim, como melhor apresentá-las. 
Por fim, levaram-se em conta os trabalhos desenvolvidos nas últimas décadas pelo LAPIMO, com o intuito de aproveitar as pesquisas já realizadas e desenvolver a lista de requisitos já incluindo o uso dos programas e técnicas anteriores.

Com base nos requisitos levantados, foi possível montar um modelo de como o esquema CADx deveria funcionar. Tendo esse modelo inicial como base, cada programa já desenvolvido que deveria participar do modelo foi exaustivamente analisado em nível de código, com o objetivo de entender as interações das diferentes classes/funções, suas entradas e saídas e limitações.

Em alguns casos a análise dos programas identificou a necessidade de alterações radicais, de modo que os respectivos programas fossem reprojetados. Estes casos e aqueles em que o programa não estava em JAVA estão detalhados nas descrições a seguir.

\subsection{Modelo Final}

Essa detalhada análise levou a alterações do modelo, adaptando o sistema ao modo como tais programas foram construídos. Assim, o esquema CADx desenvolvido neste projeto segue o esquema mostrado na Figura 14. A classe principal é a chamada CADxLAPIMO; cada nó do grafo representa uma classe e será descrito em sua respectiva seção.

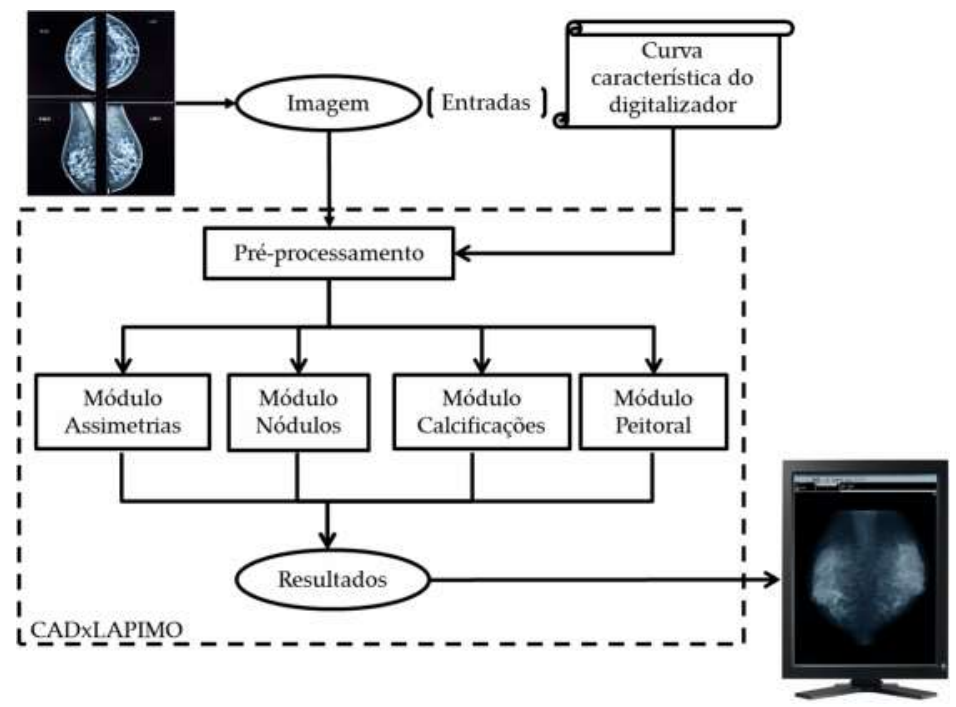

Figura 14: Esquema do programa CADx-LAPIMO. 
Para evitar confusões, a seguinte terminologia precisa ser clarificada para adequado entendimento:

i. Detecção: implica localizar algo (um sinal) na imagem como um todo ou em uma região de interesse que seja importante para o radiologista ou para os passos seguintes do esquema; esse sinal detectado é comumente denominado de forma genérica de "achado" na análise da imagem mamográfica;

ii. Segmentação: implica separar o achado do fundo da imagem, seja esse fundo a região da imagem fora da mama ou as estruturas que não importam para o diagnóstico;

iii. Classificação: implica indicar o que a região detectada e segmentada pode ser, incluindo o risco da estrutura indicar ou ser câncer.

\subsubsection{Abertura da imagem}

Para realizar a operação de abertura e manipulação primária da mamografia foi escolhida a biblioteca ImageJ (RASBAND, 2011), por ser capaz de manipular os formatos de imagem que interessam ao projeto - em particular imagens TIFF e LJPEG de 8 a 16 bits de resolução de contraste, além de oferecer várias ferramentas interessantes ao desenvolvedor. Estas ferramentas incluem um programa que permite visualizar e manipular com facilidade as imagens, assim como criar plugins e scripts para testes.

A principal classe utilizada desta biblioteca foi a ImagePlus, que contém os dados da imagem propriamente no atributo da classe ImageProcessor e as informações necessárias para apresentação da imagem nas classes ImageWindow e ImageCanvas.

A única entrada necessária para uso da classe ImagePlus é o caminho do arquivo de imagem. A seleção do método de abertura e descompactação das informações pertinentes é feita automaticamente pelo construtor. 
Já a classe ImageProcessor contém métodos que permitem alterar os valores dos pixels da imagem, possibilitando a implementação das técnicas descritas a seguir e fácil visualização dos resultados parciais do sistema. Também são incluídos métodos de seleção e recorte de RIs (regiões de interesse) e métodos de marcação na imagem.

\subsubsection{Pré-processamento}

Imagens mamográficas podem ser obtidas de variadas fontes com diferentes padrões de qualidade, dependendo dos equipamentos utilizados para sua aquisição, revelação (quando necessário) e digitalização. Nesta fase do processamento, o intuito é padronizar as imagens, tentando retirar as variáveis associadas à qualidade do processo de aquisição.

Ao longo do desenvolvimento deste projeto, o foco destas correções se tornou o método de correção baseado na curva característica do digitalizador (Correção BCC), conforme descrito a seguir. Outras correções foram sugeridas e testadas, mas decidiu-se por não implementá-las no programa final devido a sua baixa relação custo-benefício.

A correção BCC tenta remover as variações do digitalizador utilizado e padronizar os resultados de imagens digitalizadas por diferentes equipamentos. Na Figura 15 temos o esquema do módulo de pré-processamento. Para utilização da classe "PreProcessamento" do presente projeto são necessárias a imagem original e a curva característica do digitalizador utilizado, quando disponível. 


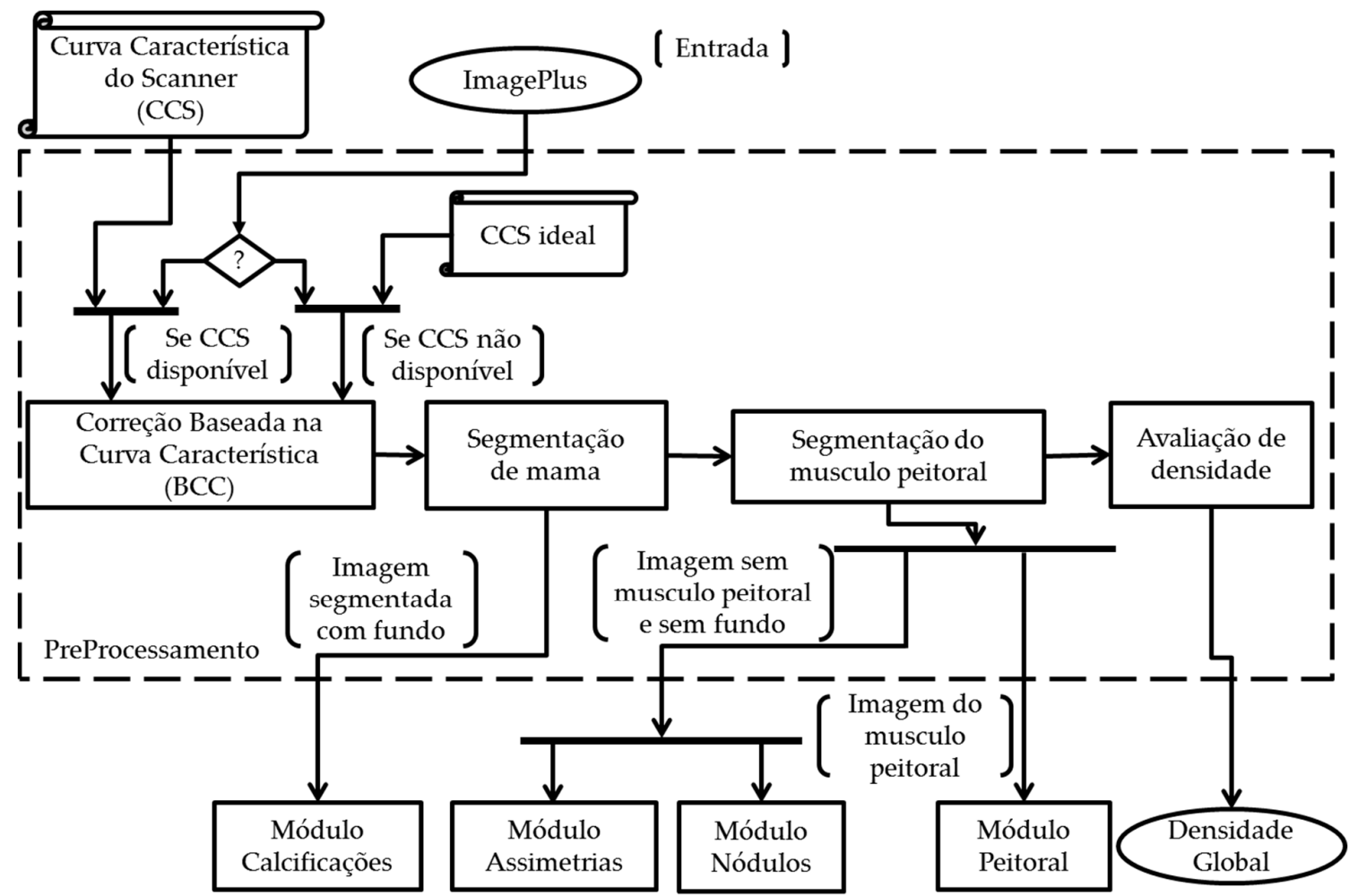

Figura 15: Esquema do módulo de pré-processamento.

a) Correção Baseada na Curva Característica (Correção BCC) (GOES, 2010)

Em seus testes inicias, a correção BCC foi avaliada usando esquemas CADe, em particular, esquema de detecção de microcalcificações e de segmentação de nódulos. Estes testes mostraram uma melhoria clara nos resultados do esquema CADe, principalmente no caso de imagens gravadas em filme e digitalizadas por scanners cuja curva característica se distanciava da do filme-referência. No entanto, nenhum teste havia sido realizado considerando os efeitos dessa correção na observação humana.

Por isso, aqui procurou-se planejar inicialmente um teste bem simples para avaliar se havia alguma diferença visual perceptível nas imagens com a correção BCC do ponto de vista de um especialista em análise de imagens mamográficas. Este teste foi feito usando-se 74 imagens das bases BancoWeb (MATHEUS e SCHIABEL, 2011) e DDSM (HEATH, BOWYER, et al., 2001), todas contendo pelo menos um achado nãodemarcado para ser usado como referência para avaliação. 
Cada imagem foi mostrada ao radiologista simultaneamente em sua versão original e transformada pela correção BCC e foi pedido que indicasse a melhor delas. Os resultados mostraram que existia uma diferença dependendo do digitalizador utilizado.

Uma vez que a existência de um impacto visual foi confirmada, para sua avaliação foram selecionas 100 imagens provenientes das bases BancoWeb (MATHEUS e SCHIABEL, 2011), DDSM (HEATH, BOWYER, et al., 2001) e INBreast (MOREIRA, AMARAL, et al., 2012), de acordo com a seguinte distribuição:

i. $\quad 15$ imagens da base BancoWeb, digitalizadas usando scanners Lumiscan com $150 \mu \mathrm{m}$ de resolução espacial e 12 bits de resolução de contraste.

ii. $\quad 25$ imagens da base INBreast, provenientes de sistemas FFDM com $70 \mu \mathrm{m}$ de resolução espacial e 14 bits de resolução de contraste.

iii. $\quad 47$ imagens da base DDSM, digitalizadas usando um Lumiscan 200 com resolução de $50 \mu \mathrm{m}$ e 12 bits de resolução de contraste.

iv. 13 imagens da base DDSM, digitalizadas usando um Howtek MultiRAD 850, com a mesma resolução acima (50 $\mu \mathrm{m}$ e 12 bits).

Inicialmente, um conjunto de teste contendo uma imagem de cada um dos tipos acima foi apresentado a radiologistas experientes e lhes foi pedido que ajustasse o brilho do monitor de acordo com suas preferências para análise das imagens. Uma vez que cada radiologista estava confortável e o brilho do monitor selecionado, isto não foi mais alterado.

Todas as imagens foram transformadas usando 3 técnicas: a correção BCC, a equalização de imagem tradicional (GONZALES e WOODS, 2008) e uma redução direta de brilho. Cada um dos especialistas foi apresentado às 4 versões (original +3 transformadas) de cada imagem. O objetivo foi ranquear as imagens de melhor para pior. Os resultados confirmaram que a tendência encontrada nas avaliações com CAD também reflete na observação direta, com os especialistas testados usualmente preferindo as imagens transformadas pela correção BCC. 
Originalmente este programa se encontrava em DELPHI (ENBARCADERO, 2014), mas, para ser parte do projeto atual, todo seu código foi convertido para JAVA. Com a oportunidade, novos testes foram realizados, redemonstrando não só a funcionalidade do método em aplicações de CADe/CADx, mas também melhora de contraste para visualização da imagem por radiologistas.

No esquema do módulo (Figura 15) temos a entrada da "Curva característica do digitalizador", sendo, até o momento, a única entrada além da imagem. Se esta curva não for fornecida ao sistema, a correção da digitalização será realizada usando a curva ideal descrita no Capítulo 4 (seção 4.1). O programa foi desenhado para receber a curva de digitalização como um arquivo de texto (extensões .txt, .dat ou similares) seguindo a regra de formato abaixo:

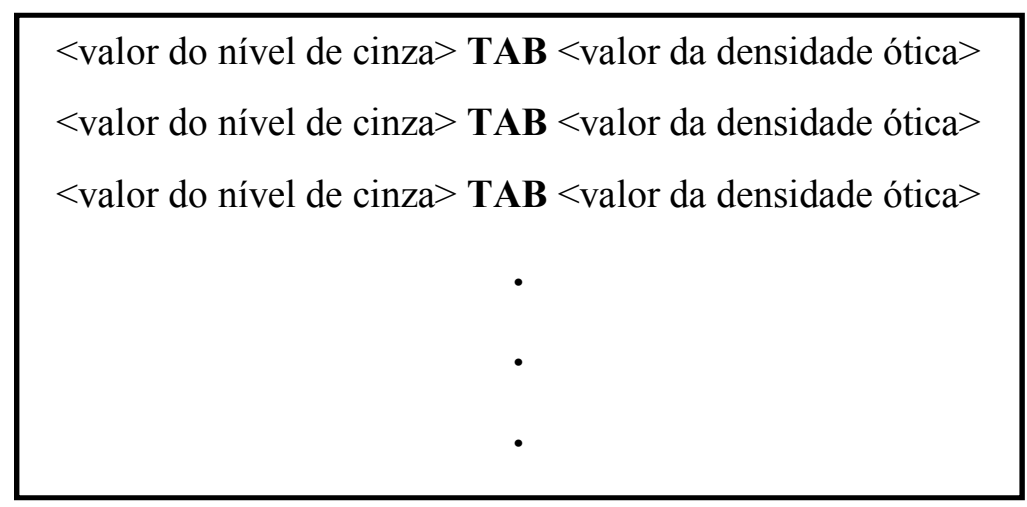

Figura 16: Formato previsto de leitura da Curva Característica

No momento, o programa contém as curvas mostradas na Figura 4, mas outras podem ser adicionadas com facilidade no futuro. Este método está integrado à classe préprocessamento.

b) Segmentação da mama (MENECHELLI, 2013)

Com o intuito de reduzir a área de manipulação durante os passos seguintes, a imagem corrigida no passo a) é segmentada de modo a separar a região da mama 
propriamente, removendo as regiões desnecessárias para o processamento (Figura 17), como o fundo e as tags de identificação. A imagem original e os limites do recorte são guardados para que, ao fim do processamento, a imagem original possa ser reconstruída para apresentação ao usuário. A imagem segmentada não faz parte do resultado final e não é apresentada ao usuário.

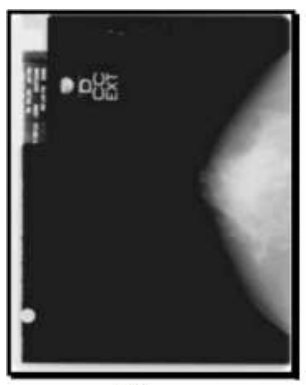

(a)

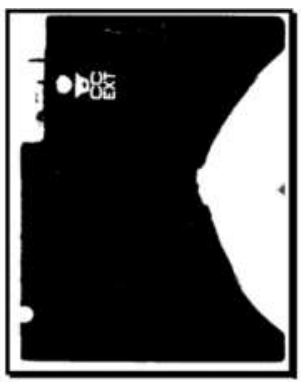

(b)

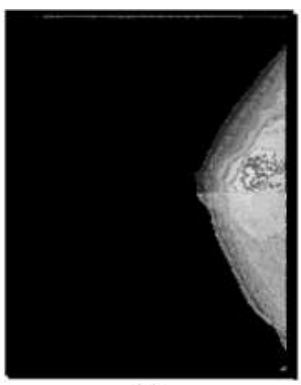

(c)

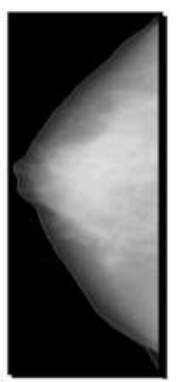

(d)

Figura 17: Exemplo de segmentação de mama (MENECHELLI, 2013). (a) Imagem original, (b) imagem (a) após limiarização, (c) imagem (a) com a mama delimitada e fundo removido, (d) imagem final para processamento.

Para avaliar o funcionamento deste método, imagens provenientes das bases

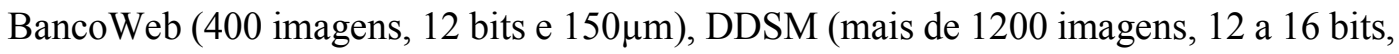
43 a $50 \mu \mathrm{m})$ e INBREAST (120 imagens, 14bits e $70 \mu \mathrm{m}$ ) foram utilizadas. Após a segmentação as imagens foram visualmente inspecionadas, verificando-se se os tags tinham sido removidos e se o tecido mamário continuava inteiramente visível. Apesar do grande número de imagens, todas foram corretamente segmentadas.

Testes com este sistema mostram que a conversão do fundo para preto provoca um grande aumento no contraste entre o fundo e a borda da mama. Esse aumento de contraste provoca detecções errôneas no método de detecção de microcalcificações (seção 5.3.3c.1 ). Por conta disso, neste programa, a imagem é separada em duas, uma versão com o fundo convertido para preto (como na Figura 17.d) e outra recortada, mas com o fundo da imagem original. A imagem com o fundo original será usada apenas na detecção de microcalcificações. 
Este método está integrado à classe pré-processamento. Sua entrada é uma imagem e a saída são as duas imagens descritas acima, com o fundo substituído por preto e com o fundo original.

c) Segmentação do músculo peitoral (MENECHELLI, 2013)

Nas imagens mamárias obtidas na posição Médio-Lateral Oblíqua (MLO), parte do músculo peitoral é visível como uma região de alta densidade. Em esquemas CADe/Dx a alta densidade da musculatura pode confundir o sistema e resultar em falsos positivos ou falsos negativos, além de alterar a classificação de densidade e, por consequência, afetar o detector de assimetrias.

Não é necessário alto grau de precisão nesta segmentação, já que uma segmentação próxima se mostra mais do que suficiente tanto para as análises do Módulo Peitoral (seção 5.3.3d) quanto para evitar erros na avaliação de densidade (seções 5.3.2d e 5.3.3a).

Para o resultado final duas imagens separadas são produzidas pelo método. A primeira é a imagem original segmentada em b) (acima) multiplicada pelo inverso da imagem binária resultante do método de segmentação (Figura 8.b), resultando em uma imagem em que o músculo peitoral é substituído por preto. A segunda imagem é a original multiplicada pela imagem binária resultante do método de segmentação (Figura 8.b), que produz uma imagem contendo apenas o músculo peitoral e o resto preto.

Originalmente, em testes realizados com 100 imagens MLO provenientes do BancoWeb (MATHEUS e SCHIABEL, 2011), todas as segmentações foram consideradas satisfatórias por especialistas (MENECHELLI, 2013).

Esse método foi desenvolvido já em JAVA, mas algumas adaptações foram necessárias para coordenar com os métodos da classe pré-processamento. Sua entrada é apenas a imagem segmentada em b e tem como saída duas imagens: da mama segmentada sem o músculo peitoral - que é utilizada no Módulo Assimetrias (seção 5.3.3a) e no 
Módulo Nódulos (seção 5.3.3b) - e a do músculo peitoral apenas, que é utilizada no Módulo Peitoral (5.3.3d).

d) Avaliação de densidade (MENECHELLI, 2013)

Em sua versão final para integração ao programa CADx, o sistema apresenta o resultado ao usuário no esquema de duas classes descrito no Capítulo 4 (seção 4.4), mas o resultado em 4 classes ainda é armazenado como variável. Futuramente um método superior possa ser desenvolvido de modo a apresentar o resultado seguindo as regras BIRADS.

Esse método foi originalmente desenvolvido já em JAVA, mas algumas adaptações foram necessárias para coordenar com os métodos da classe PreProcessamento. Em particular, o funcionamento correto dessa etapa exige que a imagem de entrada tenha passado pelos métodos de segmentação (seções b) e c) acima) ou similares, pois este método depende da avaliação do tecido mamário sem interferências do músculo peitoral ou fundo. A saída desse programa é apenas o valor numérico do resultado da classificação.

\subsubsection{Processamento}

Aqui, as imagens padronizadas na seção anterior (seção 5.3.2) serão analisadas. $O$ esquema do módulo de Processamento se encontra na Figura 18. Cada módulo corresponde a uma classe separada. 


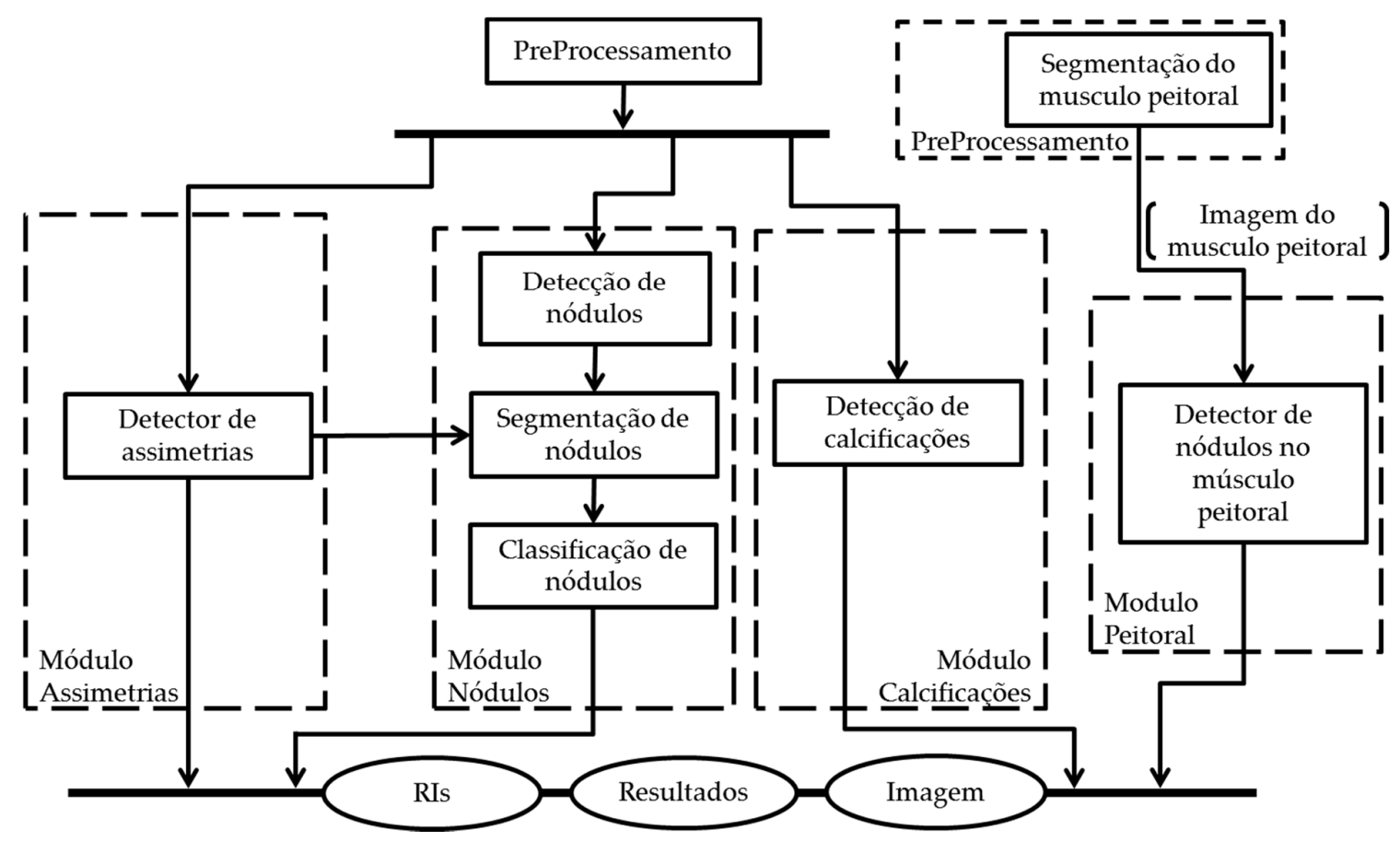

Figura 18: Esquema dos módulos de Processamento do esquema CADx.

Todos os resultados, sejam textuais, imagens ou RIs, são armazenados como atributos da classe CADxLAPIMO, assim como o resultado da avaliação de densidade (seção 5.3.2d) no pré-processamento.

Ao contrário da classe pré-processamento, o processamento é feito como um conjunto de quatro módulos separados descritos abaixo.

\section{a) Módulo Assimetrias}

Este módulo consiste de apenas uma classe, qual seja o Detector de Assimetrias locais (SCHIABEL e MENECHELLI, 2013). Conforme descrito anteriormente, este módulo está funcional em JAVA, requerendo como entrada duas imagens (mama direita e esquerda na mesma orientação) e retornando as regiões de mais alta densidade que tenham sido reconhecidas como assimetrias. 
Além de serem demarcadas no resultado final ao usuário, essas regiões são enviadas para o segmentador e classificador de nódulos com o objetivo de avaliar o risco de malignidade da assimetria.

\section{b) Módulo Nódulos}

Este módulo consiste de três classes, uma para a detecção propriamente de nódulos (b.1 ), uma para segmentação (b.2 ) e uma para classificação (b.3 ), todas descritas em sua respectiva seção abaixo. Elas são processadas em sequência com a entrada sendo a imagem segmentada resultante do pré-processamento.

\section{b.1. Deteç̧ão de nódulos (BARBOSA FILHO, 2012)}

Os sistemas de segmentação (b.2 ) e classificação de nódulos (b.3 ) foram desenvolvidos para processar regiões de interesse contendo nódulos e não imagens inteiras; portanto, torna-se necessário recortar da imagem original regiões de interesse (RIs) para sua manipulação. O programa desenhado por Barbosa Filho (BARBOSA FILHO, 2012), descrito em detalhes na seção 4.6 será utilizado para este fim.

Como o programa original não continha o pré-processamento da Correção BCC (GOES, SCHIABEL e SOUSA, 2013), descrito na seção 4.1, foi necessário refazer os testes incluindo tal correção usando imagens da base DDSM.

Este programa foi desenvolvido em JAVA e foi completamente integrado ao sistema CADx. Sua entrada é apenas a imagem segmentada e sem o músculo peitoral. Sua saída são as RIs na forma das coordenadas de retângulos que contêm toda a região detectada nesse módulo. 


\section{b.2 . Segmentação de nódulos (OTSU, 1979; RIBEIRO, 2013)}

As massas detectadas no passo acima (b.1 ) são segmentadas individualmente nesta etapa. Duas técnicas foram consideradas para esse processo: a EICAMM (RIBEIRO, 2013) - que era a mais recentemente desenvolvida com essa finalidade para aplicação no esquema - e a técnica de Otsu (OTSU, 1979).

As entradas deste módulo são as regiões retangulares fornecidas pelo módulo de detecção e, para cada imagem, duas saídas são geradas: uma imagem binária com a região branca sendo o nódulo e uma imagem em nível de cinza - que é a multiplicação da entrada pela imagem binária, resultando em uma imagem com fundo preto (valor 0 ), mas com o nódulo mantendo suas características originais.

Testes comparativos simples foram feitos entre os métodos, utilizando 44 RIs de nódulos da base INBreast. Todas as imagens da base INBreast são de um equipamento FFDM com 14 bits de resolução de contraste e $70 \mu \mathrm{m}$ de resolução espacial. Essa mesma base fornece um contorno grosseiro de cada nódulo e esse contorno foi utilizado para comparar o resultado da segmentação produzida por cada uma das duas técnicas mencionadas (Otsu e EICAMM). A taxa de acerto foi utilizada para avaliar a melhor técnica de segmentação.

Com o intuito de reduzir o ruído nas bordas da detecção cada método foi testado em sua forma original e com o uso de morfologia matemática para suavização. Em particular, foi testado o uso de abertura seguida de fechamento com um elemento estruturante no formato de disco com diâmetro de 3, 5, 7 e 9. Parta cada imagem, as 5 segmentações resultantes - a sem suavização e as 4 com suavizações usando diferentes tamanhos de elemento - foram comparadas ao contorno fornecido pela base.

Os resultados para as duas técnicas não demonstraram diferença entre si e novos testes foram realizados levando em conta a classificação de nódulos. Estes novos testes são descritos no item a seguir. 


\section{b.3 . Classificação de nódulos}

Este método é a parte central deste esquema e que o define como CADx e não CADe. Neste módulo as RIs segmentadas pelo programa de segmentação de nódulos (b.2) são classificadas entre suspeitas ou não, fornecendo uma segunda opinião e dando mais informações ao médico sobre o nódulo encontrado.

A classificação utiliza as RIs obtidas na detecção de nódulos (b.1 ) e no detector de assimetrias (seção 5.3.3a), assim como as segmentações obtidas acima (b.2 ). O classificador descrito aqui foi baseado nos estudos realizados por (RIBEIRO, 2013) descritos na seção 4.7, Capítulo 4.

Em sua versão original (RIBEIRO, 2013), este método utilizava um conjunto de 3 redes neurais que, por sua vez, utilizavam como entrada os 5 atributos abaixo:
i) Entropia da Diferença
ii) Variância
iii) Compacidade
iv) Perímetro
v) Densidade do nódulo

Durante o projeto atual, testes com mais de 500 imagens provenientes da base DDSM (HEATH, BOWYER, et al., 2001) foram realizados visando avaliar os resultados de tal classificador com a finalidade de se verificar a sua viabilidade e performance para a proposta do esquema CADx em questão. Estes testes mostraram, porém, uma necessidade de reformulação deste módulo classificador para o esquema CADx final.

Primeiramente, todos os atributos precisam ser independentes do tamanho da RI; por isso o atributo Perímetro (iv) foi removido da lista, já que nódulos maiores tendem a ter um maior perímetro que nódulos menores, mesmo que ambos sejam benignos. $\mathrm{O}$ atributo Compacidade (iii) já tem uma correspondência com o perímetro, independentemente do tamanho do nódulo ou da RI selecionada. 
Também é importante que os atributos sejam invariantes em relação à dose específica utilizada para formação da imagem. Por conta disso o atributo Densidade do Nódulo (v) foi combinado com um novo atributo chamado Densidade do Fundo, formando um único atributo chamado Densidade Relativa, calculado como a razão entre a Densidade do Nódulo e a Densidade do Fundo.

A Densidade do Fundo é calculada de modo similar à Densidade do Nódulo, conforme descrito na seção 4.7 do Capítulo 4, mas a imagem segmentada é invertida. Nesse caso, a média dos valores não zero será chamada de Densidade do Fundo.

Um aspecto interessante e útil é que, assim, o atributo Densidade Relativa, por ser a razão daquelas duas densidades anteriores, se mostra invariante em relação à dose utilizada no processo de aquisição da imagem original.

Para testar e escolher os atributos mais eficientes para classificação dos nódulos, então, 568 RIs da base DDSM (HEATH, BOWYER, et al., 2001) foram selecionadas. Todas as imagens são de 12 bits de resolução de contraste, com resolução espacial de 50 $\mu \mathrm{m}$ por pixel, e digitalizadas por um digitalizador Lumiscan 200. As RIs foram recortadas em retângulos rente aos limites do nódulo, conforme descrito no arquivo overlay de cada imagem.

No teste, todas as RIs foram pré-processadas usando a correção BCC, segmentadas pelo método de Otsu e pela EICAMM, e os cinco atributos conforme especificados acima foram extraídos das imagens resultantes das duas segmentações. Cada atributo foi avaliado separadamente em busca de informações significativas para a classificação. As classes consideradas foram apenas "maligno" e "benigno", conforme laudo fornecido pela base DDSM.

Para cada atributo foi selecionado um limiar e todas as RIs cujos valores de tal atributo estivessem acima deste limiar foram consideradas malignas, e benignas se abaixo dele. A sensibilidade e a especificidade foram calculadas para cada limiar e, caso os dois valores estivessem abaixo de 50\%, a regra foi invertida (maior do que limiar representa benigno, menor que o limiar representa maligno). O valor do limiar foi o elemento variável utilizado para construção da curva ROC. 
A avaliação foi feita com base nesta curva ROC de cada atributo. Os atributos que apresentaram os melhores resultados foram selecionados com o melhor limiar encontrado. As curvas foram construídas para as duas técnicas de segmentação separadamente, com o intuito de avaliar que técnica de segmentação deveria ser usada. No capítulo Resultados e Discussão (Capítulo 7), estas curvas são apresentadas e seus resultados discutidos em detalhes.

Os resultados desses testes indicaram que os atributos mais recomendados para a classificação são Entropia da Diferença, Variância, Compacidade e Densidade Relativa. As duas técnicas de segmentação mostraram resultados muito próximos, mas como o método de Otsu tem um custo computacional muito menor, ele foi selecionado como técnica de segmentação mais apropriada para o projeto final.

\section{c) Módulo Calcificações}

c.1. Detecção de 'clusters' de microcalcificações (NUNES, SCHIABEL e GOES, 2007; MATHEUS, FERRO NETO e SCHIABEL, 2013)

É comum que agrupamentos de microcalcificações estejam associados a câncer de mama, mesmo quando o câncer ainda está em fase inicial (EGAN, MCSWEENEY e SEWELL, 1980) por isso, é um parâmetro excelente para detecção precoce.

A detecção de microcalcificações aqui utiliza uma adaptação do sistema apresentado em (NISHIKAWA, JIANG, et al., 1992) e (NUNES, SCHIABEL e GOES, 2007). Inicialmente esse sistema havia sido projetado para trabalhar com RIs préselecionadas. Uma vez detectadas, o sistema utilizava um parâmetro de distância baseado na resolução espacial da imagem para relacionar as microcalcificações e encontrar agrupamentos (clusters).

Durante este projeto esse programa foi reconstruído para ampliar suas capacidades, permitindo o uso da técnica em imagens inteiras de qualquer resolução espacial. Atualmente este módulo funciona seguindo o esquema na Figura 19. 


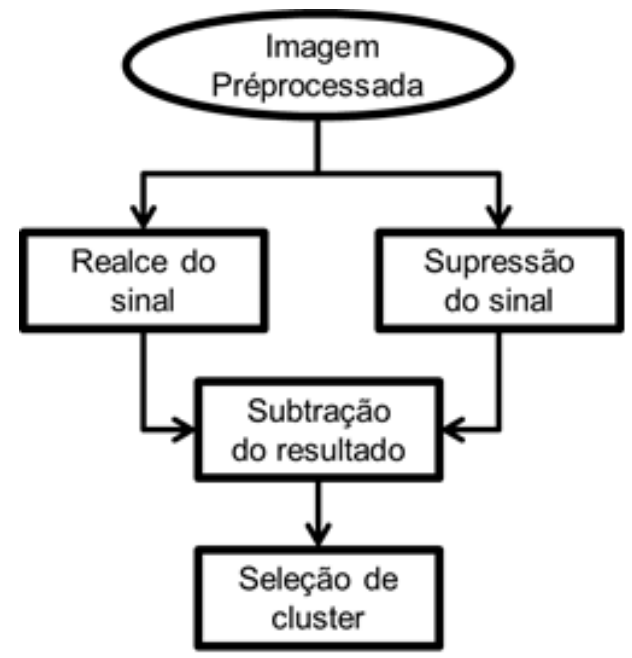

Figura 19: Esquema do módulo atual de detecção de agrupamento de calcificações

A imagem pré-processada sem o recorte da mama e sem a remoção do músculo peitoral é usada neste módulo. Ela é copiada e processada de dois modos diferentes: primeiro, usa-se um filtro do Laplaciano de uma função Gaussiana, também conhecido como função chapéu mexicano, conforme

$$
F(x, y)=\frac{1}{\pi \sigma^{4}}\left(1-\frac{x^{2}+y^{2}}{2 \sigma^{2}}\right) e^{-\frac{x^{2}+y^{2}}{2 \sigma^{2}}}
$$

Eq. 9

onde $\sigma$ é calculado com base na resolução $R$ da imagem em $\mu$ m, seguindo a Eq. 10. O valor de $\sigma$ foi determinado empiricamente em (FERRO NETO, 2012).

$$
C=\frac{P}{2 \sqrt{\pi A}}
$$

Na Figura 20 temos um exemplo de um corte central do filtro utilizado, assim como os filtros de Chan (CHAN, DOI, et al., 1998) e de Schiabel (SCHIABEL, NUNES, et al., 2000). Este filtro tem um formato similar às microcalcificações desejadas, realçando-as na imagem. 


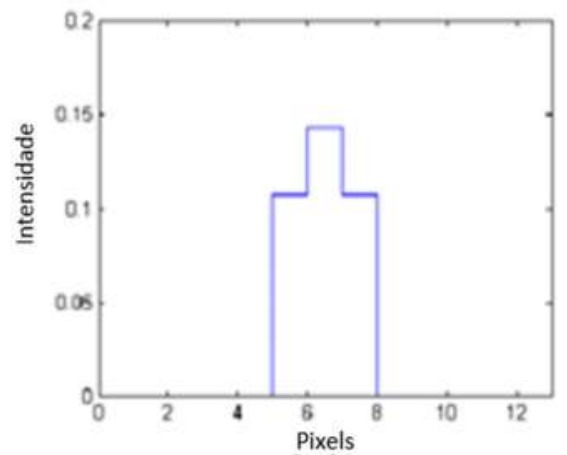

(a)

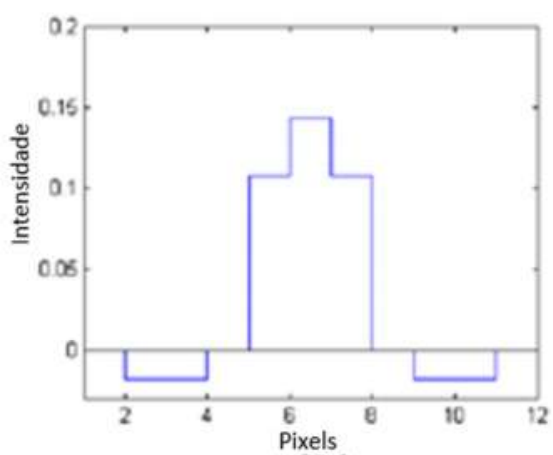

(b)

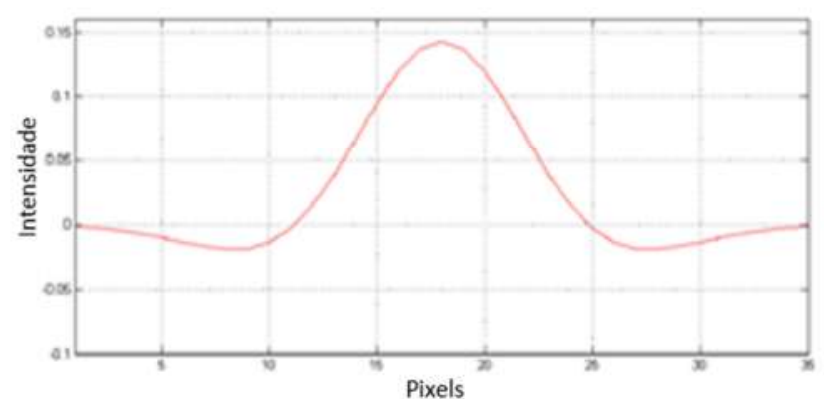

(c)

Figura 20: Filtro de realce de sinal. (a) Chan (CHAN, DOI, et al., 1998), (b) Schiabel (SCHIABEL, NUNES, et al., 2000) e (c) Versão final

O segundo passo consiste de processar a imagem de entrada usando um filtro de média de tamanho $S$, conforme Eq. 11, onde $R$ é a resolução em $\mu \mathrm{m}$. O objetivo deste filtro é atenuar as microcalcificações, deixando apenas o fundo da imagem.

$$
S=\frac{450}{R}
$$

Eq. 11

A imagem suavizada é, então, subtraída da imagem realçada, conservando-se as calcificações e removendo-se o fundo da imagem.

A imagem resultante da subtração tem seu histograma levantado e uma porcentagem dos sinais com intensidade maior é considerada uma detecção positiva de uma calcificação. Essa porcentagem é influenciada por características da imagem e seu valor foi utilizado como variável para a construção de uma curva ROC para avaliação do 
melhor valor para tal variável - chamada aqui de "topo", e cuja caracterização é detalhada no Capítulo 7 (Resultados e Discussão).

Como calcificações solitárias são comuns e em geral não são sinais indicativos de suspeita clínica, realiza-se uma seleção de clusters, mantendo-se regiões com múltiplas detecções, mas removendo-se os eventos singulares.

Para tanto, o primeiro passo é uma transformação área ponto (NISHIKAWA, 1994), que permite que as calcificações sejam reduzidas a um único ponto de detecção central. Esse método facilita a contagem de calcificações no próximo passo.

Em seguida, a imagem de resolução espacial $\mathrm{R}$ em $\mu \mathrm{m}$, dada em $\mu \mathrm{m}$, é rastreada para detectar regiões em que haja mais de três calcificações detectadas em um quadrado de lado L pixels, conforme Eq. 12. Essa definição de cluster segue as recomendações do Atlas BI-RADS (AMERICAN COLLEGE OF RADIOLOGY, 2003). Tais regiões são demarcadas como detecções positivas de clusters de microcalcificações.

$$
L=\frac{500}{R} \quad \text { Eq. } 12
$$

Este módulo tem como entrada a imagem reduzida na segmentação, mas com fundo e músculo peitoral intactos. Sua saída é uma matriz binária do mesmo tamanho da imagem de entrada com os pontos verdadeiros sendo os locais de indicativos de clusters de microcalcificações.

O detector de calcificações foi testado diretamente em relação ao laudo da demarcação presente nas duas bases utilizadas, DDSM (HEATH, BOWYER, et al., 2001) e INBrest (MOREIRA, AMARAL, et al., 2012).

As imagens da DDSM utilizadas foram imagens digitalizadas em um Lumisys 200

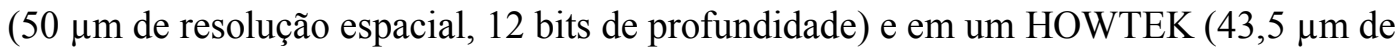
resolução espacial, 12 bits de profundidade). Um total de 130 imagens da DDSM foram selecionadas para este teste. 
No caso das imagens da INBreast, foram usadas todas as 18 imagens da base contendo clusters de calcificações demarcados.

Das 144 imagens disponíveis, 70 foram utilizadas para estabelecer a curva ROC e definir o valor da variável "topo". O conjunto completo foi utilizado para testar o sistema.

\section{d) Módulo Peitoral}

\section{d.1. Detector de nódulos no músculo peitoral}

Este módulo é o único da seção que não tem acesso à imagem do tecido mamário propriamente, usando apenas a imagem segmentada do músculo peitoral no passo 0 . A estrutura do músculo peitoral é consideravelmente mais densa e bastante homogênea em comparação à mama em si, sendo mostrada na imagem como uma região mais clara.

Estre módulo nativamente se encontra em JAVA. Sua entrada é apenas a imagem do músculo peitoral segmentada e sua saída são as coordenadas dos pontos centrais de cada linfonodo detectado.

\subsubsection{Apresentação dos resultados}

Os módulos de processamento geram três saídas que serão tratadas em diferentes modos:

i. Imagem é a imagem original pré-processada para melhorar a qualidade (método 4.1), mas reconstruídas as regiões de fundo e músculo peitoral (removidos em 4.2 e 4.3). Esta imagem é apresentada ao médico com demarcações mostrando a localização das regiões de interesse detectadas pelo detector de nódulos, de calcificações, de assimetrias e de linfonodos. 
ii. RIs: as regiões de interesse detectadas separadas para alguma manipulação desejada pelo radiologista. Isso inclui alterações de brilho e contraste para melhor visualização.

iii. Informações: por fim, um pré-laudo será compilado com todos os dados textuais resultantes dos módulos de processamento (descritos em 5.3.3). Estas informações serão utilizadas para realizar uma busca textual nos laudos da base de imagens e outra, também textual, nos resultados compilados do sistema CADx (Figura 21).

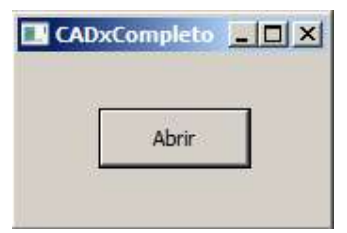

(a)
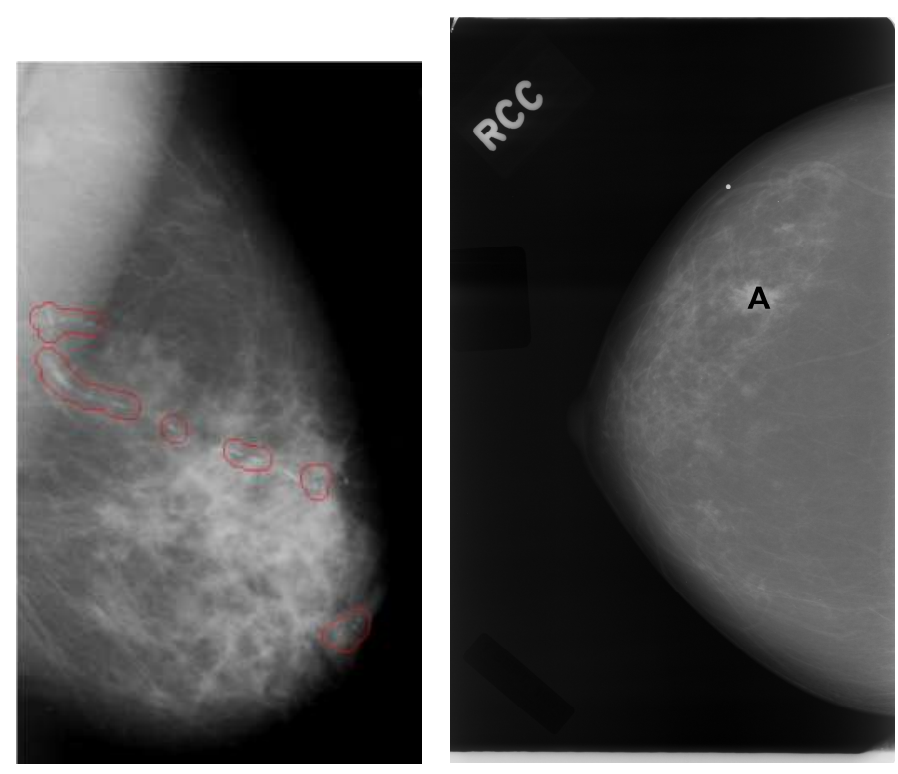

(b)

(c)

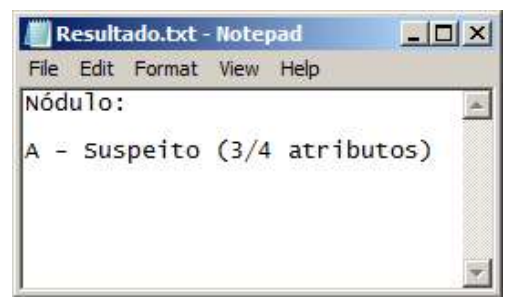


(d)

Figura 21: Exemplos de Imagens resultados. a) Início do programa, b) Exemplo de resultado da detecção de micro, c) Exemplo do resultado da detecção de nódulos, d) Exemplo de resultado do classificador

\subsubsection{Limitações do sistema}

Durante o desenvolvimento deste projeto algumas limitações do sistema foram notadas, mudando a perspectiva do trabalho apresentado aqui e de futuros projetos.

A primeira limitação está relacionada ao tempo necessário para o processamento completo de cada imagem. Cada módulo foi projetado com um tempo aceitável de processamento, porém o uso dos diferentes módulos sequencialmente (conforme descrito neste capítulo) acumula um tempo excessivo para um programa de auxílio a diagnóstico.

Considerou-se como tempo excessivo para o processamento CADe $\backslash D x$ quando a demora é consideravelmente maior do que o tempo de análise por um especialista. Com base nos estudos de Haygood (HAYGOOD, WANG, et al., 2009), um radiologista experiente leva entre 89 e 194 segundos para avaliar um exame mamográfico completo. Portanto, tempos maiores que 200 segundos ( 3 minutos $)$ por exame tornariam difícil o uso do esquema em larga escala; e tempos maiores que 400 segundos ( $\sim 7$ minutos) por exame são impraticáveis, pois seria um tempo maior do que utilizar outro especialista como segunda opinião.

Para testar o tempo médio de processamento, um conjunto de 360 imagens da base DDMS (HEATH, BOWYER, et al., 2001) foi processado na íntegra e registrados os tempos totais e parciais de processamento. Os testes foram realizados em um desktop PC utilizando um processador Intel® i5-4670K 3.4Ghz com 16GB de RAM DDR3 1600 $\mathrm{MHz}$, e as imagens estavam armazenadas em um HD interno Samsung de 2TB e 7200 rpm. Os resultados destes testes estão explicitados e discutidos no Capítulo 7, seções 7.6 e 7.7 .

Outra limitação do sistema é o acúmulo de erros, que se apresenta quando os métodos de classificação são utilizados com base nas informações obtidas pelos métodos de detecção, em particular, no caso da detecção/classificação de nódulos. Um exemplo de 
como tais erros podem-se acumular de um modo problemático ocorre quando o detector de nódulos (descrito na seção 5.3.3b.1 ) tem uma taxa média de falsos positivos de 3,5 por imagem e o classificador (seção 5.3.3b.3 ) tem uma taxa de falsos positivos de por volta de 30\%. O classificador foi desenhado para analisar regiões contendo nódulos e não regiões normais da mama; portanto, seu comportamento nesses casos não pode ser facilmente previsto, mas, assumindo que sua taxa de falsos-positivos seja a mesma, toda imagem, em média, terá pelo menos um caso de falsa detecção classificado como maligno.

Tais erros não podem ser facilmente contornados, necessitando de uma completa remodelação de todos os módulos envolvidos no projeto.

Recentemente, no entanto, o paradigma de desenvolvimento de esquemas CADe/Dx vem se alterando, com menos ênfase em detecção (CADe) e mais propriamente na interpretação (CADx) do achado (isto é, sua classificação). Isso está ligado a resultados mostrando que a maior parte dos erros no diagnóstico mamográfico corresponde à classificação e não detecção dos sinais suspeitos (MEYER, EBERLEIN, et al., 1990; KARSSEMEIJER, 2011; SCHIABEL, 2014). Em outras palavras, os radiologistas normalmente detectam corretamente as regiões suspeitas, mas as classificam incorretamente em até $15 \%$ dos casos, seja falso-positivo ou falso-negativo.

Além disso, pesquisas recentes (KARSSEMEIJER, 2011) mostram que os radiologistas preferem o uso do esquema $\mathrm{CAD}$ como uma ferramenta de auxilio sob demanda, ou seja, só utilizado quando uma dúvida surgir e com resultados o mais rápido possível. Algo similar é padrão em esquemas CAD utilizados para medição de densidade óssea em tomografia (CELENK e CELENK, 2012), em particular na tradicional técnica QCT (Quantitative Computed Tomography) (ADAMS, 1997).

No próximo capítulo, será descrita outra visão para o esquema CADx (e sua implementação), levando em conta as limitações descritas acima. Essa formulação do esquema ganhou o nome de CADx Guiado, pois elimina as etapas de detecção em troca de um método semiautomático, onde o radiologista é responsável por selecionar as regiões de interesse que deseja processar e obtém como resultado a indicação do caso como suspeito ou não. 


\section{Capítulo 6 Materiais e Métodos: CADx Guiado}

Com base nas limitações do sistema descritas no fim capítulo anterior e com a mudança de paradigma dos esquemas CAD (KARSSEMEIJER, 2011; SCHIABEL, 2014), uma versão simplificada do esquema descrito na seção 5.3 (Capítulo 5) foi projetada. Essa versão tenta seguir essa filosofia mais atual, fornecendo ao avaliador do exame informações mais sucintas e diretas, focando a análise na classificação das regiões de interesse selecionadas pelo radiologista. Esta versão, descrita neste capítulo, desconsidera o processo de detecção e tenta ser mais útil para os médicos ao se concentrar na questão da interpretação dos achados e permitir-lhe a seleção manual das regiões de interesse.

\subsection{Esquema CADx Guiado: Versão Simplificada com ênfase na} interpretação dos sinais

Nesta versão do CADx a imagem é pré-processada e apresentada ao radiologista, que tem a oportunidade de selecionar uma particular região de interesse para classificação. O sistema classifica, assim, apenas os nódulos que estiverem presentes em tal RI, tendo sido projetado para trabalhar com essa mesma estrutura demarcada nas duas imagens correspondentes às duas projeções (CC e MLO) de uma dada mama. As - agora - duas RIs (cada uma relativa a cada projeção) são classificadas e um único resultado é apresentado como resposta de saída do esquema: "suspeito" ou "não suspeito".

Esse modelo simplificado está esquematizado na Figura 22. 


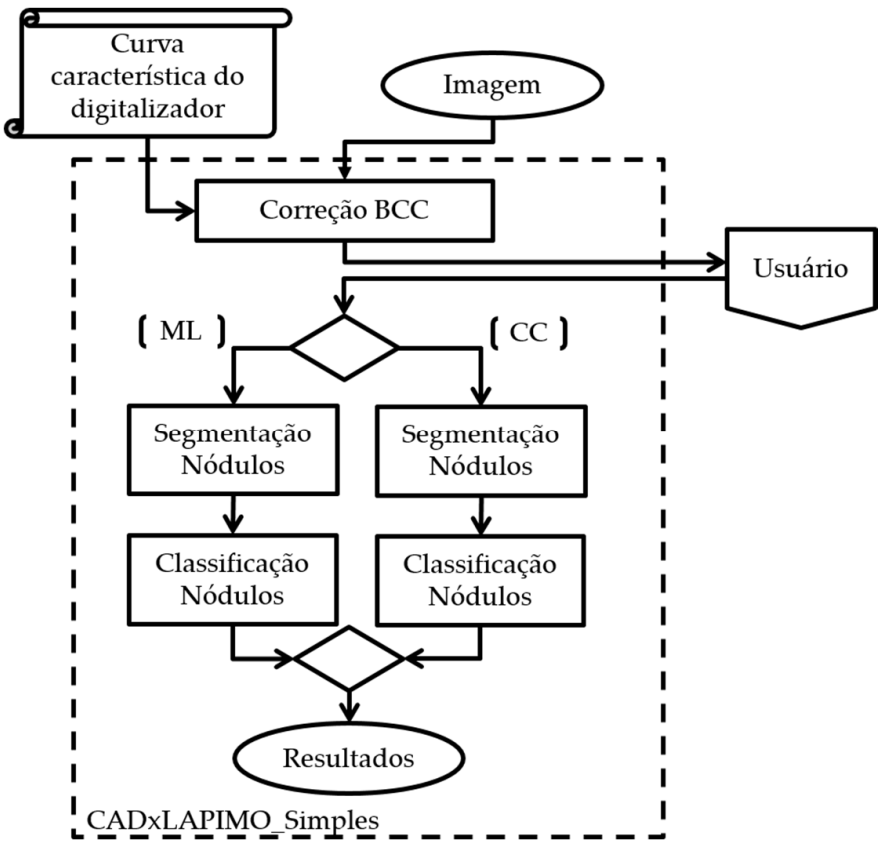

Figura 22: Esquema CADx LAPIMO Guiado

\subsection{Pré-processamento}

Nesta versão do esquema CADx, o módulo de pré-processamento consiste apenas da correção BCC descrita na seção 4.1. Os módulos de segmentação e avaliação de densidade global não têm uso neste formato do esquema, pois a seleção das regiões a serem avaliadas é feita pelo usuário, garantindo que apenas regiões consideradas pelo radiologista como pertinentes para o diagnóstico sejam analisadas. Desse modo, nessa versão, a segmentação e avaliação de densidade global não são utilizados.

O pré-processamento utilizando apenas a correção BCC representa um custo computacional drasticamente reduzido, em particular em relação à memória necessária, e, consequentemente, o tempo de processamento se reduz para apenas uma fração (1\%) do tempo registrado com a aplicação de todo o esquema descrito no capítulo anterior, conforme explicitado mais adiante no capítulo de Resultados. 
Portanto, este pré-processamento trata-se da única etapa do processo realizada antes da imagem ser apresentada ao usuário para seleção das regiões de interesse.

\subsection{Interface}

As imagens de saída do pré-processamento são apresentadas ao radiologista utilizando uma interface estendida a partir do atributo da subclasse Window integrada à classe ImagePlus utilizada pela biblioteca ImageJ (RASBAND, 2011) para apresentar imagens (Figura 23).

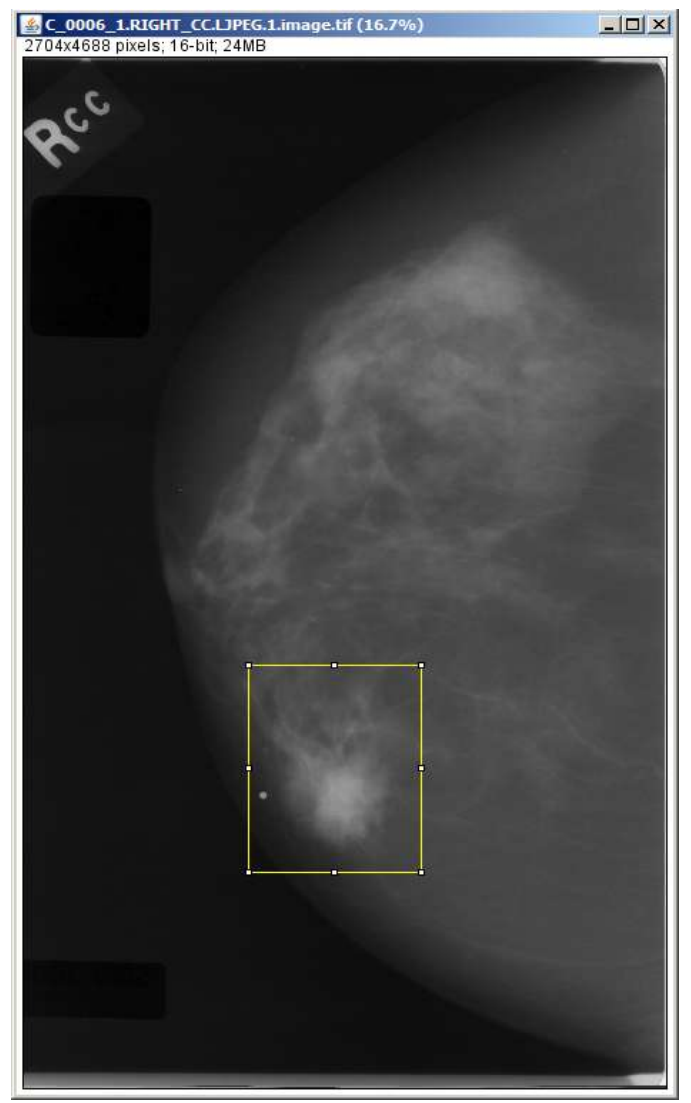

Figura 23: Exemplo de janela com uma imagem para processamento. $O$ retângulo amarelo representa uma RI selecionada.

Nesta janela o usuário tem controle do contraste e do brilho de cada imagem independentemente. Ele também pode selecionar para análise pelo sistema uma região da 
imagem na qual tenha sido capaz de identificar um nódulo. A região selecionada ficará demarcada enquanto o usuário marca o nódulo na outra orientação da mesma mama.

Junto às imagens abertas para o usuário, o software abre uma janela independente de controle (Figura 24). A principal função desta janela é comandar o processamento das RIs selecionadas usando os métodos descritos a seguir.

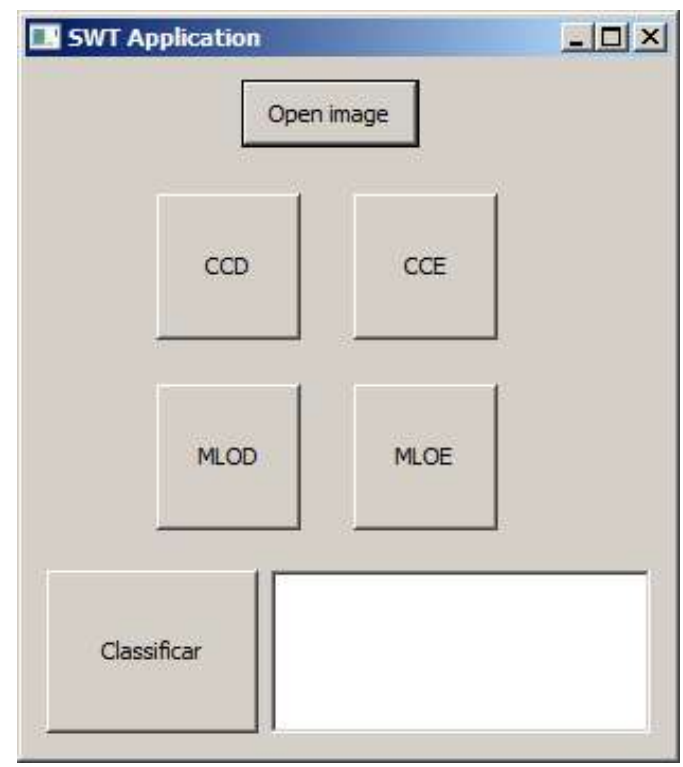

Figura 24: Janela do controle disponível junto às imagens mamográficas no esquema.

\subsection{Segmentação}

As RIs selecionadas pelo usuário na etapa anterior são segmentadas usando o método de Otsu conforme descrito na seção 5.3.3b.2 do Capítulo 5, que é parte do módulo Nódulos.

Neste caso, a entrada deste método é apenas a RI selecionada e a saída é a imagem binária do mesmo tamanho da original contendo a segmentação (branco sendo a região contendo o nódulo). 


\subsection{Classificação}

O classificador utilizado nesta versão do CADx é o mesmo descrito em 5.3.3b.3 do Capítulo 5, projetado para classificar regiões de interesse - neste caso, selecionadas pelo usuário.

Para melhorar os resultados, esta versão aproveita a capacidade de distinção do radiologista usuário ao pedir que o mesmo nódulo seja demarcado nas duas imagens correspondentes cada qual a uma das projeções (CC e MLO) da mesma mama. Com isso, o sistema classifica o nódulo representado nas duas orientações distintas e seleciona a sugestão de classificação com base nos dois resultados.

Além da RI original selecionada pelo usuário, a saída do segmentador acima é a entrada do método de classificação, ou seja, a imagem binária resultante da segmentação. A saída é uma string contendo o resultado da avaliação conjunta das duas orientações (CC e MLO) do mesmo nódulo.

Para tomar a decisão final da sugestão de classificação, o programa avalia os atributos descritos em 5.3.3b.3 do Capítulo 5 em conjunto para as duas RIs, classificando como "Suspeitos" aqueles em que um dado conjunto dos atributos indique o resultado como "Suspeito".

A escolha do número de atributos concordantes necessários para a classificação final ser "suspeita" foi empírica: pesquisou-se a melhor relação sensibilidade/especificidade para as 8 possibilidades. Para essa análise foi usado um conjunto de 568 imagens da base DDSM, todas contendo no máximo um nódulo, visível nas duas vistas e sem nenhum outro achado que pudesse interferir na análise (como calcificações). As RIs dos nódulos foram selecionadas usando as informações fornecidas pela base e cada uma foi segmentada e seus atributos extraídos conforme descrito na seção 5.3.3b.

Cada conjunto das orientações do mesmo nódulo foram pareadas e os 8 atributos foram considerados independentes. Uma classificação inicial foi obtida usando cada um 
dos atributos (conforme descrito em 5.3.3b.3 ). Para um dado nódulo ser considerado suspeito, um subconjunto destes atributos deveria classificá-lo como suspeito; o tamanho deste subconjunto foi decidido testando as 8 possibilidades (mínimo de 1 a 8 atributos classificando como suspeito) e avaliando a sensibilidade e especificidade em cada caso.

O resultado pode ser observado na Tabela 17, seção 7.4.4, Capítulo 7. Onde o número de atributos concordantes que geraram o melhor valor de sensibilidade e especificidade foi escolhido para ser o número final para o programa.

\subsection{Apresentação dos resultados}

O resultado final do classificador é apresentado de modo simples e direto ao radiologista na forma de um texto informando se o nódulo é "suspeito" ou "não suspeito", com indicações do motivo dessa classificação. O médico pode salvar este texto para futura referência. Um exemplo de como o resultado é apresentado ao usuário é ilustrado na Figura 25. 


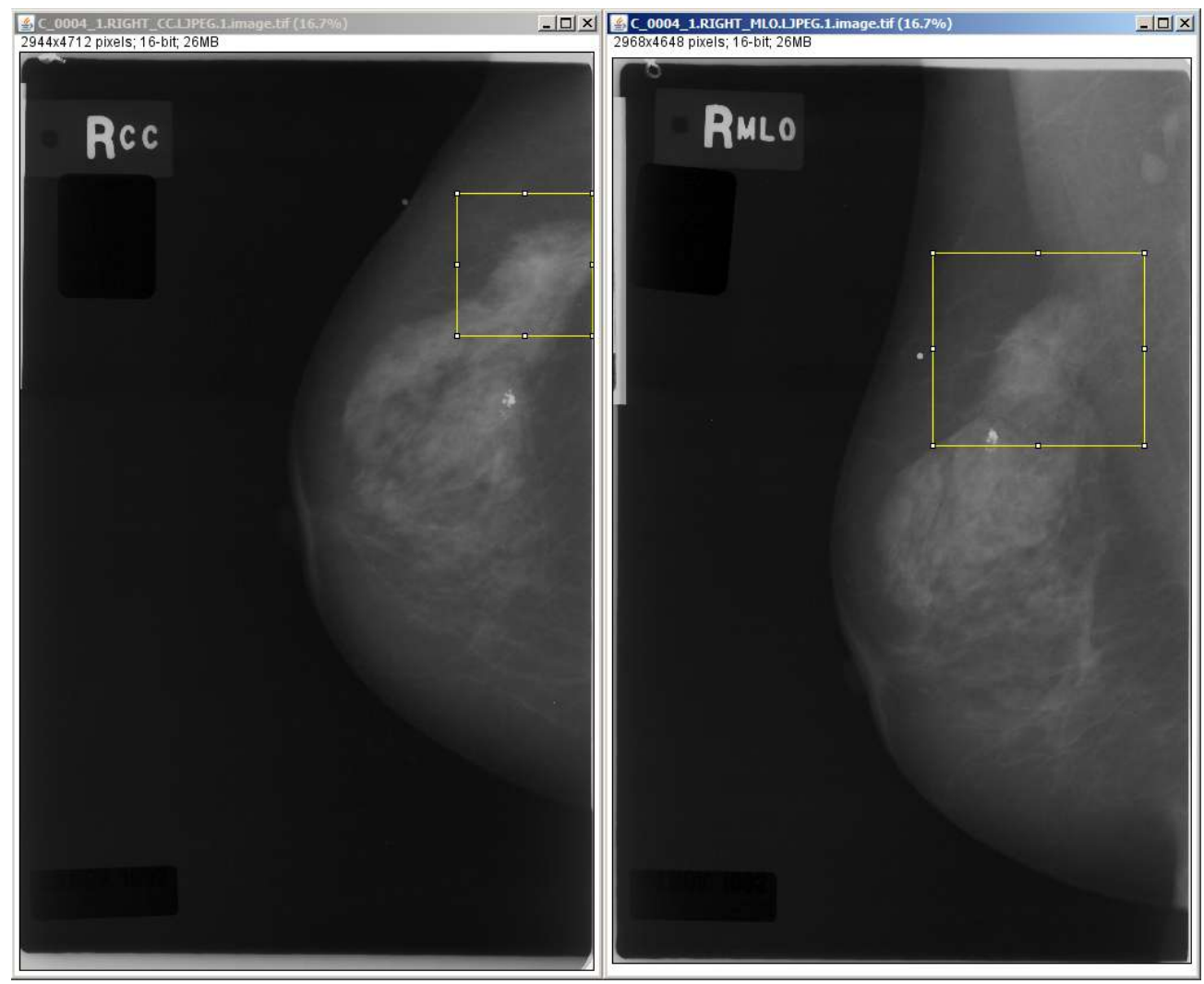

(a)

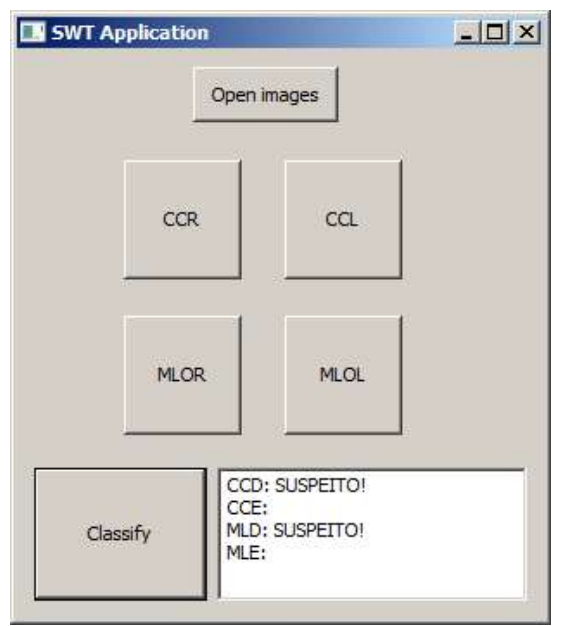

(b)

Figura 25: Exemplo de resultado do esquema Guiado. a) Exemplo de imagens demarcadas pelo usuário; b) exemplo do resultado 


\subsection{Avaliação do CADx Guiado}

Para testar a versão simplificada do CADx foram utilizadas 568 imagens da base DDSM (HEATH, BOWYER, et al., 2001), cada uma contendo um nódulo apenas e nenhum outro achado, evitando, assim, interferências no resultado do sistema, conforme já descrito na seção 6.5 anterior.

Desse modo, a seleção das regiões de interesse dependeu das demarcações da base DDSM e, então, considerou-se, para a avaliação dos resultados, como se o radiologista efetivamente tivesse detectado corretamente os nódulos naquelas imagens que, assim, foram selecionadas para classificação.

Essas imagens foram pré-processadas usando a Correção BCC, segmentadas e classificadas usando as duas orientações (vistas CC e MLO) do mesmo nódulo. A classificação final foi feita usando o melhor resultado obtido na análise de número de atributos concordantes conforme descrito no fim da seção 6.5 acima. O resultado do CADx foi, então, comparado com a classificação informada pela base DDSM. A partir disso, foram calculadas as taxas de sensibilidade, de especificidade e a acurácia do programa.

Durante os testes com as 568 imagens, o tempo de processamento de cada imagem foi armazenado, permitindo calcular uma média do tempo de processamento para diferentes tamanhos de nódulos.

Todos estes resultados estão explicitados na seção 7.7, CADx Guiado do Capítulo 7 


\section{Capítulo 7 Resultados e Discussão}

O objetivo deste trabalho foi estruturar um esquema CADe/Dx completo, composto pelos programas separadamente desenvolvidos no LAPIMO. A integração dos vários programas e projetos num único esquema viável para testes e uso clínico exige uma análise detalhada dos códigos utilizados, incluindo reescrever os programas quando necessário.

Uma preocupação constante durante todo o desenvolvimento do projeto foi a versatilidade do programa final, ou seja, é de grande importância que o programa seja capaz de funcionar em múltiplas arquiteturas e sistemas operacionais. Isso é devido ao seu futuro uso clínico, ou seja, usualmente sistemas Windows, mas também para que ele possa ser usado via web em servidores base LINUX.

Outro ponto importante é que o programa seja intrinsicamente modular, ou seja, que os diferentes métodos e técnicas sejam construídos de modo independente, permitindo que futuras atualizações e adições sejam realizadas sem a necessidade de reescrever o código todo.

As características descritas nos parágrafos anteriores levaram o programa a ser desenvolvido na linguagem JAVA (ORACLE, 2014), que garante que o mesmo possa ser utilizado em qualquer sistema que suporte a JVM (Java Virtual Machine) e seja orientado a objeto.

Para estruturar as diferentes técnicas desenvolvidas para o esquema CADx sob a forma de um programa consistente, foi necessário recorrer a técnicas de implementação por engenharia de software (PRESSMAN, 2010). Uma vez que todos os módulos pertinentes ao programa final estavam em pleno funcionamento, foi possível revisar o esquema até alcançar o resultado atual, conforme mostrado anteriormente na Figura 14.

Cada módulo, antes de ser agregado ao sistema, tem que ser analisado com o intuito de entender como os passos anteriores (pré-processamento) interagem e o afetam. Além disso, cada módulo tem métodos próprios de pré-processamento que precisam ser 
removidos, reposicionados no esquema geral ou aplicados para aquele módulo apenas, decisão que só pode ser tomada depois de testes com diferentes combinações de préprocessamento.

Assim, cada módulo descrito nos capítulos anteriores foi estruturado como uma classe dentro de uma biblioteca nomeada pelo seu autor. O intuito disso é facilitar a busca pelas informações, já que a pesquisa será normalmente feita através de artigos, dissertações e teses, assim como facilitar o crédito aos autores em futuros artigos que usem aquelas bibliotecas e classes.

Nas seções a seguir, os resultados obtidos nos testes de cada módulo e do esquema como um todo são descritos e discutidos.

\subsection{Correção BCC (GOES, 2010)}

A classe de correção de digitalização (4.1, Capítulo 4) foi desenvolvida para melhorar a imagem para processamento e não para observação humana direta. Por conta disso, ainda que fosse empregada como pré-processamento interno do esquema computacional para as etapas subsequentes, foi necessário avaliar se a imagem a ser apresentada ao radiologista deveria ou não passar por esta correção. Então, o seguinte simples teste foi projetado: o radiologista seria apresentado a duas cópias da mesma imagem, uma corrigida e outra não, e deveria selecionar qual seria a melhor para análise radiológica.

A análise dos conjuntos de imagens foi realizada por um radiologista experiente em um monitor apropriado para visualização de imagens radiológicas digitais - NIO 3MP (E-3620) da $\mathrm{BARCO}^{2}$. Cada imagem foi apresentada em duas versões não demarcadas, a original e a corrigida pelo método (GOES, 2010). Para cada avaliação, as imagens foram posicionadas uma à direita e outra à esquerda da tela aleatoriamente.

\footnotetext{
${ }^{2}$ Kortrijk, Bélgica
} 
O radiologista tinha a opção de escolher uma das duas imagens como sendo "melhor", ou seja, a imagem que considerava mais apropriada utilizar para avaliar um caso. Durante a avaliação, o radiologista poderia apenas reposicionar as imagens e alterar seu tamanho (zoom), sem ter acesso a nenhum controle de contraste, brilho ou similar.

Nos testes realizados para este trabalho foram selecionadas 25 imagens provenientes do scanner Lumiscan 50 e 49 imagens provenientes do scanner L200, cujas curvas características estão na Figura 26. Todas as imagens selecionadas continham algum tipo de achado (benigno ou maligno), fornecendo um ponto de referência na análise comparativa; porém, a radiologista não foi informada deste fato, evitando assim que a procura pelo achado interferisse no resultado final.

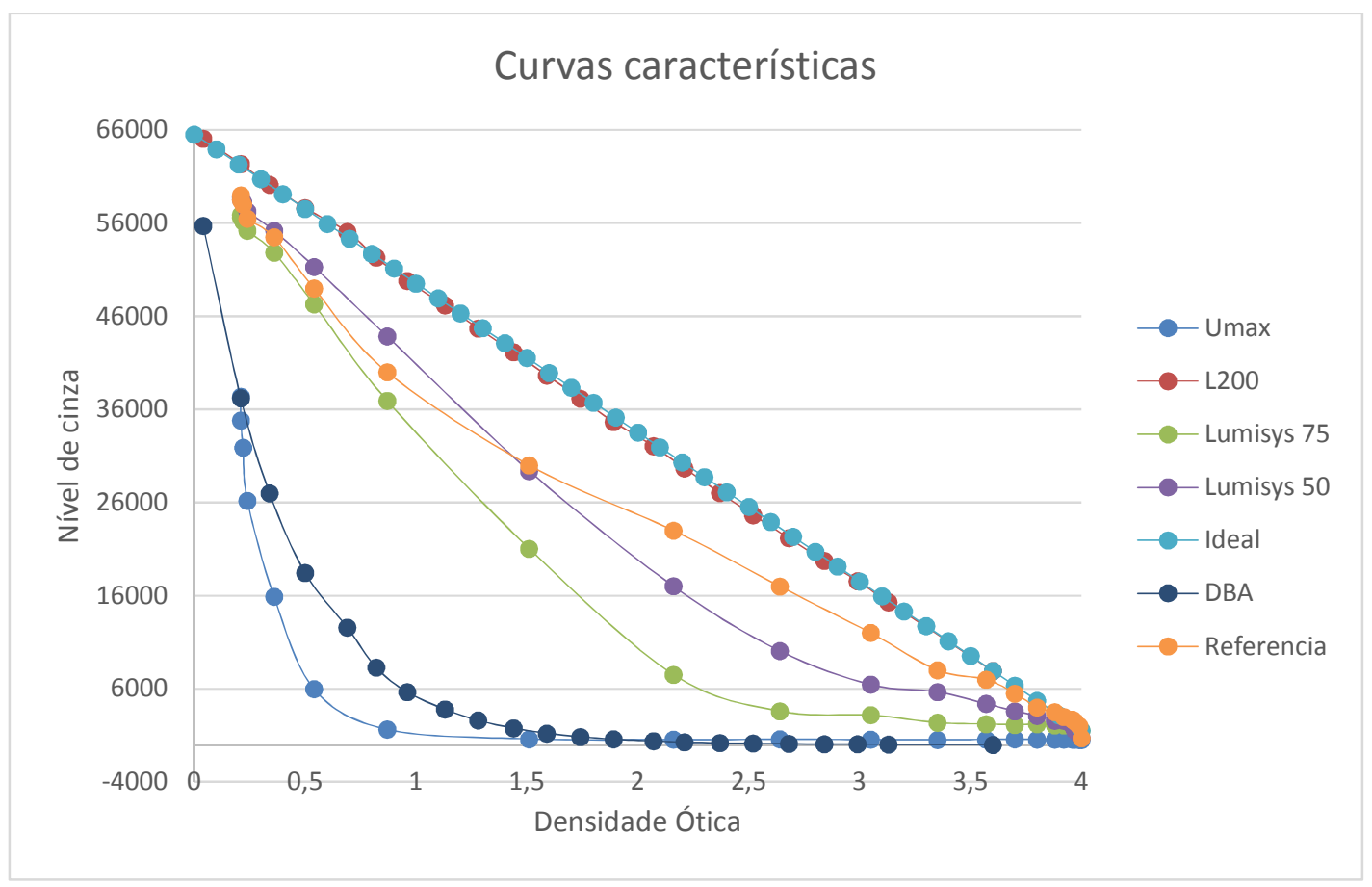

Figura 26: Curvas característica dos digitalizadores e do filme referência (GOES, SCHIABEL e SOUSA, 2013)

$\mathrm{Na}$ Tabela 2 temos os resultados dos testes. 
Tabela 2: Resultados obtidos nos testes do pré-processamento para correção da curva característica da digitalização

\begin{tabular}{|c|c|c|c|c|}
\hline Digitalizador & $\begin{array}{c}\text { Número de } \\
\text { imagens }\end{array}$ & $\begin{array}{c}\text { Original } \\
\text { "melhor" }\end{array}$ & $\begin{array}{c}\text { Corrigida } \\
\text { "melhor" }\end{array}$ & $\begin{array}{c}\text { Corrigida } \\
\text { "melhor" } \\
\text { percentual }\end{array}$ \\
\hline Lumiscan 50 & 25 & 13 & 12 & $48 \%$ \\
\hline Lumiscan 200 & 49 & 7 & 42 & $86 \%$ \\
\hline
\end{tabular}

Na Tabela 2, a coluna Original "melhor" é o número de imagens originais consideradas melhores pela especialista, e a coluna Corrigida "melhor" é análoga, agora para as imagens corrigidas.

No caso do digitalizador L50 os resultados foram, num primeiro momento, inconclusivos. Com apenas $48 \%$ das imagens corrigidas sendo consideradas melhores, o resultado não fornece suficiente informação sobre o processamento, discussão com o especialista consultado indica que a mudança de contraste produzida nas imagens do Lumiscan 50 pela técnica de correção é muito pequena para permitir uma diferenciação significativa entre a qualidade de cada par de imagens (original ou corrigida). Já para o conjunto de imagens originárias do digitalizador L200, o especialista deu preferência as imagens corrigidas em $86 \%$ das imagens testadas, demonstrando que, pelo menos para este especialista, os resultados da correção são preferenciais na grande maioria dos casos.

A diferença de resultados entre os grupos de imagens dos digitalizadores está relacionada às diferenças entre as suas respectivas curvas características (Figura 26). O L50 tem uma curva característica muito próxima do filme referência (Figura 26 (a) e (c)) em formato e valores, o que significa que o método provoca poucas mudanças no resultado final. Isso, portanto, é o que explica a observação exposta no início do parágrafo anterior, já que, na verdade, praticamente não há necessidade de correção de contraste para as imagens provenientes daquele equipamento, pela sua característica de transferência (DO x níveis de cinza). Já o L200 tem uma curva que se aproxima de uma 
reta, o que explica as grandes alterações no contraste das imagens quando o método de correção é aplicado.

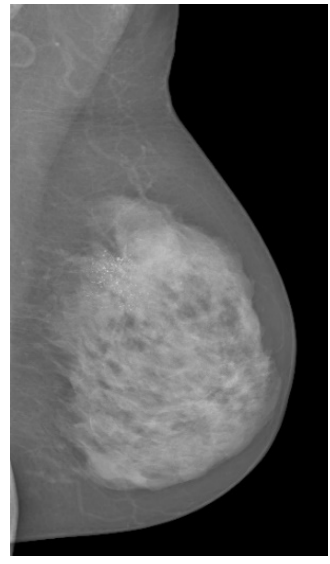

(a)

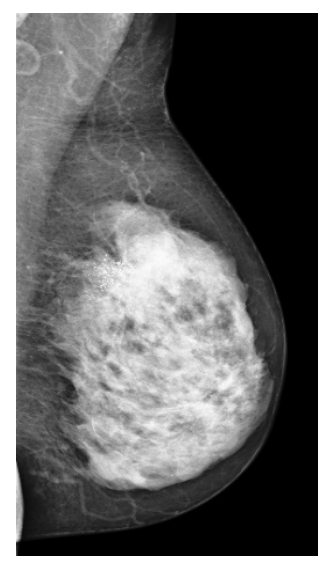

(b)

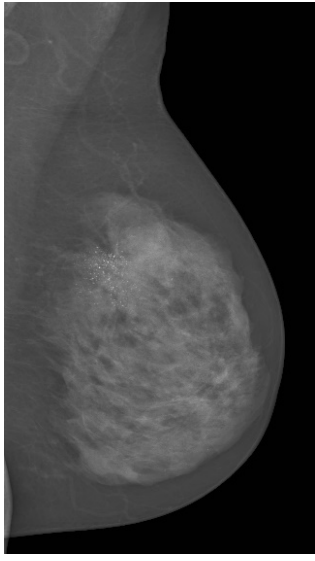

(c)

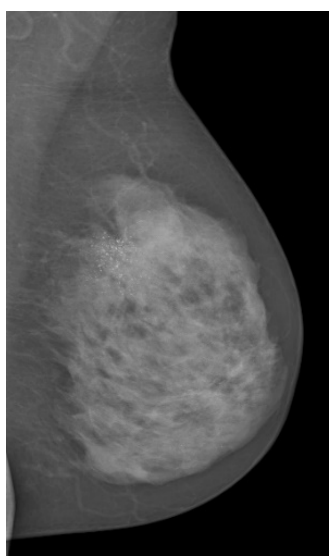

(d)

Figura 27: Exemplo das transformações utilizadas no teste da correção BCC. (a) Imagem original, (b) Imagem Equalizada (GONZALES e WOODS, 2008), (c) Correção BCC e (d) Imagem com brilho reduzido

Uma vez que estes testes mostram uma preferência visual pelas imagens corrigidas no caso de alguns digitalizadores, um teste mais complexo foi realizado usando dois especialistas com mais de 10 anos de experiência em análise mamográfica. Cada um 
foi apresentado a 100 conjuntos de 4 imagens (totalizando 400 imagens), cada conjunto, conforme Figura 27, trazendo:

- Imagem original;

- $\quad$ Imagem equalizada (GONZALES e WOODS, 2008);

- Imagem corrigida pela técnica BCC (GOES, 2010);

- $\quad$ Imagem com o brilho reduzido;

O valor da redução do brilho foi selecionado visualmente, buscando um valor que escurecesse a imagem, mas mantivesse visível a delimitação da pele. Os testes foram feitos com uma redução de 256 , representado $6 \%$ do valor máximo para as imagens de 12 bits e $1,5 \%$ para as imagens de 16bits. É importante ressaltar que o contraste da imagem praticamente não é alterado por esta técnica, já que todos os pixels são subtraídos pelo mesmo valor, ou seja, a diferença entre dois pixels continua a mesma, exceto pelas regiões com valor de pixel menores que 256 (que são zeradas então).

As 100 imagens utilizadas tinham as seguintes características:

v. 15 imagens da base BancoWeb; digitalizadas usando scanners Lumiscan com $150 \mu \mathrm{m}$ de resolução espacial e 12 bits de resolução de contraste.

vi. $\quad 25$ imagens da base INBreast; provenientes de sistemas FFDM com $70 \mu \mathrm{m}$ de resolução espacial e 14 bits de resolução de contraste.

vii. $\quad 47$ imagens da base DDSM; digitalizadas usando um Lumiscan 200 com resolução de $50 \mu \mathrm{m}$ e 12 bits de resolução de contraste.

viii. $\quad 13$ imagens da base DDSM; digitalizadas usando um Howtek MultiRAD 850, com a mesma resolução acima (50 $\mu \mathrm{m}$ e 12 bits).

As quatro imagens de cada conjunto foram mostradas simultaneamente e foi pedido aos especialistas para ranquear da melhor (primeiro lugar) para a pior (quarto lugar). Os resultados podem ser vistos na Tabela 3. 
Tabela 3: Resultado comparativo das técnicas aplicadas nas imagens. Classificação é a classificação percentual das imagens naquela posição e Melhora é um cálculo mais direto para comparação

\begin{tabular}{|c|c|c|c|c|c|}
\hline \multirow{2}{*}{ Tipo } & \multicolumn{4}{|c|}{ Classificação } & \multirow{2}{*}{ Melhora } \\
\cline { 2 - 5 } & $\mathbf{1}^{\mathbf{0}}$ & $\mathbf{2}^{\mathbf{0}}$ & $\mathbf{3}^{\mathbf{0}}$ & $\mathbf{4}^{\mathbf{0}}$ & $\mathbf{- 2 7 . 4 \%}$ \\
\hline Original & $4.1 \%$ & $15.9 \%$ & $64.8 \%$ & $15.2 \%$ & $\mathbf{- 4 9 . 2 \%}$ \\
\hline Equalização tradicional & $20.7 \%$ & $4.8 \%$ & $5.5 \%$ & $69.7 \%$ & $\mathbf{- 4 9} \%$ \\
\hline Correção BCC & $52.4 \%$ & $20.7 \%$ & $16.6 \%$ & $9.7 \%$ & $\mathbf{+ 4 4 . 1 \%}$ \\
\hline Redução de brilho & $22.8 \%$ & $58.6 \%$ & $13.1 \%$ & $5.5 \%$ & $\mathbf{+ 3 2 . 4 \%}$ \\
\hline
\end{tabular}

O valor de "Melhora" é um valor para auxiliar a comparação entre as técnicas e é calculado de modo que, se a técnica em questão resultar sempre na imagem considerada $1^{\text {a }}$, o valor de "Melhora" será $100 \%$; caso a técnica resulte sempre na pior imagem, o resultado será $-100 \%$. Para tanto, calcula-se o valor do seguinte modo:

- $\quad+1$ para cada resultado na $1^{\mathrm{a}}$ posição;

- $\quad+1 / 3$ para cada resultado na $2^{\mathrm{a}}$ posição;

- $\quad-1 / 3$ para cada resultado na $3^{\mathrm{a}}$ posição;

- $\quad$-1 para cada resultado na $4^{\mathrm{a}}$ posição;

O valor de "Melhora" é, então, dividido pelo número de imagens, resultando no valor percentual mostrado na Tabela 3 .

Em geral, os melhores resultados parecem vir da aplicação da correção BCC. Este método resultou na maioria das imagens classificadas como a melhor ( $1^{\circ}$ lugar) e obteve a melhor taxa de melhora. Em aproximadamente $77 \%$ dos casos, a imagem resultante da correção BCC foi considerada pelos radiologistas como melhor do que a imagem original. 
Surpreendentemente, o segundo melhor resultado foi encontrado com a Redução de brilho, apesar do contraste da imagem ser o mesmo que o original. A imagem com Redução de Brilho foi considerada melhor que a original em $84 \%$ dos casos.

Os piores resultados foram obtidos da técnica de equalização convencional, como demonstrado na Tabela 3. A imagem equalizada só foi considerada melhor que a original em $30 \%$ dos casos.

Para comparação, na Tabela 4, as opiniões dos especialistas foram comparadas entre si. Os valores na Tabela 4 comparam diretamente a classificação das imagens entre os dois especialistas. Por volta de $64 \%$ das imagens classificadas como a melhor por um especialista recebeu a mesma classificação do outro. Também, em cerca de $86 \%$ dos casos, a imagem classificada como melhor estava entre as duas melhores classes $\left(1^{\circ} \mathrm{ou}\right.$ $2^{\circ}$ lugar) do outro especialista. No caso das imagens classificadas como a pior por um deles, em $82 \%$ dos casos o outro especialista concordou com a classificação e $91 \%$ das imagens classificadas como pior por um especialista foram classificadas nas duas piores classes ( $3^{\circ}$ e $4^{\circ}$ lugar) pelo outro. Nas classes intermediárias ( $2^{\circ}$ e $3^{\circ}$ lugar $)$ existe mais conflito entre os especialistas, mas se as duas classes forem consideradas como uma só posição intermediária, a concordância entre os especialistas é de $70 \%$.

Tabela 4: Comparação entre especialistas

\begin{tabular}{|c|c|c|c|c|c|}
\hline \multicolumn{2}{|c|}{} & \multicolumn{4}{|c|}{ Classificação de R2 } \\
\cline { 3 - 6 } \multicolumn{2}{|c|}{} & $\mathbf{1}^{\mathbf{0}}$ & $\mathbf{2}^{\mathbf{0}}$ & $\mathbf{3}^{\mathbf{0}}$ & $\mathbf{4}^{\mathbf{0}}$ \\
\hline \multirow{3}{*}{$\begin{array}{c}\text { Classificação } \\
\text { de R1 }\end{array}$} & $\mathbf{1}^{\mathbf{0}}$ & $64 \%$ & $22 \%$ & $10 \%$ & $4 \%$ \\
\cline { 2 - 6 } & $\mathbf{2}^{\mathbf{o}}$ & $23 \%$ & $51 \%$ & $20 \%$ & $5 \%$ \\
\cline { 2 - 6 } & $\mathbf{3}^{\mathbf{0}}$ & $8 \%$ & $22 \%$ & $61 \%$ & $9 \%$ \\
\cline { 2 - 6 } & $\mathbf{4}^{\mathbf{0}}$ & $5 \%$ & $5 \%$ & $9 \%$ & $82 \%$ \\
\hline
\end{tabular}

Isso mostra que, apesar dos especialistas não concordarem em todos os casos, existe uma grande similaridade em suas escolhas, especialmente no caso das melhores e piores imagens. Como este teste é baseado na opinião dos especialistas, algumas diferenças de preferência são esperadas. 
Para uma análise mais detalhada, as tabelas a seguir (Tabela 5 a Tabela 8) descrevem os resultados individuais de cada digitalizador considerado nos testes.

Tabela 5: Resultados por fonte (BancoWeb)

\begin{tabular}{|c|c|c|c|c|c|}
\hline \multirow{2}{*}{ Tipo } & \multicolumn{4}{|c|}{ Classificação } & \multirow{2}{*}{ Melhora } \\
\cline { 2 - 5 } & $\mathbf{1}^{\mathbf{0}}$ & $\mathbf{2}^{\mathbf{0}}$ & $\mathbf{3}^{\mathbf{0}}$ & $\mathbf{4}^{\mathbf{0}}$ & \\
\hline Original & $3.3 \%$ & $26.7 \%$ & $40.0 \%$ & $30.0 \%$ & $\mathbf{- 3 1 . 1 \%}$ \\
\hline $\begin{array}{c}\text { Equalização } \\
\text { tradicional }\end{array}$ & $60.0 \%$ & $6.7 \%$ & $6.7 \%$ & $26.7 \%$ & $\mathbf{3 3 . 3} \%$ \\
\hline $\begin{array}{c}\text { Correção } \\
\text { BCC }\end{array}$ & $10.0 \%$ & $26.7 \%$ & $26.7 \%$ & $36.7 \%$ & $\mathbf{- 2 6 . 7 \%}$ \\
\hline $\begin{array}{c}\text { Redução de } \\
\text { brilho }\end{array}$ & $26.7 \%$ & $40.0 \%$ & $26.7 \%$ & $6.7 \%$ & $\mathbf{2 4 . 4 \%}$ \\
\hline
\end{tabular}

Tabela 6: Resultados por fonte (INBreast)

\begin{tabular}{|c|c|c|c|c|c|}
\hline \multirow{2}{*}{ Tipo } & \multicolumn{4}{|c|}{ Classificação } & \multirow{2}{*}{ Melhora } \\
\cline { 2 - 5 } & $\mathbf{1}^{\mathbf{0}}$ & $\mathbf{2}^{\mathbf{0}}$ & $\mathbf{3}^{\mathbf{0}}$ & $\mathbf{4}^{\mathbf{0}}$ & \\
\hline Original & $8.6 \%$ & $14.3 \%$ & $42.9 \%$ & $34.3 \%$ & $\mathbf{- 3 5 . 2 \%}$ \\
\hline $\begin{array}{c}\text { Equalização } \\
\text { tradicional }\end{array}$ & $25.7 \%$ & $0.0 \%$ & $11.4 \%$ & $62.9 \%$ & $\mathbf{- 4 1 . 0 \%}$ \\
\hline $\begin{array}{c}\text { Correção } \\
\text { BCC }\end{array}$ & $45.7 \%$ & $31.4 \%$ & $20.0 \%$ & $2.9 \%$ & $\mathbf{4 6 . 7 \%}$ \\
\hline $\begin{array}{c}\text { Redução de } \\
\text { brilho }\end{array}$ & $20.0 \%$ & $54.3 \%$ & $25.7 \%$ & $0.0 \%$ & $\mathbf{2 9 . 5 \%}$ \\
\hline
\end{tabular}

Tabela 7: Resultados por fonte (DDSM L200)

\begin{tabular}{|c|c|c|c|c|c|}
\hline \multirow{2}{*}{ Tipo } & \multicolumn{3}{|c|}{ Classificação } & \multirow{2}{*}{ Melhora } \\
\cline { 2 - 5 } & $\mathbf{1}^{\mathbf{0}}$ & $\mathbf{2}^{\mathbf{o}}$ & $\mathbf{3}^{\mathbf{0}}$ & $\mathbf{4}^{\mathbf{0}}$ & \\
\hline Original & $1.4 \%$ & $13.9 \%$ & $77.8 \%$ & $6.9 \%$ & $\mathbf{- 2 6 . 9 \%}$ \\
\hline $\begin{array}{c}\text { Equalização } \\
\text { tradicional }\end{array}$ & $2.8 \%$ & $2.8 \%$ & $2.8 \%$ & $93.1 \%$ & $\mathbf{- 9 0 . 3 \%}$ \\
\hline
\end{tabular}




\begin{tabular}{|c|c|c|c|c|c|}
\hline $\begin{array}{c}\text { Correção } \\
\text { BCC }\end{array}$ & $69.4 \%$ & $16.7 \%$ & $12.5 \%$ & $0.0 \%$ & $\mathbf{7 0 . 8} \%$ \\
\hline $\begin{array}{c}\text { Redução de } \\
\text { brilho }\end{array}$ & $26.4 \%$ & $66.7 \%$ & $6.9 \%$ & $0.0 \%$ & $\mathbf{4 6 . 3 \%}$ \\
\hline
\end{tabular}

Tabela 8: Resultados por fonte (DDSM Howtek)

\begin{tabular}{|c|c|c|c|c|c|}
\hline \multirow{2}{*}{ Tipo } & \multicolumn{4}{|c|}{ Classificação } & \multirow{2}{*}{ Melhora } \\
\cline { 2 - 5 } & $\mathbf{1}^{\mathbf{0}}$ & $\mathbf{2}^{\mathbf{0}}$ & $\mathbf{3}^{\mathbf{0}}$ & $\mathbf{4}^{\mathbf{0}}$ & \\
\hline Original & $11.1 \%$ & $5.6 \%$ & $83.3 \%$ & $0.0 \%$ & $\mathbf{- 1 4 . 8 \%}$ \\
\hline $\begin{array}{c}\text { Equalização } \\
\text { tradicional }\end{array}$ & $27.8 \%$ & $16.7 \%$ & $5.6 \%$ & $50.0 \%$ & $\mathbf{- 1 8 . 5 \%}$ \\
\hline $\begin{array}{c}\text { Correção } \\
\text { BCC }\end{array}$ & $55.6 \%$ & $16.7 \%$ & $11.1 \%$ & $16.7 \%$ & $\mathbf{4 0 . 7 \%}$ \\
\hline $\begin{array}{c}\text { Redução de } \\
\text { brilho }\end{array}$ & $5.6 \%$ & $61.1 \%$ & $0.0 \%$ & $33.3 \%$ & $\mathbf{- 7 . 4 \%}$ \\
\hline
\end{tabular}

Os resultados das tabelas acima são similares ao caso geral, exceto por alguns fatores discutidos a seguir. Em todos, exceto um caso, a Correção BCC (GOES, SCHIABEL e SOUSA, 2013) forneceu os melhores resultados, Redução de Brilho foi o segundo melhor e a Equalização (GONZALES e WOODS, 2008) foi o pior resultado.

Uma exceção ocorreu com as imagens da base BancoWeb (MATHEUS e SCHIABEL, 2011), onde a Equalização foi considerada melhor e a Correção BCC a pior. A razão para a diferença de resultados usando as imagens do BancoWeb parecem vir da drástica diferença do modo como as imagens são digitalizadas. Como mostrado na Figura 26 todos os scanners que originaram as imagens usadas neste teste têm curvas próximas do "ideal linear", exceto pelas imagens da base BancoWeb, cuja curva característica se aproxima consideravelmente da curva de referência usada na correção BCC. Isso significa que o ganho do uso da correção BCC é pequeno para imagens da base BancoWeb, que já correspondem a um processo de digitalização mais apropriado para o melhor contraste na faixa de valores mais significativa para a mamografia quando comparada a outras fontes.

Nota-se que, surpreendentemente, uma curva característica similar a uma reta não é ideal para este problema, pois as diferenças de contraste na região clara da imagem 
(onde se concentram as informações mais significativas quanto à imagem mamográfica) se tornam menos evidentes. O uso deste método parece mostrar que isso é independente do treinamento e tendência do especialista, já que o método produz melhorias claras dos resultados em sistemas CAD.

Também é importante considerar que cada radiologista tem suas preferências em relação a níveis de contraste, brilho, saturação, etc. Como o teste foi realizado com apenas dois radiologistas não se pode desconsiderar vícios e tendências individuais.

Por conta dos claros resultados positivos da Correção BCC, todos os testes realizados neste trabalho, cujos resultados estão explicitados nas seções a seguir, utilizaram a correção BCC como uma de suas técnicas de pré-processamento.

Os resultados descritos nesta seção foram previamente publicados no SPIE Medical Imaging 2014 (MATHEUS, VERÇOSA, et al., 2014).

\subsubsection{Influencia na Detecção de Nódulos}

O método de detecção de nódulos usado no esquema CADx (seção 5.3.3, Capítulo 5) foi desenvolvido já levando em conta os métodos de segmentação de mama e musculo peitoral (seção 5.3.2, Capítulo 5) do pré-processamento. Por conta disso, a única influencia que poderia mudar seus resultados seria a correção BCC (seção 4.1, Capítulo 4).

Testes do sistema de Detecção de Nódulos (BARBOSA FILHO, 2012) incluindo a Correção BCC (GOES, SCHIABEL e SOUSA, 2013), foram realizados usando por volta de 100 imagens aleatoriamente selecionadas da base DDSM.

Nenhum dos resultados mostrou diferença após a correção BCC. A comparação foi feita pixel a pixel entre as imagens com e sem a correção BCC, mas em nenhum caso as detecções se alteraram. Até onde foi possível determinar, a correção BCC não tem nenhum efeito sobre o método de detecção desenvolvido por Barbosa Filho.

7.2 Detector de calcificações (MATHEUS, FERRO NETO e SCHIABEL, 2013) 
Para obter as variáveis descritas na secção 5.3.3c.1 do Capítulo 5 foi necessário testar o programa com várias combinações de variáveis para cada imagem. Uma vez encontrado o melhor resultado possível, ele era avaliado de modo a tentar encontrar relações entre os valores obtidos no melhor caso para cada imagem diferente.

Em (FERRO NETO, 2012), foi realizado um detalhado conjunto de testes com o intuito de ampliar e atualizar o filtro de realce de (SCHIABEL, NUNES, et al., 2000). O objetivo foi desenvolver um filtro escalável para diferentes resoluções das imagens, mantendo a estrutura próxima da calcificação real. Dessa análise surgiram as equações explicitadas na seção 5.3.3c, Capítulo 5 (Eq. 9 a Eq. 12) e outras variáveis. Por último fícou uma variável de sensibilidade do sistema, que define quão sensível o sistema será na detecção de calcificações antes da análise de “clusters". Essa variável de sensibilidade foi definida pelo nome "topo".

A fim de encontrar o melhor valor para a variável "topo", foi determinada uma curva FROC, a partir de testes com 60 imagens selecionadas da base DDSM. A melhor relação custo-benefício foi utilizada na versão final do programa. Tal curva obtida está mostrada na Figura 28.

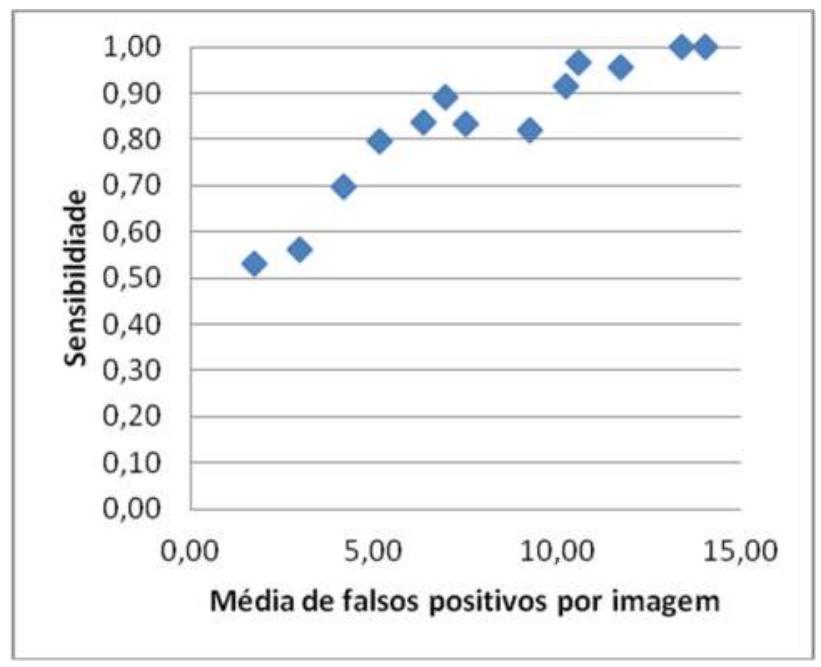

Figura 28: Curva FROC do detector de calcificações usando 60 imagens provenientes da base DDSM. 
Considerando a curva da Fig. 28, foi possível determinar que a melhor relação custo-benefício se apresenta quando a variável "topo" vale $0,08 \%$.

Utilizando mais 70 imagens da base DDSM, totalizando 130 imagens, e considerando a variável "topo" como $0,08 \%$, registrou-se uma sensibilidade de $89 \%$ com 6,9 clusters falsos positivos por imagem.

Um problema frequentemente encontrado nestes testes é o fato de que várias imagens da base DDSM apresentam círculos de alto contraste provenientes de pequenas marcações de chumbo utilizadas para indicar sinais de pele, verrugas ou cicatrizes nas imagens mamográficas (Figura 29). Estas esferas são colocadas pelos técnicos na pele da paciente antes da aquisição da imagem para serem usadas como referência pelo radiologista. $\mathrm{O}$ alto contraste dos círculos resultantes na imagem é tal que, normalmente, o local é considerado uma detecção positiva. Apesar dos radiologistas naturalmente ignorarem tais marcações, os pontos foram considerados falsos-positivos de modo a avaliar de modo justo o esquema proposto. Desconsiderando tais marcações a taxa de falsos-positivos cai para 5,9 por imagem, uma redução de $14 \%$.

No caso das imagens de sistemas FFDM da base INBreast, só havia 18 casos contendo microcalcificações, o que não é o suficiente para elaborar uma curva FROC estatisticamente significativa. Empiricamente, o melhor custo-benefício foi registrado com a variável "topo" em $0,10 \%$, o que conduziu a uma sensibilidade de $89 \%$ mas apenas 1,4 falsos-positivos por imagem.

Considerando os dois conjuntos de imagens, ou seja, o da base DDSM e o da INBreast selecionados (num total de 148 imagens), o melhor resultado se mostrou com a variável "topo" mantida com o valor $0,10 \%$, o que produziu sensibilidade global de $92 \%$ e 6,9 falsos positivos por imagem. Valores menores da variável "topo" são capazes de reduzir a taxa de falsos-positivos, mas a sensibilidade decai drasticamente para valores menores do que $0,10 \%$.

Apesar da melhora na sensibilidade, a taxa de falsos-positivos do conjunto completo (DDSM + INBreast) resultou igual ao alto valor encontrado no caso da DDSM 
apenas. Este resultado não foi proposital, sendo encontrado pelo ponto de inflexão da curva FROC e concidentemente obtendo o mesmo valor do caso anterior.

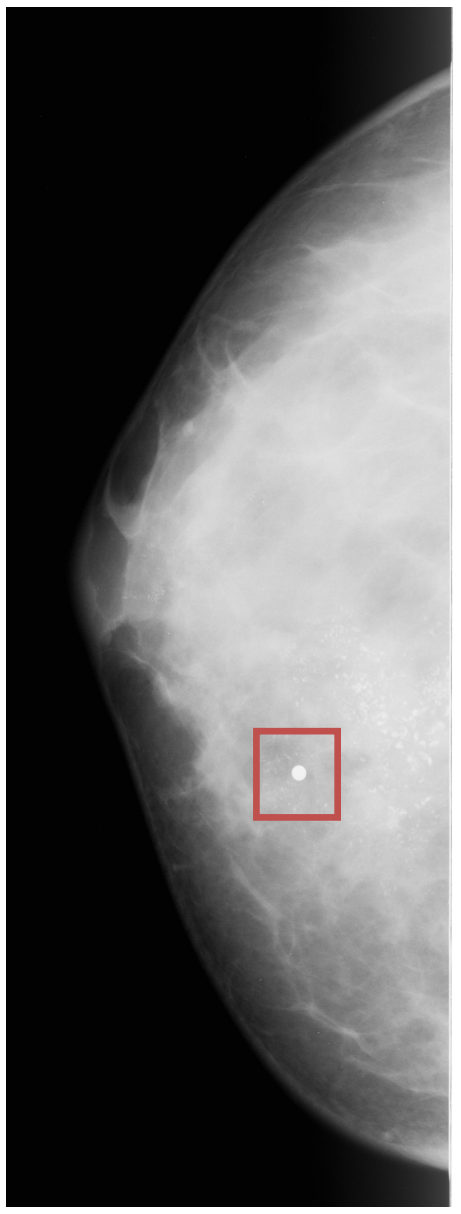

(a)

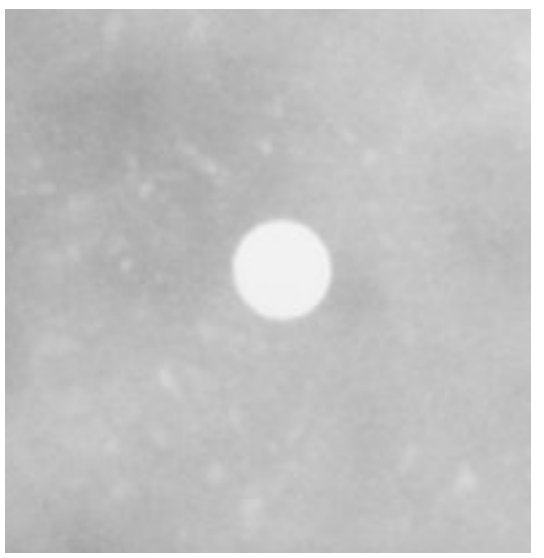

(b)

Figura 29: Exemplo das marcações de chumbo. a) Imagem completa com marcação. b) Zoom da marcação

Usando a informação de densidade em padrão BI-RADS, fornecida pela base, foi possível separar as 130 imagens da DDSM usadas nos testes entre mamas densas e mamas lipossubstituídas. Para efeito desta avaliação, os padrões de densidade I e II do BI-RADS foram considerados referentes a lipossubstituídas e os padrões III e IV, a densas. 
Assumindo essa divisão, o conjunto ficou composto de 68 imagens de mamas lipossubstituídas e 62 de densas.

Para as imagens lipossubstituídas, os resultados produziram $80 \%$ de sensibilidade com 8,2 falsos-positivos por imagem e, nas imagens densas, 99\% de sensibilidade com 5,4 falsos-positivos.

Normalmente, a identificação de microcalcificações é consideravelmente mais difícil em mamas densas, já que a maior intensidade média do fundo tende a esconder o achado na inspeção visual. Os resultados do detector, porém, foram no caminho oposto, pois, no caso de mamas densas, a identificação pelo método descrito acima é mais sensível e com menos falsos-positivos que para o outro conjunto.

Uma comparação visual dos casos leva à conclusão de que regiões contendo ruído, seja causado na aquisição da imagem ou na digitalização, frequentemente têm a forma de pequenos pontos claros. Nas mamas lipossubstituídas, com o tecido menos denso portanto, mais escuro na imagem - tal ruído se assemelha a calcificações e é marcado como tal; já nas mamas densas, com o tecido mais denso - portanto, mais claro na imagem - tal ruído se camufla e, assim, deixa de ser detectado (como um falso-positivo).

O ruído explica não só a maior taxa de falsos-positivos nos casos lipossubstituídos, mas também a menor sensibilidade, pois o método descrito aqui tem como um dos seus passos a seleção das regiões mais proeminentes pela variável "topo" (descrita em detalhes na seção 5.3.3c, Capítulo 5). Considerando que microcalcificações, devido ao seu tamanho diminuto, frequentemente se apresentam com baixo contraste e são difíceis de diferenciar, a similaridade entre o ruído nas imagens lipossubstituídas e os casos mais sutis de microcalcificação levam o sistema a erroneamente detectar ruídos como regiões mais proeminentes para o achado.

Com base nos trabalhos descritos no artigo de revisão de (RANGAYYAN, AYRES e DESAUTELS, 2007), foi possível fazer uma comparação entre os estudos estabelecidos na área e os resultados encontrados aqui. Na Tabela 9 os resultados dessa comparação são explicitados. 
Tabela 9: Resultados de deteç̧ão de calcificações por algumas técnicas descritas na literatura em comparação com os testes do nosso esquema

\begin{tabular}{|c|c|c|}
\hline Referência & $\begin{array}{c}\text { Sensibilidade } \\
\mathbf{( \% )}\end{array}$ & $\begin{array}{c}\text { Taxa de falsos } \\
\text { positivos / } \\
\text { imagem }\end{array}$ \\
\hline Detector de calcificações (geral) & 92 & 6,9 \\
\hline Detector de calcificações (mamas densas) & 99 & 5,4 \\
\hline Detector de calcificações (FFDM) & 89 & 1,4 \\
\hline (STRICKLAND, 1996) & 91 & 3 \\
\hline (WEI, YANG, et al., 2005) & 90 & 0,75 \\
\hline (YU, LI e HUANG, 2006) & 92 & 0,5 \\
\hline (YU e GUAN, 2000) & 90 & \\
\hline
\end{tabular}

Em todos os exemplos comparativos mostrados na Tabela 9, os testes foram realizados apenas com imagens provenientes de sistemas FFDM. Os resultados do método descrito neste trabalho para imagens FFDM são proximos aos obtidos na literatura. $\mathrm{O}$ resultado geral, ou seja, incluindo imagens digitalizadas a partir de filmes tem uma sensibilidade comparável, mas uma taxa de falsos positivos por imagem consideravelmente maior.

Os resultados mostram que o uso deste método é viável no caso de imagens FFDM, localizando a grande maioria dos clusters de calcificações da imagem (89\%), com poucas detecções falsas (1,4 por imagem). Certamente, este resultado é devido ao menor ruído nas imagens FFDM, em comparação às obtidas em filme-digitalizador.

Já no caso de imagens filme-digitalizador, a sensibilidade de detecção é a mesma obtida com as imagens FFDM (89\%), mas a taxa de falsos positivos é muito mais alta (6,9 por imagem), o que pode levar o radiologista a ignorar completamente as marcações do método em sua avaliação.

Assim, o caso geral (isto é, o conjunto completo considerando imagens FFDM + filme-digitalizador) tem uma sensibilidade ainda mais alta do que a observada para a 
avaliação das situações individuais, mas a alta taxa de falsos-positivos pode produzir a mesma consequência descrita acima, o que leva a considerar que, sem novos ajustes e alterações do esquema, este módulo só apresenta resultados promissores quando usado com imagens FFDM.

Por outro lado, como é bem reconhecido que os radiologistas têm uma maior dificuldade na detecção de microcalcificações em casos de mamas densas (EGAN, MCSWEENEY e SEWELL, 1980), ressalta-se a importância dos resultados deste detector com mamas densas, cuja alta taxa de sensibilidade (99\%), apesar da taxa de falsos-positivos ainda ser alta (5,4 falsos-positivos por imagem), permitiria ao radiologista se focar apenas nas regiões demarcadas pelo sistema, sem receio de "deixar passar" clusters de microcalcificações.

É importante ressaltar também que o uso de imagens digitalizadas a partir de filmes vem-se reduzindo drasticamente, tanto no Brasil quanto no mundo, com a substituição por sistemas DR (ou seja, a mamografia do tipo FFDM) ou mesmo sistemas $\mathrm{CR}^{3}$. Isso é devido à maior praticidade de uso e arquivamento, ao eliminar o uso de filmes, e pela melhoria da qualidade da imagem, frequentemente menos ruidosa e com melhor contraste.

A qualidade de imagens digitalizadas pode deixar muito a desejar, dependendo da qualidade do filme original e do digitalizador utilizado. Por exemplo, no caso das imagens da base DDSM, os digitalizadores utilizados têm curvas características próximas de uma reta, resultando em imagens com contraste fraco para muitas análises, conforme discutido na seção 7.1 deste capítulo. Além disso, testes feitos por Ribeiro (RIBEIRO, 2013) nas imagens da DDSM mostraram que, para usar as imagens para classificação de nódulos, uma série de pré-processamentos se mostraram necessários, o que não ocorreu em testes similares com as imagens da base BancoWeb, desenvolvida em nosso grupo (MATHEUS e SCHIABEL, 2011). Confirmando tais resultados, durantes os testes com radiologistas

\footnotetext{
${ }^{3}$ Computed Radiography (Radiologia Computadorizada)
} 
treinados (seções 7.1, 7.4.1 e 7.4.2 deste capítulo) aquelas imagens frequentemente foram descritas como "foscas" ou "nubladas".

Por conta disso, e apesar do número menor de imagens, os resultados muito superiores obtidos com as imagens FFDM da base INBreast são muito importantes para uma avaliação do módulo de detecção de microcalcificações. Afinal essa análise corresponde a um tipo de imagem mais próximo do que logo será utilizado universalmente para diagnóstico mamográfico.

\subsection{Segmentação de nódulos}

Dois métodos foram avaliados neste projeto com o intuito de escolher qual o mais adequado para segmentação de nódulos de acordo com a proposta do esquema CADxLAPIMO: Método de Otsu (OTSU, 1979) e EICAMM (RIBEIRO, 2013).

Os testes foram feitos utilizando um conjunto de 44 imagens da base INBreast (MOREIRA, AMARAL, et al., 2012) - que representa todas as imagens da base com nódulos demarcados. Como os arquivos da base incluem um contorno rudimentar de cada nódulo demarcado, esse contorno foi considerado referência para efeitos comparativos nos testes.

Cada nódulo foi recortado de cada imagem em um retângulo cujas bordas são 10 pixels maiores do que os limites horizontais e verticais do contorno conforme descrito na base. Então, cada recorte foi segmentado automaticamente utilizando as duas técnicas aqui consideradas.

Para reduzir a taxa de ruídos na borda da segmentação e melhorar a qualidade dos contornos obtidos pelas técnicas testadas, cada imagem passou por um processo de suavização utilizando morfologia matemática. Especificamente, foram utilizados aberturas e fechamentos com elementos circulares cujos diâmetros foram variados em todos valores ímpares entre 3 e 10 pixels.

Os resultados obtidos pelas diferentes técnicas foram comparados ao contorno preenchido fornecido pela base, ou seja, a região interna ao contorno foi preenchida com 
branco em uma imagem binária. Essa imagem será referida nesse caso como imagem referência (Figura 30).

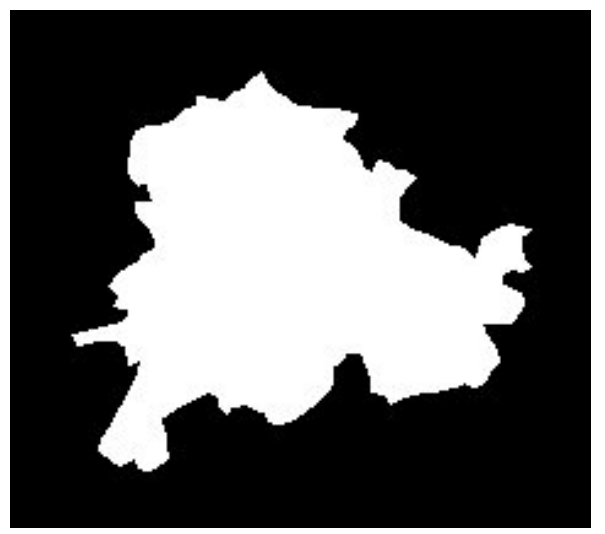

Figura 30: Exemplo de imagem referência para os testes de avaliação comparativa entre as técnicas de Otsu e EICAMM para segmentação de nódulos.

A imagem referência foi multiplicada pela imagem resultante de cada técnica acima (também binária) (Figura 31), o número de pixels brancos foi contado e dividido pelo número de pixels brancos na imagem referência. Este número será referido aqui como taxa de acerto nódulo.

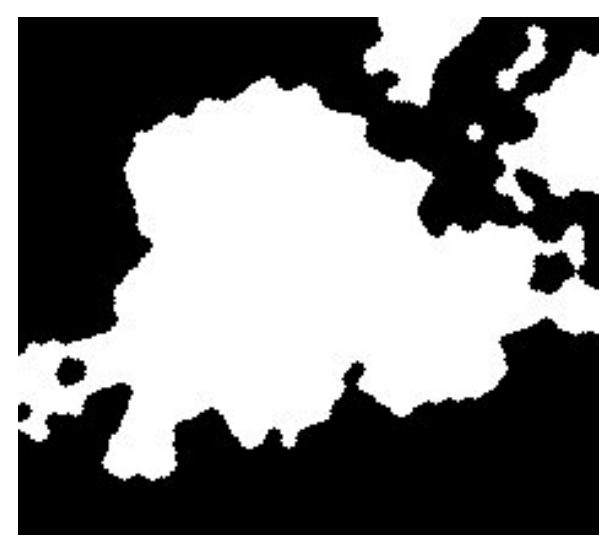

Figura 31: Exemplo da imagem segmentada (no caso, pela técnica de Otsu). 
Em seguida as duas imagens (referência e resultante) foram invertidas (Figura 32) binariamente e novamente multiplicadas, de modo agora a comparar as regiões negativas da imagem, isto é, as regiões em que a imagem resultante não correspondia à segmentação referencial. Novamente, os valores brancos resultantes foram contados e divididos pela região preta da imagem referência. Este número será referido como taxa de acerto fundo.

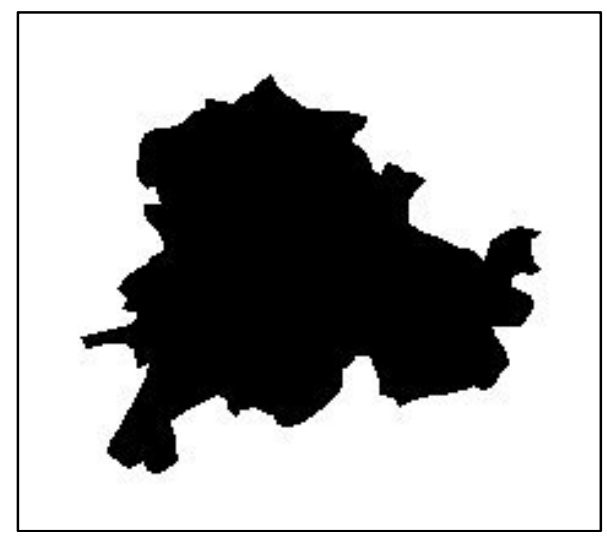

(a)

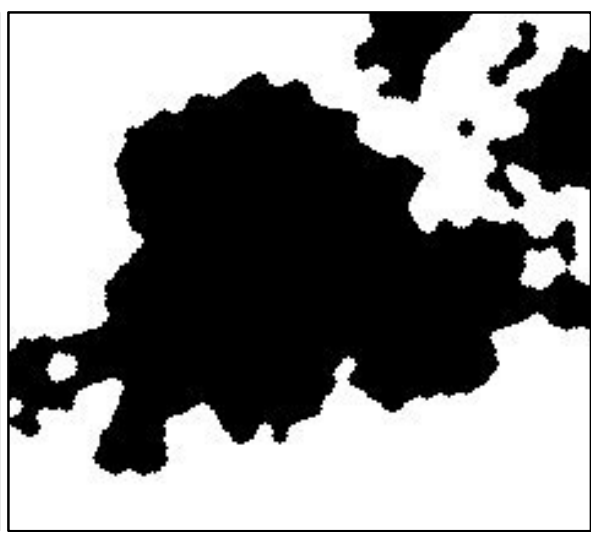

(b)

Figura 32: Exemplo do cálculo da taxa de acerto fundo. (a) Imagem referência invertida, (b) Imagem segmentada pela técnica de Otsu, invertida.

A média das duas taxas de acerto resulta na taxa de acerto global. Para cada imagem as taxas de acerto globais das duas técnicas foram calculadas. Isso se repetiu para cada tamanho do elemento estruturante das técnicas morfologicas.

Avaliando cada técnica separadamente, os melhores resultados são a EICAMM com elemento estruturante de tamanho 3 , com $82,1 \%$ de acerto médio, e Otsu com o elemento estruturante de tamanho 7 , com $80,4 \%$ de acerto médio.

Levando-se em conta a taxa de acerto apenas, a técnica EICAMM tem resultados melhores, porém dois fatos importantes precisam ser levados em conta nesta escolha: tempo e robustez do sistema.

Cada região de interesse segmentada pela técnica EICAMM leva, em média, cinco minutos para ser completamente processada, enquanto a de Otsu possibilita sementar a 
mesma região, em média, em um segundo. Tal diferença de tempo de processamento (em torno de 300 vezes) faz com que o uso de EICAMM seja inviável no caso da aplicação em tempo real do esquema - para uso clínico concomitante ao processo de avaliação do exame, por exemplo.

Outro fator que precisa ser levado em conta é a robustez da técnica. No caso da EICAM, ocorreram erros catastróficos no processo de segmentação em cerca de $5 \%$ das RIs. Erros foram considerados catastróficos quando a técnica não consegue completar a segmentação após uma hora de processamento, causa travamento do computador ou provoca uma mensagem de erro; em um dos casos, o processamento foi interrompido após 6 horas sem sucesso na segmentação. Isso, contudo, não foi registrado em qualquer processo utilizando a técnica de Otsu.

Desse modo, levando-se em conta também esses dois fatores e a diferença pequena na qualidade da segmentação, a técnica de Otsu foi considerada mais confiável e eficiente para implementação no esquema. Para efeito de confirmação, ambas as técnicas foram novamente comparadas sob a óptica do método de classificação (seção 7.4.4), o que possibilitou determinar resultados mais conclusivos sobre qual técnica o esquema final deveria utilizar.

\subsection{Classificação de nódulos}

O esquema descrito neste trabalho tem como principal característica o fato de ser um esquema CADx, ou seja, ser capaz de realizar classificação dos achados em busca de malignidade. Por conta disso, vários testes e avaliações foram realizados, utilizando as diferentes iterações do classificador ao longo do projeto.

7.4.1 Efeito da classificação de contornos na opinião de radiologistas experientes

Os testes iniciais do método de classificação de nódulos se concentraram em avaliar os efeitos da classificação pelo CADx na opinião de radiologistas experientes. 
Nestes testes o programa original de classificação por contorno (RIBEIRO, 2006) foi utilizado. Estes testes comparativos foram realizados requisitando a um radiologista experiente (chamado daqui para frente de R1) que selecionasse, a partir de mamografias completas, um conjunto de RIs contendo nódulos. O resultado foi 69 RIs avaliadas e classificadas por R1.

Essas mesmas imagens, mas apenas as RIs, foram, então, apresentadas a outro radiologista experiente (chamado aqui de R2) usando um monitor apropriado para visualização de imagens médicas ${ }^{4}$. R2 foi requisitado a avaliar as RIs sem nenhuma outra informação e, em seguida, com auxílio das informações proporcionadas pelo esquema CADx, considerando a classificação de nódulos por contorno (seções 4.7.1 e 4.7.2 do Capítulo 4), foi instado a rever sua avaliação, mantendo-a ou modificando-a. O mesmo procedimento foi realizado para dois outros radiologistas (referidos como R3 e R4).

Os resultados estão apresentados na Tabela 10, onde temos o resultado comparativo em relação a R1 (tomado como referência) do esquema computacional e dos 3 outros radiologistas, considerando a avaliação por eles produzida com e sem auxílio do esquema CAD.

Como R1 teve acesso aos exames completos e selecionou as imagens, pode-se considerar que sua avaliação é provavelmente mais precisa, e, portanto, é a que está sendo tomada como referência.

O sistema computacional de classificação isoladamente apresentou uma taxa média de concordância com R1 de 65\%. Já os radiologistas (com acesso apenas às RIs) apresentaram, em média, uma taxa de concordância com R1 de $60 \%$. Uma vez disponíveis os resultados do CADx aos radiologistas (que, em função das informações provenientes do esquema, podiam mudar sua opinião inicial), sua taxa de concordância com a referência R1 teve um aumento médio de 15\% (atingindo uma média de 69\%). A melhora foi mais evidente em R2 (42\%) e, ao contrário, R3 teve uma redução de $8 \%$ na sua concordância.

\footnotetext{
${ }^{4}$ NIO 3MP (E-3620) da BARCO (Kortrijk, Bélgica)
} 
Tabela 10: Resultado comparativo com R1, considerando a avaliação antes e depois do auxílio do esquema CADx

\begin{tabular}{|c|c|c|c|c|c|c|c|}
\hline \multirow[b]{2}{*}{$\begin{array}{c}\text { Classe } \\
\text { (por R1) }\end{array}$} & \multicolumn{7}{|c|}{ Concordância } \\
\hline & CAD & $\mathbf{R} 2$ & $\mathrm{R} 2+\mathrm{CAD}$ & R3 & $R 3+C A D$ & R4 & R4 + CAD \\
\hline Circunscrita & $69 \%$ & $56 \%$ & $56 \%$ & $93 \%$ & $94 \%$ & $50 \%$ & $94 \%$ \\
\hline Obscurecida & $54 \%$ & $23 \%$ & $69 \%$ & $50 \%$ & $36 \%$ & $0 \%$ & $36 \%$ \\
\hline Microlobulada & $86 \%$ & $64 \%$ & $86 \%$ & $31 \%$ & $25 \%$ & $15 \%$ & $25 \%$ \\
\hline Mal definida & $40 \%$ & $30 \%$ & $40 \%$ & $38 \%$ & $17 \%$ & $56 \%$ & $17 \%$ \\
\hline Espiculada & $69 \%$ & $44 \%$ & $63 \%$ & $79 \%$ & $75 \%$ & $56 \%$ & $75 \%$ \\
\hline $\begin{array}{c}\text { Média } \\
\text { ponderada }\end{array}$ & $65 \%$ & $45 \%$ & $64 \%$ & $61 \%$ & $56 \%$ & $73 \%$ & $86 \%$ \\
\hline Melhora \% & & & $42 \%$ & & $-8 \%$ & & $+18 \%$ \\
\hline
\end{tabular}

Note-se que se tratou de uma avaliação comparativa detalhada, pois foi levado em consideração como cada radiologista classificou a estrutura presente em cada RI em termos do seu contorno. Quando se considera, no entanto, apenas a distinção entre casos malignos e benignos, têm-se os resultados da Tabela 11 .

Neste caso, a concordância média dos outros radiologistas com R1 foi de $74 \%$, sem o CADx. Após a apresentação das informações do CADx, a média não se alterou, pois dois dos especialistas (R2 e R3) apresentaram um aumento no grau de concordância com a referência da ordem de $20 \%$ e $15 \%$, respectivamente, e R4 teve uma redução de $9 \%$ na concordância. O motivo desta redução de concordância em R4 ainda não está claro, considerando que a concordância da classificação por contorno aumentou.

Tabela 11: Resultados comparativos com R1, considerando malignidade apenas 


\begin{tabular}{|c|c|c|c|c|c|c|c|}
\cline { 2 - 9 } \multicolumn{1}{c|}{} & \multicolumn{7}{c|}{ Concordância } \\
\hline $\begin{array}{c}\text { Classe } \\
\text { (por R1) }\end{array}$ & CAD & R2 & R2 + CAD & R3 & R3 + CAD & R4 & R4 + CAD \\
\hline Benigna & $88 \%$ & $67 \%$ & $84 \%$ & $62 \%$ & $74 \%$ & $62 \%$ & $58 \%$ \\
\hline Maligna & $65 \%$ & $62 \%$ & $77 \%$ & $59 \%$ & $67 \%$ & $92 \%$ & $81 \%$ \\
\hline Média & $80 \%$ & $65 \%$ & $81 \%$ & $61 \%$ & $71 \%$ & $73 \%$ & $67 \%$ \\
\hline Melhora \% & & \multicolumn{2}{|c|}{$20 \%$} & & $15 \%$ & & $-9 \%$ \\
\hline
\end{tabular}

Estes resultados mostram que o uso do sistema CADx afetou sensivelmente as classificações realizadas pelos profissionais experientes, em geral para melhor. No entanto, um dos radiologistas testados parece ter sido afetado negativamente pelo uso do esquema. Testes em escalas maiores - aumentando o número de radiologistas e de imagens avaliadas - precisam ser feitos para uma estatística mais precisa dos benefícios do uso do esquema CADx descrito aqui.

\subsubsection{Efeito da classificação geral na opinião de radiologistas experientes}

A partir de novo desenvolvimento do programa de classificação de nódulos (RIBEIRO, 2013), conforme descrito no Capítulo 4 (seção 4.7.2), foi realizado novo teste do efeito do CADx sobre a opinião médica. O teste foi montado considerando 147 exames (78 contendo nódulos malignos e 69 benignos), totalizando 588 imagens selecionados a partir da base DDSM (HEATH, BOWYER, et al., 2001). As imagens utilizadas foram todas digitalizadas num scanner Lumisys 200, com $50 \mu \mathrm{m}$ de resolução espacial e 12 bits de resolução de contraste.

Os exames foram aleatoriamente selecionados, aproveitando as demarcações da base DDSM para estabelecer as RIs e sinalizar ao radiologista o local do nódulo que deveria ser avaliado. Em alguns casos mais de um achado estava presente na imagem, mas foi pedido que apenas o nódulo demarcado fosse avaliado.

A segmentação foi realizada utilizando a técnica EICAMM, a partir da RI demarcada pela base, e a classificação utilizou o programa de classificação geral de 
nódulos de Ribeiro (seção 4.7.1, Capítulo 4). Dificuldades apresentadas pelo programa ao manipular as imagens da base DDSM - conforme já havia sido comentado naquele mesmo trabalho (RIBEIRO, 2013) - levaram a utilizar aqui apenas os atributos de textura, contorno e densidade neste teste. A investigação, então, foi realizada com uma radiologista especialista, em dois passos:

1) Cada exame (4 imagens/exame) foi-lhe apresentado com o nódulo demarcado nas imagens, e solicitada a sua avaliação em relação a tal achado de modo a classificá-lo como maligno ou benigno apenas.

2) Após cerca de 2 semanas, os mesmos exames foram-lhe mostrados novamente, em ordem aleatoriamente alterada. Desta vez, porém, todas as imagens foram apresentadas junto com a informação do resultado produzido pelo esquema classificador de nódulos. Novamente, as avaliações foram apenas "maligno" ou "benigno".

Nos dois passos acima, a radiologista tinha quanto tempo desejasse para avaliar cada exame e podia aplicar zoom livremente. Brilho e contraste não puderam ser alterados, ou seja, as imagens foram apresentadas conforme a base as fornece.

$\mathrm{Na}$

Tabela 12 são apresentados os resultados anotados a partir desse teste: da avaliação da radiologista sem auxílio do CADx (primeira coluna), do resultado produzido pelo esquema CADx (segunda coluna) e da opinião da radiologista com auxílio do informe proveniente do CADx (terceira coluna).

Esses resultados mostram que não só os dados da avaliação da radiologista apresentaram um aumento de 5,5\% na taxa de sensibilidade (de 92,3\% para 97,4\%), mas também uma melhora de 18,3\% na especificidade (de 63,7\% para 75,4\%). Isso aponta de forma categórica para um aumento de precisão no diagnóstico, ainda que os testes tenham sido realizados com apenas uma radiologista. Apesar de não ter sido possível, por uma série de fatores logísticos, ampliar estes testes, analisando os resultados de uma quantidade maior de radiologistas, os dados da Tabela xx permitem inferir a utilidade da ferramenta representada por esse esquema CADx, pelo menos para uma parte dos 
médicos, por possibilitar um aumento tanto da sensibilidade quanto a especificidade do radiologista num aspecto que é bastante sensível na mamografia: a interpretação relativa aos achados no exame.

Tabela 12: Resultados da opinião da Radiologista com e sem auxílio do CADx

\begin{tabular}{|c|c|c|c|c|c|c|}
\cline { 2 - 7 } \multicolumn{1}{c|}{} & \multicolumn{2}{c|}{ Radiologista } & \multicolumn{2}{c|}{ Esquema CADx } & \multicolumn{2}{c|}{ Radiologista + CADx } \\
\cline { 2 - 7 } \multicolumn{1}{c|}{} & Casos & Taxa (\%) & Casos & Taxa (\%) & Casos & Taxa (\%) \\
\hline Sensibilidade & 72 & 92,3 & 71 & 91,0 & 76 & 97,4 \\
\hline Especificidade & 44 & 63,7 & 54 & 78,3 & 52 & 75,4 \\
\hline Falsos Positivos & 25 & 36,3 & 15 & 21,7 & 17 & 24,6 \\
\hline
\end{tabular}

É importante esclarecer que o objetivo deste teste não era avaliar o esquema CADx, mas avaliar a consequência do uso de CADx na opinião de um radiologista experiente. Por conta disso as taxas do esquema CADx na Tabela 12 são os resultados usando todos os casos como treinamento, diferente dos resultados que serão mostrados na seção 7.4.3.

\subsubsection{Avaliação e validação do método de classificação final}

$\mathrm{Na}$ descrição original do método de classificação geral de (RIBEIRO, 2013) foi reportada uma série de dificuldades na classificação de imagens com nódulos provenientes da base DDSM (HEATH, BOWYER, et al., 2001), em particular ligado ao contraste das imagens.

A DDSM é a maior base de imagens mamográficas publicamente disponível no momento, sendo bem estabelecida e aceita internacionalmente. Além disso, o fato de que os achados estão demarcados de modo simples torna seu uso prático para experimentos em larga escala.

Testes com o esquema descrito em (RIBEIRO, 2013) confirmaram a dificuldade com o contraste das imagens provenientes da base DDSM. Por conta disso, um novo 
estudo foi realizado em cima dos atributos utilizados no método, tentando avaliar quais deveriam ser utilizados na classificação. Os testes relativos a essa nova investigação estão apresentados a seguir e referem-se à avaliação de 568 imagens da base DDSM contendo nódulos.

No classificador geral de (RIBEIRO, 2013) foram utilizados os seguintes seis atributos:

- Entropia da Diferença

- Variância

- Compacidade

- Perímetro

- Densidade do nódulo

É importante, porém, que todos os atributos sejam independentes das características mais maleáveis das imagens, como, por exemplo, o seu nível de brilho e o tamanho da RI.

O atributo perímetro é intrinsecamente dependente do tamanho da imagem; além disso, ele já é levado em conta no cálculo da compacidade, que, por sua vez, é independente do tamanho da imagem. Por isso, o perímetro foi descartado na estruturação do programa final de classificação.

O atributo Densidade do Nódulo é dependente do brilho da imagem quando avaliado separadamente, ou seja, imagens mais claras vão apresentar resultados diferentes de imagens mais escuras, ainda que o mesmo nódulo esteja sendo avaliado. Para evitar diferenças por conta do brilho, o atributo de densidade foi alterado para uma razão de densidades chamada densidade relativa e calculada usando a Eq. 13.

$$
D_{\text {Relativa }}=\frac{D_{\text {nódulo }}}{D_{\text {fundo }}}
$$

Eq. 13

onde $\boldsymbol{D}_{\text {fundo }}$ é a densidade do fundo da imagem, calculada conforme descrito na seção 5.3.3b.3 . Levando em conta as alterações descritas acima, os atributos que passaram a ser usados na versão final do classificador foram: 
- Entropia da Diferença

- Variância

- Compacidade

- Densidade relativa

Cada atributo foi testado independentemente utilizando as 568 RIs provenientes da base DDSM, tendo sido elaborada uma curva ROC para cada atributo (Figura 33 a Figura 36). O parâmetro variante para construção das curvas ROC foi o limiar de classificação, ou seja, a partir de qual valor do dado atributo a classificação muda de "nãosuspeito" para "suspeito".

Para uma melhor compreensão da curva ROC é necessário definir claramente os termos utilizados nesta seção e na seção 7.7, a seguir neste capítulo. Normalmente os termos verdadeiro-positivo (VP), falso-positivo (FP), verdadeiro-negativo (VN) e falsonegativo (FN) são associados ao processo de detecção de um sinal ou objeto, como no caso de detector de microcalcificações (seção 5.3.3c, Capítulo 5) e do detector de nódulos (5.3.3b, Capítulo 5).

No caso da classificação de nódulos, o sinal sempre existe, mas pode ser maligno ou benigno e o programa de classificação fornece repostas "suspeito" ou "não-suspeito". Para manter a terminologia compatível com a análise estatística e com a literatura será considerado que o sinal positivo é o caso maligno e o sinal negativo é o benigno. $\mathrm{Na}$ Tabela 13 temos a tabela verdade levando em conta a diferença de nomenclatura.

Tabela 13: Tabela verdade para avaliação de classificação

\begin{tabular}{|c|c|c|c|}
\cline { 3 - 4 } \multicolumn{2}{c|}{} & \multicolumn{2}{c|}{ Resposta do classificador } \\
\cline { 3 - 4 } \multicolumn{2}{c|}{} & Suspeito & Não-suspeito \\
\hline \multirow{2}{*}{$\frac{0}{\grave{\nu}}$} & Maligno & VP & FN \\
\cline { 2 - 4 } & Benigno & FP & VN \\
\hline
\end{tabular}

Por consequência, os termos descritos na seção 2.3 do Capítulo 2 precisam ser revistos sob uma óptica diferente. A seguir os termos Sensibilidade, Especificidade e 
Acurácia são analisados levando em conta as modificações necessárias para seu uso na avaliação de classificadores.

- Sensibilidade: representa a taxa de casos malignos que foram corretamente identificados como "suspeitos" pelo programa. Em termos práticos, esse valor representa a taxa de nódulos malignos que o programa corretamente identifica, com (1 Sensibilidade) representando a taxa de nódulos malignos que o programa identifica incorretamente como "não-suspeito". Pode ser calculado como a quantidade de VP dividido pelo número de amostras malignas.

- Especificidade: representa a taxa de casos benignos corretamente identificados como "não-suspeitos" pelo programa. Em termos práticos, esse valor representa a taxa de nódulos benignos que o programa corretamente identifica, com (1 - Especificidade) representando a taxa de nódulos benignos que o programa identifica incorretamente como "suspeitos". Pode ser calculado como a quantidade de VN dividido pelo número de amostras benignas.

- Acurácia: representa a taxa de acerto do programa, ou seja, a porcentagem de acerto do programa, independentemente da classificação correta. Pode ser calculado como a soma de VP mais VN dividido pelo número total de amostras.

A curva ROC foi grafada usando a relação da Sensibilidade x (1 - Especificidade) para diferentes limiares dos atributos de classificação. Usando a curva ROC foi possível escolher, em cada caso, a melhor relação custo-benefício, pelo ponto mais próximo do limite superior esquerdo do gráfico. Os melhores custos-benefícios estão explicitados na Tabela 14.

Os resultados individuais, mostrados na Tabela 15 e da Figura 33 a Figura 36, não são extraordinários do ponto de vista de eficácia; porém, quando usados em conjunto, esses atributos conduzem a resultados muito superiores. Cada atributo gera uma classificação independente, (suspeito ou não-suspeito) e a classificação final baseia-se em um certo número de atributos concordando na classificação. Para decidir o número mínimo de atributos que deveriam concordar para a indicação de sinal suspeito, a 
sensibilidade e a especificidade foram calculadas para todas as possibilidades, resultando na Tabela 15.

Tabela 14: Resultados da avaliação dos atributos para determinar a melhor relação custo-benefício.

\begin{tabular}{|c|c|c|}
\hline Atributo & Sensibilidade & Especificidade \\
\hline Entropia da Diferença & $76 \%$ & $64 \%$ \\
\hline Variância & $57 \%$ & $69 \%$ \\
\hline Compacidade & $58 \%$ & $52 \%$ \\
\hline Densidade Relativa & $63 \%$ & $54 \%$ \\
\hline
\end{tabular}

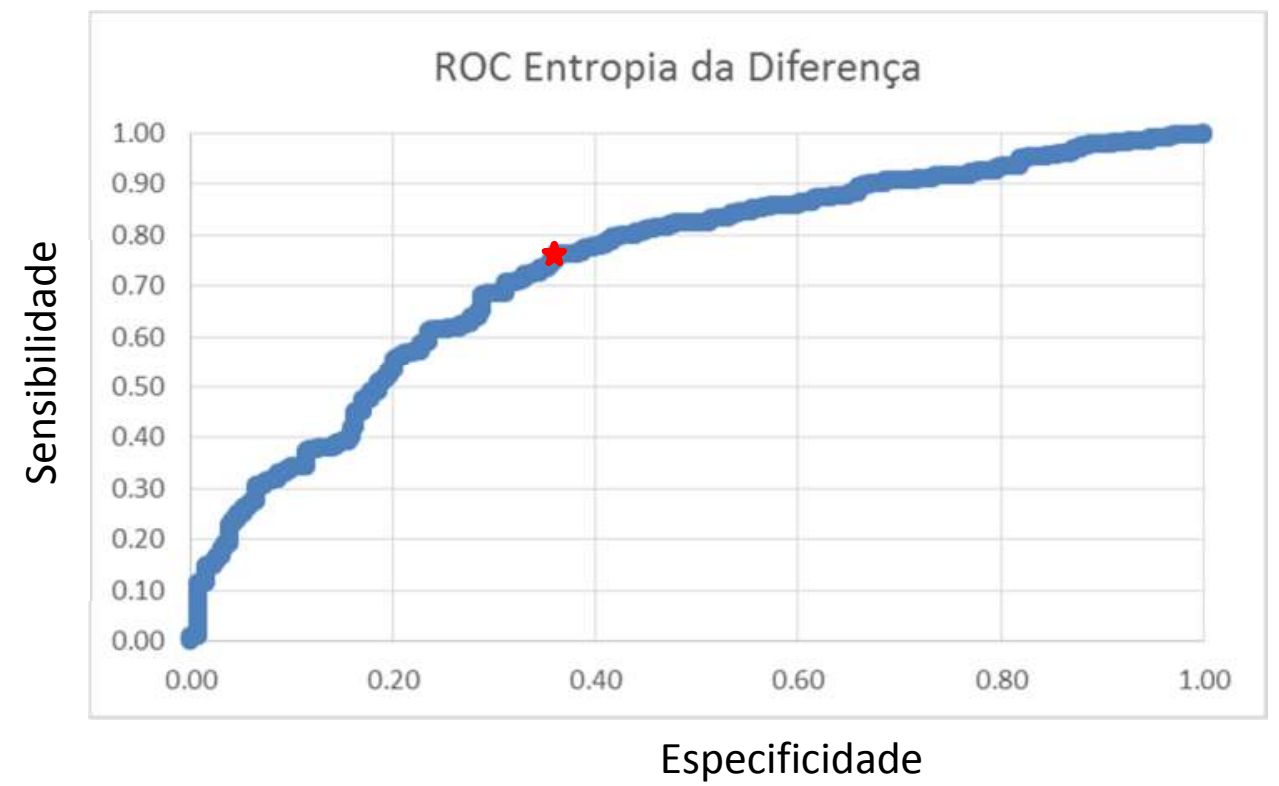

Figura 33: Curva ROC do atributo Entropia da Diferença. A marcação mostra a melhor relação custo-benefício 


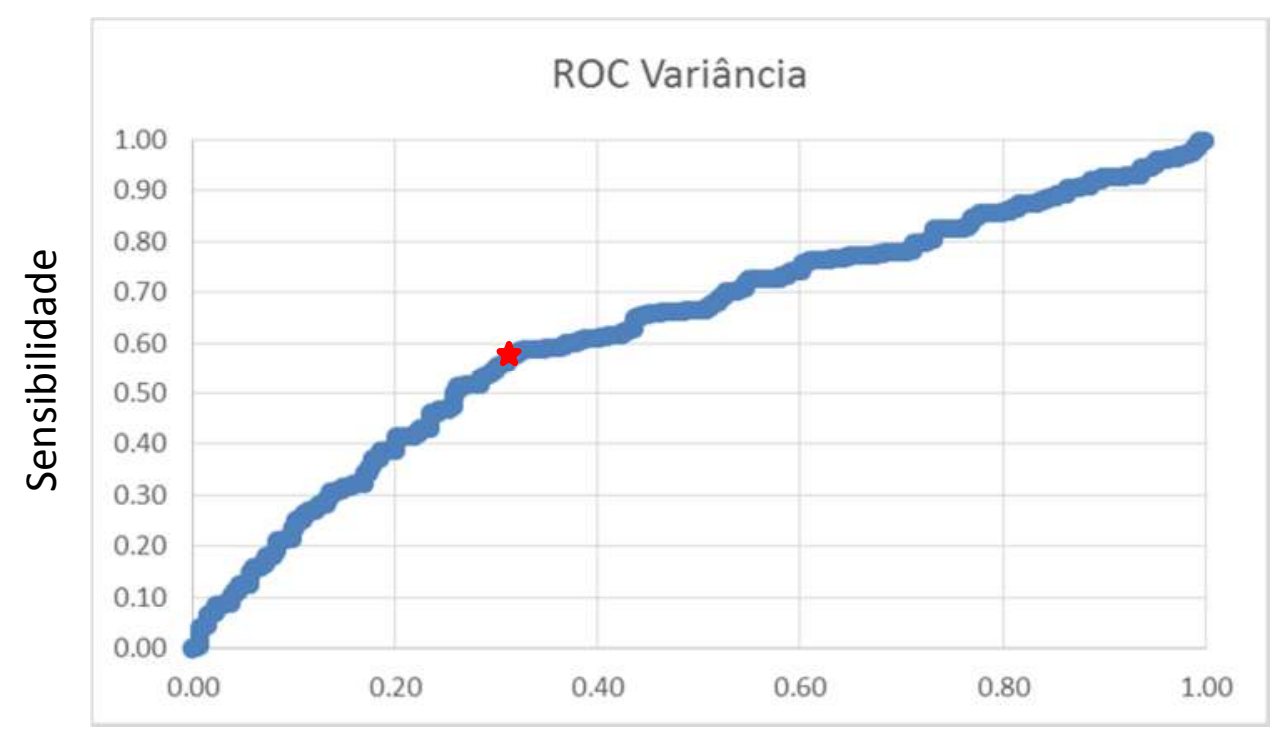

Especificidade

Figura 34: Curva ROC do atributo Variância. A marcação mostra a melhor relação custobenefício

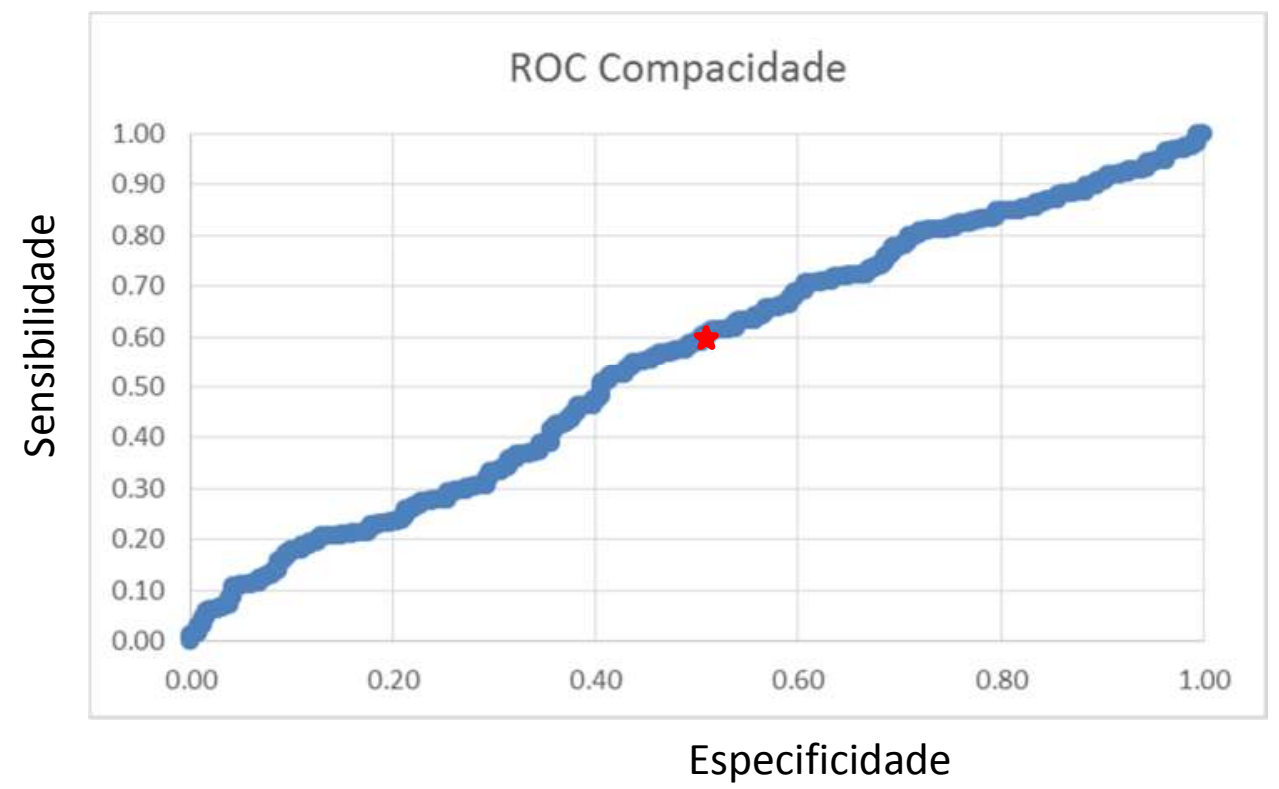

Figura 35: Curva ROC do atributo Compacidade. A marcação mostra a melhor relação custo-benefício 


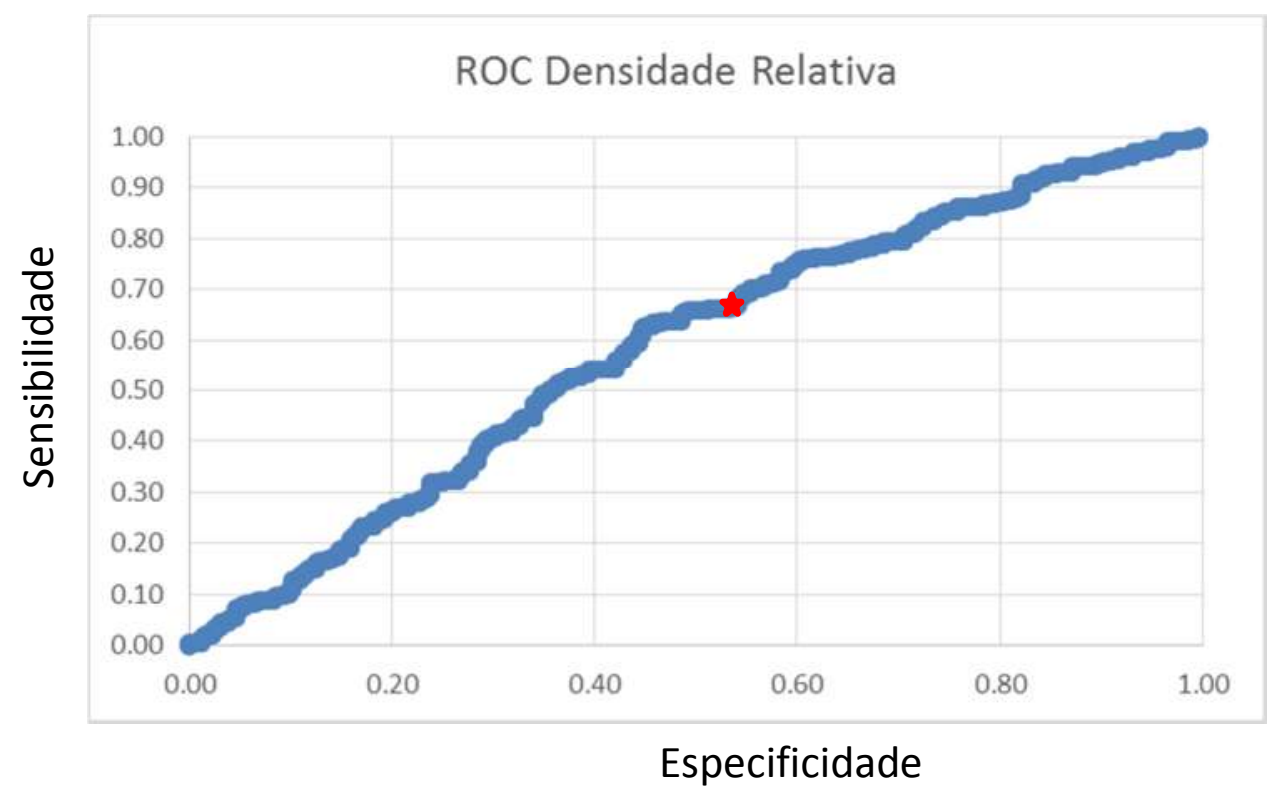

Figura 36: Curva ROC do atributo Densidade Relativa. A marcação mostra a melhor relação custo-benefício

Na Tabela 15, estão explicitados os resultados de Sensibilidade, Especificidade e Acurácia para cada possibilidade de concordância mínima entre os quatro atributos avaliados. Por exemplo, a coluna com concordância $2+$ representa os resultados quando uma concordância mínima de 2 atributos marca o sinal como suspeito. Como o número de atributos é pequeno, é possível calcular o resultado para todas as 4 possibilidades de concordância e analisar qual o melhor resultado para o esquema.

Tabela 15: Resultados para diferentes concordâncias entre os atributos necessárias para classificação como suspeito

\begin{tabular}{|c|c|c|c|c|}
\cline { 2 - 5 } \multicolumn{1}{c|}{} & \multicolumn{4}{c|}{ Concordância } \\
\cline { 2 - 5 } \multicolumn{1}{c|}{} & $\mathbf{1 +}$ & $\mathbf{2 +}$ & $\mathbf{3 +}$ & $\mathbf{4 +}$ \\
\hline Sensibilidade & $96 \%$ & $78 \%$ & $58 \%$ & $8 \%$ \\
\hline Especificidade & $27 \%$ & $69 \%$ & $83 \%$ & $98 \%$ \\
\hline Acurácia & $47 \%$ & $72 \%$ & $75 \%$ & $71 \%$ \\
\hline
\end{tabular}


À primeira vista, o resultado encontrado para uma concordância de pelo menos 3 atributos parece ser a melhor, pois produziu uma acurácia de $75 \%$, o valor mais alto no comparativo. No entanto, a baixa sensibilidade em comparação à concordância $2+$, deixa em dúvida qual limiar deveria ser utilizado.

Como a proposta deste classificador é que seja utilizado para avaliação de suspeita de câncer, é importante reduzir a possibilidade de um falso-negativo, que poderia levar a paciente a não obter o tratamento necessário para sua condição. Por conta disso, em sua versão final, este classificador utiliza a concordância de, pelo menos, 2 atributos para declarar o caso como suspeito.

Importante salientar que, apesar da decisão de declarar como suspeito a partir de 2 atributos concordantes, o objetivo do presente programa é fornecer ao radiologista o máximo de informações possíveis, incluída a quantidade de atributos que declararam o caso como suspeito. A intenção é que, com treino e uso, o radiologista leve em conta não só a declaração de suspeita do programa, mas a quantidade de atributos concordantes.

Usando a informação de densidade fornecida pela base DDSM no padrão BIRADS, é possível avaliar os casos dividindo em mamas lipossubstituídas (BI-RADS I e II) e mamas densas (BI-RADS III e IV). Considerando mamas lipossubstituídas apenas, o melhor resultado se apresenta sem nenhuma alteração no método, com uma acurácia de $76 \%$, sensibilidade de $77 \%$ e especificidade de $76 \%$.

No caso das mamas densas sem alteração no método, obtém-se acurácia de 59\%, sensibilidade de 53\% e especificidade de 59\%. Porém, o melhor resultado ocorre quando a concordância passa a ser de 3 ou mais atributos, produzindo uma acurácia de $73 \%$ (sensibilidade 69\% e especificidade 73\%). Assumindo que o sistema corretamente identificou a densidade da mama usando o método descrito na seção 4.4 do Capítulo 4, e usando o melhor resultado de concordância correspondente seria possível obter uma acurácia total de $75 \%$, sensibilidade de $76 \%$ e especificidade de $75 \%$.

O motivo da diferença no caso denso está ligado à dificuldade de definição de bordas e similaridade da densidade do tecido mamário com a densidade do nódulo. Por conta disso o esquema precisa ser menos sensível para evitar um excesso de falsos- 
positivos, gerando a necessidade de aumentar a concordância mínima para uma classificação como suspeito.

A validação do método foi feita usando o método leave-one-out, separando um dos casos de cada fez e reavaliando as curvas ROC e resultados para as diferentes concordâncias. Os resultados foram muitos próximos dos resultados obtidos no treinamento.

Para garantir que a técnica estava sendo corretamente avaliada a técnica ten-fold foi usada, em que o conjunto de imagens é divido em 10 partes aleatórias e 9 são usadas para treino e a décima para testes. Os testes são repetidos até que todos os 10 conjuntos tenham sido o conjunto de teste. As médias dos resultados também foram muito próximas dos resultados de treinamento mostradas acima.

\subsubsection{Avaliação do método de segmentação de nódulos sob a óptica da classificação}

Os testes descritos acima (seção 7.4.3) foram realizados duas vezes, cada uma utilizando um dos métodos de segmentação descritos no Capítulo 5 - Otsu (OTSU, 1979) e EICAMM (RIBEIRO, 2013). O intuito foi avaliar como os resultados da classificação seriam influenciados pelo método de segmentação e, com isso, permitir uma decisão final sobre qual técnica de segmentação utilizar.

No entanto, os resultados dos testes foram praticamente idênticos para os dois métodos de segmentação. Considerando cada atributo individualmente ou considerando o resultado final, as diferenças devidas ao método de segmentação utilizado são por volta de $0,1 \%$. Como essa alteração do resultado só aparece abaixo do valor do desvio padrão, tal diferença é desprezível e, portanto, a utilização dos dois métodos produz praticamente os mesmos resultados.

Levando em conta os fatores descritos na seção 7.3, ou seja, tempo de processamento e taxa de erros, o método de Otsu foi escolhido para segmentação no programa final. 


\subsection{Comparação do módulo classificador com a literatura}

Usando os resultados descritos na seção 7.4.1 deste capítulo, é possível realizar uma comparação com os de trabalhos correlatos na literatura, avaliando as diferenças de método. Os principais trabalhos exemplificados nesta seção utilizam imagens da base DDSM (HEATH, BOWYER, et al., 2001), permitindo uma melhor comparação entre o trabalho apresentado aqui e a literatura.

O trabalho de (LIU e TANG, 2014) utiliza 31 atributos de textura e geometria, analisados através de uma técnica chamada Support Vector Machines (SVM) para classificar entre benignos e malignos. Os testes deste trabalho utilizaram 826 imagens e obtiveram uma acurácia de 93\% na classificação. Já o trabalho de (DONG, LU, et al., 2015) utiliza 32 atributos variados e utiliza a técnica de árvores aleatórias para a classificação. Seus testes foram feitos com 200 imagens e obtiveram uma acurácia de $97 \%$.

Apesar dos valores de acurácia serem altos para os dois trabalhos, é importante analisar as diferenças entre eles e o módulo de classificação apresentado aqui. Primeiramente, o trabalho de Dong utiliza um conjunto bastante restrito de imagens para avaliação do seu classificador (apenas 200 imagens), o que pode gerar um resultado distorcido. Uma evidência disso pode ser vista na

Tabela 12 na seção 7.4.2 deste capítulo, onde são bem melhores os resultados do mesmo módulo classificador cujos resultados são apresentados na seção 7.4.3, com acurácia de $85 \%$ ao ser testado em um conjunto de apenas 125 imagens aleatoriamente selecionadas.

Independentemente da quantidade de imagens, ambos trabalhos são similares em seu método para resolver o problema de classificação: uso de mais de 30 atributos por imagem e técnicas avançadas (SVM e árvores aleatórias) para análise dos atributos. Isso quer dizer que, para cada uma das imagens classificadas por estes esquemas, seja para o treinamento da técnica heurística ou para uso normal do programa, é necessário extrair todos os mais de 30 atributos e, como consequência, a complexidade do processo e os custos computacionais são muito superiores aos do esquema apresentado nesta tese. 
Além disso, o uso de técnicas avançadas, como SVM e árvores de decisão, são intrinsecamente limitadas pelo conjunto utilizado em seu treinamento, ou seja, a técnica é treinada tentando buscar uma solução para o problema de separação em classes usando um dado conjunto de imagens, sendo difícil prever as consequências do uso em conjuntos de imagens com diferentes características.

Também é importante ressaltar que estas técnicas têm um alto custo computacional para seu treinamento inicial, quando todas as imagens usadas no treinamento são avaliadas, seus atributos extraídos e os dados analisados em busca de padrões que possam ser usados na classificação. Isso significa que o processo de treinamento requer quantidade elevada de imagens e é computacionalmente caro, tornando difícil retreinar as técnicas de decisão no caso de mudanças nas características das imagens.

Normalmente, tal treinamento é feito apenas uma vez, construindo um conjunto de comparações capaz de tomar uma decisão rapidamente quando os atributos de uma nova imagem são apresentados ao sistema. No entanto, estas técnicas foram desenvolvidas para localizar padrões dentro do conjunto de imagens de treinamento, padrões esses que, normalmente, não são óbvios para um humano observando o mesmo conjunto de informações. Portanto, não é possível prever as consequências de usar tipos de imagens para o qual o sistema não foi treinado, mesmo que as diferenças de tipo sejam conhecidas. Por exemplo, quando lidando com técnicas como SVM e árvore aleatória, não é possível prever os resultados com imagens FFDM se o sistema foi treinado com imagens filme + digitalizador e vice-versa. Para garantir a correta funcionalidade de sistemas deste tipo, seria necessário retreinar o sistema caso haja qualquer mudança, mesmo que pequena, no tipo de imagem; entretanto, conforme discutido acima, isso é um grave problema quanto aos custos computacionais.

Outros artigos da literatura da área utilizam bases de imagens diferentes da DDSM, dificultando a comparação, e apresentam limitações similares àquelas descritas acima. Em particular, os trabalhos compilados por Rangayyan em seu artigo de revisão (RANGAYYAN, AYRES e DESAUTELS, 2007), foram realizados com uma quantidade extremamente limitada de imagens e/ou com as mesmas limitações por número de atributos e complexidade de decisão discutidas acima. Por exemplo: 
i. (BRZAKOVIC, LUO e BRZAKOVIC, 1990) obtém uma acurácia de $85 \%$, mas utiliza apenas 25 imagens em seus testes;

ii. (RANGAYYAN, MUDIGONDA e DESAUTELS, 2000) tem acurácia de $82 \%$ usando 54 imagens. Neste trabalho, a segmentação foi feita manualmente por especialistas.

iii. (SAHINER, CHAN, et al., 2001) consegue uma acurácia de 89\% testando 249 massas, mas usa por volta de 70 atributos e uma técnica de decisão não especificada no artigo.

iv. Por último, (MUDIGONDA, RANGAYYAN e DESAUTELS, 2000) tem acurácia de 74,4\% usando 39 imagens. Apesar do número pequeno de imagens, sua acurácia é mais baixa devido ao conjunto de casos raros utilizados, contendo 4 imagens circunscritas malignas e 7 espiculadas benignas.

Independentemente dos resultados obtidos, todos os artigos acima utilizam bases privadas dos autores, tornando uma comparação mais detalhada inviável.

Já a técnica descrita em (NASCIMENTO, MARTINS, et al., 2013), utilizando 360 imagens da base DDSM, obtém informações derivadas de uma transformada Wavelet, ou seja, a imagem deixa de ser uma matriz de intensidades luminosas no espaço 2D (eixos X-Y) e passa a ser uma matriz de intensidades de Wavelets, conforme mostrado na Figura 37. Visualmente, a imagem resultante não faz sentido, mas contém a mesma informação do ponto de vista matemático e computacional.

A análise de (NASCIMENTO, MARTINS, et al., 2013) é feita usando atributos provenientes da imagem transformada. Por conta disso, não possível informar ao usuário que atributos levaram à decisão da classificação, já que os mesmos não têm significado para a visualização humana.

Levando em conta os fatores descritos acima, o valor do trabalho descrito nesta tese é ressaltado. Primeiramente, o método proposto aqui tem um baixo custo computacional para seu treinamento, exigindo apenas a construção da curva ROC e 
localização do ponto de inflexão. Este processo pode ser feito de modo simples e automático, permitindo que possam ser consideradas alterações de tipo de imagem, corrigindo o treinamento sem grandes custos, conforme mencionado acima.

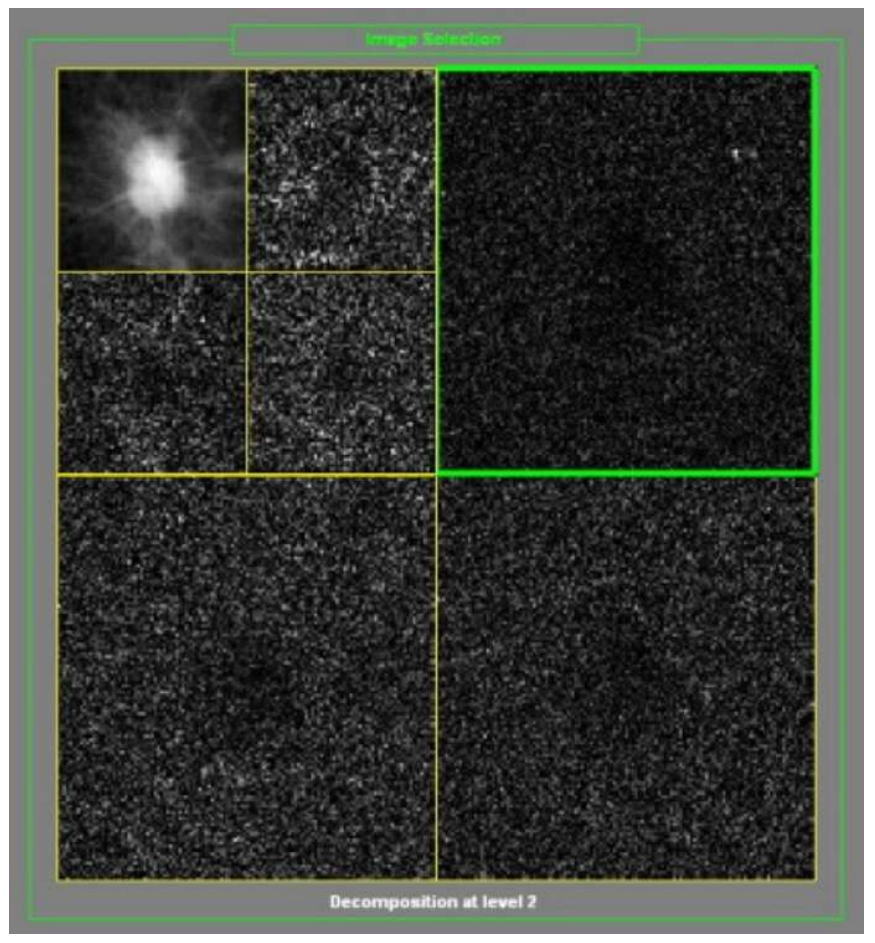

Figura 37: Exemplo de nódulo transformado usando Wavelet. Imagem de (ABUBAKER, 2012)

Como cada atributo é avaliado independentemente com sua própria curva ROC, o processo de treinamento tem uma complexidade com crescimento linear, ou seja, aumentar o número de atributos (em futuros desenvolvimentos) aumentaria linearmente o custo computacional e complexidade do treinamento necessário, o que significa um custo baixo mesmo para uma grande quantidade de atributos, pois cada um dos atributos é avaliado individualmente até o momento da classificação final, onde apenas a quantidade de atributos que indicam suspeita é considerada. 
Comparativamente, no caso de sistemas mais complexos (SVM e árvore aleatória, por exemplo), a complexidade e o custo podem crescer exponencialmente com o número de atributos utilizados, pois cada atributo é avaliado em relação a todos os outros.

Além disso, o esquema descrito neste trabalho tenta emular o processo de análise feito pelo radiologista, buscando observar as mesmas características usadas por esse profissional para diagnóstico de imagens mamográficas. De fato, os quatro atributos usados na análise descrita aqui têm uma direta correlação com três características sempre observadas pelos especialistas nesse tipo de avaliação diagnóstica: forma/contorno (Compacidade), densidade (Densidade Relativa) e textura (Entropia da Diferença e Variância) do achado. Isso permite que o sistema informe ao usuário não só a classificação final, mas também explicite a origem da decisão de modo simples e direto, usando características que o radiologista está acostumado a buscar na imagem.

A função primordial de um sistema CADx é de auxiliar e informar o radiologista, não de ser usado independentemente. Isso implica que o tipo de informação usado pelo sistema e como ela é apresentada ao usuário tem consequência em como o mesmo vai interpretar os resultados e como esses dados vão influenciar o seu diagnóstico final.

Por conta disso, é importante ressaltar que o trabalho apresentado aqui teve sua influência em radiologistas experientes testada com resultados favoráveis, conforme descrito na seção 7.4.2 deste capítulo. Nenhum dos outros trabalhos comentados aqui foi testado em sua aplicação prática, ou seja, em conjunto com o radiologista treinado.

\subsection{Tempo de Processamento}

Para avaliar o tempo de processamento do esquema CADx como um todo, um conjunto de 360 imagens da base DDSM (HEATH, BOWYER, et al., 2001) foi utilizado. Os 90 exames completos foram escolhidos aletoriamente dentre os exames dos tipos B e $\mathrm{C}$, ou seja, exames que foram digitalizados no digitalizador Lumisys (todas imagens com 12 bits e resolução espacial de $50 \mu \mathrm{m}$, o que representa arquivos de aproximadamente 27 MB $-2.800 \times 4.600$ pixels cada). Os testes foram realizados utilizando um computador 
com processador i5-4670K 3.4Ghz, 16GB de RAM DDR3 $1600 \mathrm{MHz}$ e as imagens estavam armazenadas em um HD interno Samsung de 2TB e 7200 rpm.

Os resultados desse teste estão explicitados na Tabela 16, abaixo:

Tabela 16: Tempo médio de processamento por imagem dos diferentes módulos

\begin{tabular}{|c|c|}
\hline Módulo & $\begin{array}{c}\text { Tempo médio de } \\
\text { processamento (s) }\end{array}$ \\
\hline Pré-processamento & 63,1 \\
\hline Assimetrias* & 0 \\
\hline Nódulos & 107,8 \\
\hline Calcificações & 26,1 \\
\hline Peitoral & 21,6 \\
\hline Total & 218,7 \\
\hline
\end{tabular}

Os dados apresentados na Tabela 16 são tempos médios por imagem. No caso do módulo de assimetrias, a medição do tempo foi zero, pois os atributos são calculados durante a etapa de pré-processamento, sendo apenas comparados e demarcados no módulo de Assimetrias.

Assim, o sistema completo leva, em média, 218,7 segundos - ou seja, aproximadamente 3 minutos e 40 segundos - para processar uma imagem MLO e 197,1 segundos $-3 \min 20 \mathrm{~s}$-, para processar imagens $\mathrm{CC}$, devido ao módulo peitoral. Isso representa uma média de 13 minutos e 50 segundos para cada exame completo (4 imagens).

Esse resultado aponta que não só o tempo médio de processamento é alto para cada exame, como também existe uma grande variação de valores ao redor da média: o tempo mais curto de processamento por imagem é de 40,0 segundos e o maior é de 3.110,1 segundos, ou seja, quase 51 minutos. Do ponto de vista prático, portanto, esse longo e 
variado tempo de processamento torna muito difícil o uso deste programa diretamente pelo radiologista quando o mesmo recebe um exame para análise. Isso entraria em conflito com o tempo médio de 89 a 194 segundos por exame que um radiologista requer (HAYGOOD, WANG, et al., 2009), se o exame fosse ser avaliado pelo CADx simultaneamente.

Uma possibilidade para superar essa questão seria o uso deste programa dentro da estrutura PACS (Picture Archiving and Communication System - Sistema de Arquivamento de Imagens e Comunicação) do hospital, ou seja, quando um exame fosse realizado e inserido no PACS, o esquema CADx iniciaria o processamento. Se o tempo entre a realização do exame e a análise pelo radiologista for maior que uma hora, então, a maioria dos exames já estaria totalmente avaliada pelo esquema CADx naquele momento, e o resultado disponível para o radiologista.

Esta possibilidade ilustra uma das vantagens do desenvolvimento em JAVA, pois, contanto que o sistema operacional utilizado no PACS do hospital não seja um sistema proprietário de uma empresa especifica, ele deverá ter suporte para JAVA e o esquema CADx será executado normalmente.

\subsection{CADx Guiado}

Conforme descrito no Capítulo 5 seção 5.3 .5 ("Limitações do sistema"), e exemplificado nos resultados acima (seção 7.5), o esquema CADx descrito inicialmente tem problemas associados ao tempo de processamento e à taxa final de falsos positivos. Além disso, a gradativa mudança de paradigma sobre a função e uso de esquemas CAD em direção à classificação e obtenção de resultados em tempo real levou este projeto a um caminho diferente de seu desenho original.

O esquema CADx guiado não é responsável por qualquer detecção, apenas executa pré-processamento e determina uma classificação tomando por foco as regiões selecionadas pelo usuário. 
Assim, aproveitando que as RIs são selecionadas pelo usuário e não por um sistema de detecção automatizada, é possível confiar que os achados na mesma mama em diferentes projeções seja o mesmo, isto é, o radiologista pode marcar com confiança o mesmo nódulo nas duas projeções da mesma mama e o nódulo ser analisado como um só. Caso o nódulo só esteja visível em uma das projeções, os resultados serão idênticos aos apresentados na seção 7.4.3.

Testes com as mesmas 568 imagens utilizadas na avaliação do classificador final (seção 7.4.3) geraram os resultados apresentados na Tabela 17. Similarmente à Tabela 15 , os resultados estão separados pela quantidade de atributos que precisam concordar para o nódulo ser declarado como suspeito; porém, neste caso, os quatro atributos do mesmo nódulo em cada projeção são considerados juntos, elevando a possibilidade para até 8 atributos concordantes.

Tabela 17: Resultados para diferentes concordâncias entre os atributos necessárias para classificação como suspeito no CADx Guiado

\begin{tabular}{|c|c|c|c|c|c|c|c|c|}
\cline { 2 - 9 } \multicolumn{1}{c|}{} & \multicolumn{8}{c|}{ Concordância } \\
\cline { 2 - 9 } \multicolumn{1}{c|}{} & $\mathbf{1 +}$ & $\mathbf{2 +}$ & $\mathbf{3 +}$ & $\mathbf{4 +}$ & $\mathbf{5 +}$ & $\mathbf{6 +}$ & $\mathbf{7 +}$ & $\mathbf{8 +}$ \\
\hline Sensibilidade & $100 \%$ & $98 \%$ & $84 \%$ & $78 \%$ & $58 \%$ & $44 \%$ & $13 \%$ & $2 \%$ \\
\hline Especificidade & $10 \%$ & $37 \%$ & $65 \%$ & $74 \%$ & $79 \%$ & $91 \%$ & $98 \%$ & $99 \%$ \\
\hline Acurácia & $37 \%$ & $55 \%$ & $71 \%$ & $75 \%$ & $72 \%$ & $77 \%$ & $73 \%$ & $70 \%$ \\
\hline
\end{tabular}

As colunas "Concordância" representam a quantidade mínima de atributos que precisam indicar suspeita para que o sistema classifique um dado sinal como suspeito.

Assim como feito para a análise dos dados da Tabela 15, à primeira vista o melhor resultado está na concordância $6+$, com uma acurácia de $77 \%$, mas, novamente, a baixa sensibilidade em comparação com a concordância 4+ leva a uma dúvida de qual limiar utilizar.

Pelos mesmo motivos discutidos na seção 7.4.3, a concordância utilizada no programa final foi de pelo menos 4 atributos de modo a garantir uma redução da taxa de 
falsos-negativos. Assim como no caso anterior, a quantidade de atributos concordantes é informada ao radiologista para auxiliar sua decisão final.

Em comparação aos resultados mostrados na seção 7.4.3 deste capítulo, temos uma melhora de $4,6 \%$ na acurácia e $6,8 \%$ na especificidade.

Esta versão do CADx, porém, leva aproximadamente 3 segundos para abrir, préprocessar e apresentar as 4 imagens do exame. O processamento, uma vez selecionadas as RIs pelo usuário, leva aproximadamente 4 segundos para cada par de RIs - cada par representando um nódulo nas duas projeções (CC e MLO).

Considerando o tempo de processamento obtido nestes testes, esta versão do programa, portanto, teria uma grande virtude porque poderia ser facilmente utilizada para auxiliar o radiologista em tempo real, ou seja, no momento que uma dúvida surgir, as regiões poderiam ser selecionadas e o resultado ser apresentado sem atrapalhar o fluxo normal da análise do médico.

\subsection{CADx Web}

Aproveitando a versatilidade da linguagem JAVA, foi possível implementar uma versão $W e b$ dos programas CADx descritos acima dentro do servidor Linux do laboratório LAPIMO.

As duas versões do esquema estão funcionais e ativas no endereço http://lapimo.sel.eesc.usp.br/lapimo/TesteWeb/, com os mesmos resultados e funcionalidades descritas no Capítulo 5 (CADx Completo) e Capítulo 6 (CADx Guiado). Embora até o momento da escrita deste trabalho, a adaptação de interfaces ainda estivesse em desenvolvimento, tal sistema já está funcional e é possível sua utilização, conforme demonstrado na Figura 38.

A versão $W e b$ do esquema processa a imagem fornecida pelo usuário inteiramente no servidor, sem necessitar de qualquer processamento pelo equipamento do usuário. Por conta disso, qualquer pessoa com uma conexão à internet pode fazer uso do esquema, 
independentemente do seu software / hardware, incluindo tablets e até mesmo smartphones.

No momento o uso do sistema é bastante direto, solicitando do usuário apenas o upload das imagens a serem analisadas usando os espaços previstos, ambos contendo um botão chamado "Escolher arquivo" para, em seguida, clicar no botão "Enviar" (Figura 38.a). Após um tempo - tipicamente de 2 a $4 \mathrm{~s}-$ o resultado será apresentado (Figura 38.b) de modo direto ao usuário no próprio browser de internet utilizado.

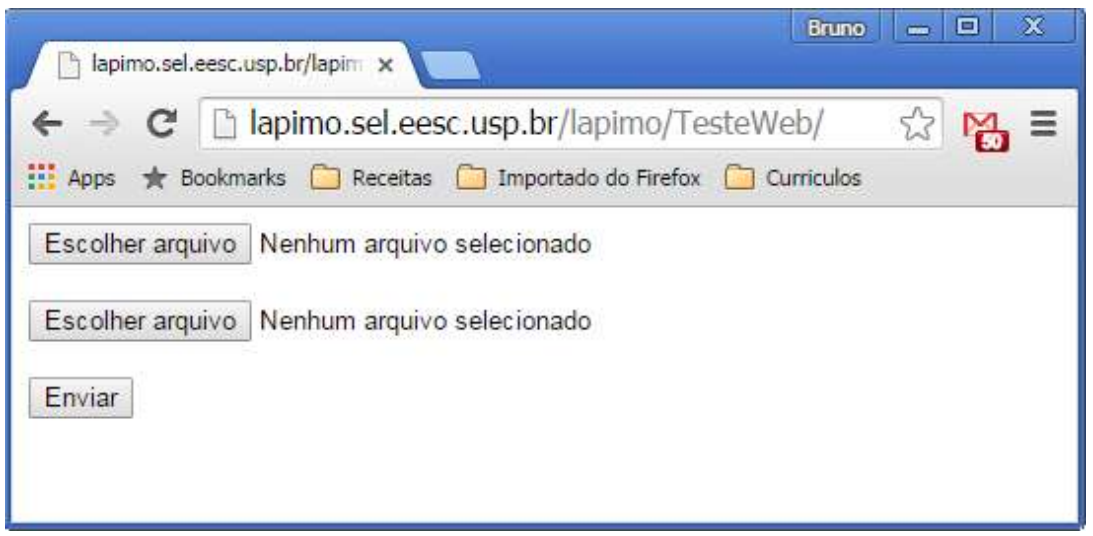

(a)

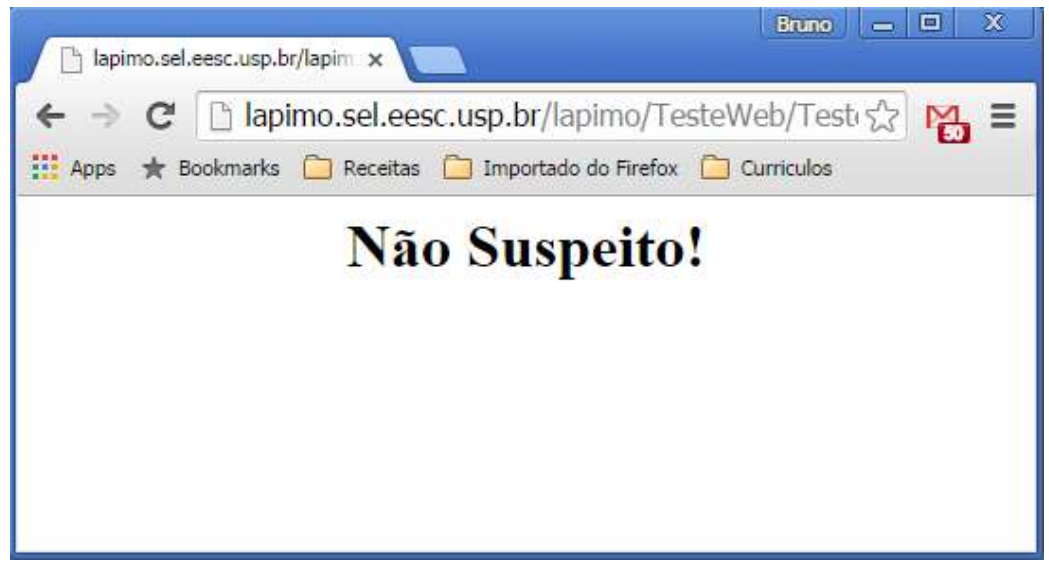

(b)

Figura 38: Exemplo de uso do esquema CADx Guiado Web. a) Interface inicial, b) apresentação do resultado. 


\section{Capítulo 8 Conclusão}

O primeiro e principal objetivo deste trabalho foi o desenvolvimento de um esquema CADe $\backslash D x$ mamográfico, unificando mais de 10 anos de pesquisa do laboratório LAPIMO, capaz de auxiliar na análise e diagnóstico de câncer de mama.

Após uma detalhada análise dos métodos desenvolvidos anteriormente (Capítulo 4), uma estrutura básica do esquema foi projetada e o desenvolvimento iniciado (Capítulo 5). Cada passo do desenvolvimento exigiu testes e avaliações dos módulos, em particular, estudando os efeitos das técnicas de pré-processamento selecionadas em cada parte posterior do esquema (Capítulo 5 e Capítulo 7).

Um método foi completamente desenvolvido neste trabalho: o de detecção de clusters de microcalcificações, com base nos filtros de detecção de Chan (CHAN, DOI, et al., 1998) e Schiabel (SCHIABEL, NUNES, et al., 2000), descrito em detalhes na seção 5.3.3c, Capítulo 5. Testes mostraram que, apesar do esquema apresentar uma alta taxa de falsos positivos em imagens da base DDSM (filme + digitalizador), quando utilizado em imagens menos ruidosas (FFDM) provenientes da base INBreast, os resultados foram muito superiores, sendo, pelo menos, equivalentes aos melhores resultados da literatura (seção 7.2, Capítulo 7).

Além disso, testes considerando conjunto de imagens apenas de mamas definidas como densas pelo padrão BI-RADS descrito na base apresentaram resultados promissores, com uma altíssima sensibilidade (99\%), apesar de uma taxa de falsospositivos de 5,4 por imagem. Como, normalmente, microcalcificações em mamas densas são muito mais difíceis e demoradas de ser detectadas por radiologistas, a possibilidade de fazer uso da alta sensibilidade do módulo e analisar apenas as regiões recomendadas pelo CADe seria viável e uma útil ferramenta de apoio nesse tipo de caso.

No módulo nódulos (seção 5.3.3b, no Capítulo 5), dois métodos tiveram que ser amplamente alterados para o design final: o de segmentação e o de classificação de nódulos. No caso da segmentação, o método originalmente usado, EICAMM, não se 
mostrou robusto o suficiente (seções 7.3 e 7.4.4, no Capítulo 7) e foi substituído pelo mais tradicional método de Otsu.

Já o método de classificação foi mantido, mas com drásticas reformulações. Os atributos selecionados no método original (seção 4.7, no Capítulo 4) foram reavaliados e alterados (seção 5.3.3b, no Capítulo 5) de modo a serem mais específicos e mais resistentes a alterações no tipo de imagem.

Tanto o método de classificação original quanto o método reformulado foram testados para avaliar seus efeitos na opinião dos radiologistas. Os resultados foram promissores, mostrando que, para a maioria dos radiologistas colaboradores que se submeteram aos testes, os efeitos são positivos (seção 7.4, no Capítulo 7).

Em sua forma final, a quantidade reduzida de atributos (apenas 4) e o uso direto da curva ROC para estabelecer limiares independentes de classificação desses atributos produziram um método com baixo custo computacional tanto no uso comum quanto no treinamento da técnica de decisão. Isso permite que o sistema seja mais robusto e com custos menores para adaptação a mudanças de tipo e características das imagens usadas. Além disso, o uso de atributos com uma correlação mais direta a características de forma/contorno, densidade e textura facilita a transmissão de informação do esquema CADx para o radiologista usuário, sem inundá-lo com informações de difícil interpretação.

Uma vez que o primeiro objetivo foi alcançado e o esquema CADe/Dx completo estava pronto e funcional, uma análise detalhada do sistema completo revelou uma série de limitações relativas à aplicação na prática clínica (seção 5.3.5 do Capítulo 5) que precisavam ser abordadas. Estas limitações incluem um tempo de processamento excessivo (seção Error! Reference source not found., no Capítulo 7) e o acúmulo de erros quando um nódulo falsamente detectado é classificado como suspeito, podendo levar a dúvidas no diagnóstico final.

As limitações do sistema CADe \Dx Completo e uma mudança de foco a nível mundial no estudo de CAD mamográfico - demostradas em artigos (KARSSEMEIJER, 2011; SCHIABEL, 2014) e palestras em congressos importantes da área (Re-thinking 
CAD for the next generation, por Eliot L. Siegel, SPIE 2014) - levaram a uma mudança na linha de desenvolvimento do presente trabalho.

Uma nova versão do esquema foi desenvolvida com um enfoque exclusivo em classificação, chamado de CADx Guiado (Capítulo 6 ). Essa versão requer que o radiologista selecione as regiões de interesse a serem classificadas e, então, realiza a classificação em tempo real, proporcionando uma segunda opinião imediatamente, focada nas regiões consideradas de interesse clínico.

No CADx Guiado, o pré-processamento foi reduzido apenas ao método mais eficiente do CADe $\backslash$ Dx Completo, a Correção BCC (seção 4.1, no Capítulo 4) (GOES, 2010). Os métodos de detecção foram removidos e apenas a segmentação e classificação de massas foram mantidas (seções 6.4 e 6.5, no Capítulo 6 ). Uma nova interface foi desenhada (seção 6.3, no Capítulo 6 ) para permitir que o radiologista possa selecionar facilmente uma RI para classificação. Nesta versão, o sistema faz uso da capacidade de distinção do radiologista para realizar a classificação de um dado nódulo usando as duas projeções da mama (seção 6.5, no Capítulo 6 ).

Medidas de tempo de processamento mostraram que a classificação de um nódulo usando as duas projeções leva aproximadamente 4 segundos (seção 7.7, no Capítulo 7). O tempo é suficientemente curto para não afetar o tempo usual de análise de um exame, permitindo uma resposta imediata a qualquer ponto de dúvida do radiologista.

Atingido o segundo objetivo do projeto, a estruturação tanto do esquema CADe $\backslash$ Dx Completo como do CADx Guiado foi feita usando orientação a objeto; portanto, cada módulo descrito no Capítulo 5 e no Capítulo 6 são classes com seus métodos definidos para fácil uso. Por consequência, os desenvolvimentos realizados durante este trabalho podem ser facilmente utilizados como uma biblioteca para futuros projetos na área de $\mathrm{CAD}$. Inicialmente a biblioteca será disponibilizada apenas para uso interno do LAPIMO, mas, futuramente, poderá ser disponibilizada para outros desenvolvedores que desejem acesso.

O desenvolvimento em JAVA, cuja grande vantagem é a versatilidade dos softwares, permitiu que o terceiro e último objetivo do projeto, uma versão on-line dos 
esquemas, fosse facilmente alcançado. O servidor do LAPIMO utiliza um sistema operacional Unix sem interface gráfica; porém com a remoção da interface com o usuário e construção de uma classe de controle simples, o esquema CADelDx Completo está funcional em sua versão web. Uma interface para permitir que o usuário selecione a RI no browser está sendo desenvolvida, com isso o esquema CADx Guiado poderá ser utilizado via web com a mesma funcionalidade do software.

Com isso, foram alcançados os objetivos propostos para este trabalho: criação de um programa CADx (que acabou sendo estabelecida em duas versões) em pleno funcionamento; adaptação e desenvolvimento de uma biblioteca JAVA para o CAD; e desenvolvimento de uma versão Web desse sistema. Cada um destes esquemas computacionais é voltado para uma finalidade diferente e, por consequência, tem suas restrições.

Em particular, no esquema CADe/Dx Completo, o tempo de processamento é muito alto para uso geral, isto é, uso do esquema CADe/Dx pelo radiologista no momento que a imagem é recebida por ele, sem que isso afete o fluxo normal de trabalho do mesmo.

Conforme sugerido no fim do Capítulo 5, este esquema só poderá ser utilizado amplamente em casos para os quais o tempo entre a produção da imagem e a análise diagnóstica seja maior do que uma hora - por exemplo, se integrado a um PACS que permita o uso de software JAVA. É possível que um estudo de otimização possa ser realizado neste software e, futuramente, o tempo de processamento possa ser reduzido. Ainda assim, convém lembrar que, via-de-regra, os procedimentos comuns de elaboração do laudo diagnóstico radiológico superam em muito esse tempo, pois a paciente se submete à exposição e, uma vez geradas as necessárias imagens, essas seguem para um arquivo a fim de que sejam visibilizadas juntamente com as de outros exames do dia pelo(s) radiologista(s) responsável(is) pela avaliação. E isso se dá, normalmente, num horário específico, às vezes, muitas horas após a realização do exame por aquela paciente - que deverá retornar ao setor um ou dois dias depois para buscar o laudo impresso. Logo, num ambiente desse tipo, o alto tempo de processamento comentado em relação a esse esquema completo não representa um problema. 
Adicionalmente, é possível notar que o esquema CADx Guiado pode ser utilizado em tempo real, embora, conforme sua estruturação inicial, não traga nenhum dos métodos de detecção. Seu uso pode ser facilmente implementado em qualquer computador capaz de rodar JAVA, possivelmente até equipamentos móveis (smartphones e tablets).

A biblioteca CADLAPIMO para JAVA contém todas as classes e métodos descritos neste trabalho, mais todas as classes auxiliares necessárias para os passos intermediários. Sua única restrição é a necessidade da biblioteca open acess ImageJ, que é a base de todos os métodos descritos neste trabalho.

Por último, a versão CADx Web consiste de um site que poderá ser usado por qualquer radiologista, contanto que ele tenha acesso à internet. $\mathrm{O}$ processamento é realizado remotamente no servidor do laboratório LAPIMO, sem necessitar de nada instalado no computador do usuário.

\subsection{Desenvolvimentos futuros}

Este trabalho abre múltiplas portas para futuros projetos, permitindo que próximas pesquisas sejam feitam com pleno uso dos métodos e funcionalidades desenvolvidas aqui. Por exemplo:

i. Ampliação e desenvolvimento de novas técnicas de pré-processamento, com o intuito de uniformizar as imagens independentemente da fonte de sua aquisição;

ii. Implementação e avaliação de técnicas mais modernas de segmentação de nódulos, em particular uso de level-set (OSHER e SETHIAN, 1988) e seus desenvolvimentos recentes;

iii. Associação do detector de microcalcificações com o classificador de nódulo, aumentado a probabilidade de declaração como "suspeito" se o nódulo tiver microcalcificações associadas; 
iv. Ampliação do número de atributos avaliados para classificação de nódulos, sempre mantendo baixo o custo computacional para sua avaliação;

v. Obtenção de uma fonte de imagens FFDM, demarcadas por especialistas, suficientemente grande para possibilitar a realização de testes estatisticamente mais significativos de todos os módulos do programa;

vi. Avaliação das consequências do uso dos programas (em todas as suas versões) na opinião de especialistas, tanto em situação laboratorial como clínica. 


\section{Capítulo 9 Referências}

ABRAN, A.; MOORE, J. W. Guide to the Software Engineering Body of Knowledge. 2004. ed. [S.1.]: IEEE, 2004.

ABUBAKER, A. Mass lesion detection using wavelet decomposition transform and support vector machine. International Journal of Computer Science \& Information Technology (IJCSIT), v. 4, n. 2, p. 33-46, 2012.

ADAMS, J. E. Single and dual energy X-ray absorptiometry. Eur. Radiol., v. 7, n. 2, p. 20-31, 1997.

ADOBE DEVELOPERS ASSOCIATION. TIFF: REvision 6.0 - Techinical specification. [S.1.]: [s.n.], 1992.

AMERICAN COLLEGE OF RADIOLOGY. American College of Radiology (ACR) Breast Imaging Reporting and Data System Atlas (BI-RADS ${ }^{\circledR}$ Atlas). American College of Radiology website, 2003. Disponivel em: <http://www.acr.org/QualitySafety/Resources/BIRADS/Mammography>. Acesso em: 20 august 2013.

ANDERSON, B. et al. Guideline implementation for breast healthcare in lowincome and middle-income countries: overview of the Breast Health Global Initiative Global Summit 2007. Cancer, v. 113, n. 8, p. 2221-2243, Oct 2008. ISSN 10.1002.

BARBOSA FILHO, J. R. B. Um Método Automático De Deteç̧ão De Massas Em Mamografias Por Meio De Redes Neurais (MESTRADO). [S.1.]. 2012.

BRZAKOVIC, D.; LUO, X. M.; BRZAKOVIC, P. An approach to automated detection of tumors in mammograms. IEEE Transactions on Medical Imaging, v. 9, n. 3, p. 233-241, 1990.

BYOUS, J. JAVA TECHNOLOGY: AN EARLY HISTORY. Sun Microsystem, 2003. Disponivel em: <http://java.sun.com/features/1998/05/birthday.html >. Acesso em: 2003.

BYWOOD, P. et al. National Horizon Scanning Unit Horizon scanning report: Computer Aided Detection Systems in Mammography. Adelaide. 2004.

CELENK, C.; CELENK, P. Bone Density Measurement Using Computed Tomography. In: SABA, L. Computed Tomography - Clinical Applications. [S.1.]: InTech, 2012. p. 123-136. 
CHAN, H.-P. et al. Computer-aided detection of microcalcifications in mammograms: methodology and preliminary clinical study. Investigative Radiology, $\mathrm{v}$. 23, n. 9, p. 664-671, 1998.

CHAN, H.-P. et al. Improvement of radiologists' characterization of ammmographic masses by using computer-aided diagnosis: an ROC study. Radiology, v. 23 , n. 9 , p. $817-827,1999$.

CHENG, H. D. et al. Computer-aided detection and classification of microcalcification in mammograms: a survey. Pattern Recognition, v. 36, n. 12, p. 2967, 2003.

COLLINS, T. J. ImageJ for microscopy. BioTechniques: Imaging Frontiers, v. 43, n. 1, p. 25-30, 2007. ISSN doi 10.2144/000112517.

COMON, P. Independent Component Analysis, a New Concept? Signal Processing, v. 36, n. 6, p. 287-314, 1994.

DAVIES, D. H.; DANCE, D. R. Automatic computer detection of clustered calcification in digital mammograms. Physics in Medicine and Biology, v. 35, n. 8, p. 1111-1118, 1990.

DONG, M. et al. An Efficient Approach for Automated Mass Segmentation and Classification in Mammograms. Journal of Digital Imaging, March 2015. ISSN DOI $10.1007 / \mathrm{s} 10278-015-9778-4$.

EGAN, R. L.; MCSWEENEY, M. B.; SEWELL, C. W. Intramammary calcifications without an associated mass in benign and malignant diseases. Radiology, v. 137, n. 1 , p. $1-7,1980$.

ELTOUKHY, M. M.; FAYE, I.; SAMIR, B. B. Automatic detection of breast masses in digital mammograms using pattern matching. IEEE EMBS Conf. on Biomedical Engineering \& Science, p. 87-92. Kuala Lumpur, Malaysia: [s.n.]. 2010.

ENBARCADERO. Delphi XE6. Delphi XE6, 2014. Disponivel em: $<$ http://www.embarcadero.com/products/delphi $>$. Acesso em: 08 agosto 2014.

FERRARI, R. et al. Automatic identification of the pectoral muscle in mammograms. IEEE Trans. on Medical Imaging, v. 23, n. 2, p. 232-246, 2004.

FERRO NETO, J. D. S. Expansão de técnica de deteç̧ão de agrupamentos de microcalcificações em mamografias digitais. São Carlos: Universidade de São Paulo Escola de Engenharia de São Carlos, 2012. 
GEORGIAN-SMITH, D.; MOORE, R. H.; HALPERN, E. Blinded Comparison of Computer-Aided Detection with Human Second Reading in Screening Mammography. AJR Women's Imaging, n. 189, p. 1135-1141, 2007.

GIGER, M. I. Computer analyzes of iamges in the detection and diagnosis of breast cancer. Seminars in ultrasond, CT and MRI, v. 25, p. 411-418, 2004.

GIGER, M. L.; CHAN, H.-P.; BOONE, J. Anniversary Paper: History and status of CAD and quantitative image analysis: The role of Medical Physics and AAPM. Medical Physics, v. 35, n. 12, p. 5799-5820, December 2008. ISSN 10.1118/1.3013555.

GOES, R. D. F. Investigações sobre digitalização de imagens mamográficas: padronização da qualidade da imagem e seu efeito no desempenho de esquemas de processamento. EESC - USP. São Carlos, p. 178. 2010.

GOES, R. F.; SCHIABEL, H.; SOUSA, M. A. Z. Automatic scanning software based on the characteristic curve of mammograms digitizers. Journal of Electronic Imaging, v. 22, n. 013024, p. 1 - 9, 2013.

GONZALES, R. C.; WOODS, R. E. Digital image processing. New Jersey: Prentice Hall, 2008.

HADJIISKI, L.; CHAN, H.-P.; SAHINER, B. E. A. Improvement in radiologists' characterization of malignant and benign breast masses on serial mammograms with computer-aided diagnosis: an ROC study. Radiology, v. 233, p. 255-265, 2004.

HALL, F. Breast imaging and computer-aided detection. The New England Journal of Medicine, v. 356, n. 14, p. 1464-1466, 2007.

HAMILTON, E. JPEG File Interchange Format. Joint Photographic Experts Group. [S.1.]. 1992.

HARALICK, R. M.; SHANMUGAM, K.; DISTEIN, I. Textural features for image classification. IEEE Trans. on Systems, Man, and Cybernetics - SMC, v. 3, n. 6, p. 610-621, 1973.

HAYGOOD, T. M. et al. Timed Efficiency of Interpretation of Digital and FilmScreen Screening Mammograms. American Journal of Roentgenology, v. 1, n. 192, p. 216-220, Jan 2009. ISSN 10.2214/AJR.07.3608.

HEATH, M. et al. The Digital Database for Screening Mammography. Proceedings of the Fifth International Workshop on Digital Mammography. [S.1.]: Medical Physics Publishing. 2001. p. 212-218. 
HU, M.-K. Visual Pattern Recognition by Moment Invariants. IRE Transactions on Information Theory, v. 8, n. 2, p. 179-187, 1962.

HYVÄRINEN, A.; KARHUNEN, J.; OJA, E. Independent Component Analysis. [S.1.]: John Wiley \& Sons, 2001.

IMAMURA, K. et al. Microcalcifications of Breast Tissue: Appearance on Synchrotron Radiation Imaging with $6-\mu \mathrm{m}$ Resolution. American Journal of Roentgenology, v. 190, n. 4, April 2008. ISSN 1546-3141.

INSTITUTO NACIONAL DO CÂNCER. INCA, 2014. Disponivel em: $<$ http://www2.inca.gov.br/>. Acesso em: 20 Maio 2014.

JIAN, Y.; NISHIKAWA, R. M.; PAPAIOANNOU, J. Requirement of microcalcification detection for computerized classification of malignant and benign clustered microcalcification. SPIE Internetional Symposium Medical Imaging - Image Processing. [S.1.]: [s.n.]. 1998. p. 313-317.

KALLERGI, M. Computer-aided diagnosis of mammographic microcalcification clusters. Medical Physics, v. 31, n. 2, p. 314-326, 2004.

KARSSEMEIJER, N. CAD: more than a perception aid. Medical Physics Web, Winter 2011. 6.

KODAK. Kodak Mammography CAD ENGINE, 2004. Disponivel em: $<$ http://www.fda.gov/MedicalDevices/ProductsandMedicalProcedures/DeviceApprovals andClearances/Recently-ApprovedDevices/ucm079437.htm>. Acesso em: 5 september 2013.

LAI, S. M.; LI, X.; BISCHOF, W. F. On techniques for detecting circumscribed masses in mammograms. IEEE Transactions on Medical Imaging, v. 8, p. 377-386, 1989.

LEE, T.; LEWICKI, M. S.; SEJNOWSKI, T. J. ICA Mixture model for unsupervised classification of non-gaussian classes and automatic content switching in blind signal separation. IEEE Transactions on Pattern Analysis and Machine Inteligence, v. 22, n. 10, p. 1078-1089, 2000.

LIU, X.; TANG, J. Mass Classification in Mammograms Using Selected Geometry and Texture Features, and a New SVM-Based Feature Selection Method. IEEE SYSTEMS JOURNAL, v. 8, n. 3, p. 910-920, 2014.

LUO, P.; QIAN, W.; ROMILLY, P. CAD-Aided Mammogram Training. Journal of the Association of University Radiologists, v. 12, n. 8, p. 1039-1048, 2005. 
MASTERS, T. Advanced Algorithms for Neural Networks. New York: Wiley, 1995.

MATHEUS, B. R. N.; SCHIABEL, H. Online Mammographic Images Database for Development and Comparison of CAD Schemes. Journal of Digital Imaging, v. 24, n. 3, p. 500-506, Jun 2011.

MATHEUS, B.; FERRO NETO, J. D. S.; SCHIABEL, H. Clustered microcalcification detection scheme for mammographic images. The 17th International Conference on Image Processing, Computer Vision, \& Pattern Recognition. Las Vegas: [s.n.]. 2013. p. 904-908.

MATHEUS, B.; SCHIABEL, H. A CADx scheme in mammography: considerations of a novel approach. Porto, Portugal: Proc. of 7th International Conference on Advanced Engineering Computing and Applications in Sciences. 2013.

MATHEUS, B. et al. Study of quality perception in medical images based on comparison of contrast enhancement techniques in mammographic images. Proc. SPIE 9037, Medical Imaging 2014: Image Perception, Observer Performance, and Technology Assessment. San Diego: SPIE. 2014. p. 9.

MATHWORKS. Matlab - Tha Language of Technichal computing. Matlab - Tha Language of Technichal computing, 2014. Disponivel em: $<$ http://www.mathworks.com/products/matlab/>. Acesso em: 08 agosto 2014.

MENECHELLI,. Caracterização de sinais secundários em imagens mamográficas por redes neurais artificiais para auxílio ao diagnóstico do câncer de mama (MESTRADO). EESC - USP. São Carlos, p. 141. 2013.

MEYER, J. E. et al. Biopsy of occult breast lesions. Analysis of 1261 abnormalities. Journal of the American Medical Association, v. 263, n. 17, p. 23412343, 1990.

MOREIRA, I. et al. INbreast: toward a full-field digital mammographic database. Academic radiology, Reston, v. 19, n. 2, p. 236-48, Feb 2012. ISSN 1878-4046.

MORTON, M. J. et al. Screening Mammograms: Interpretation with Computeraided Detection—Prospective Evaluation. RSNA; Radiology, v. 239, n. 2, 2006.

MUDIGONDA, N. R.; RANGAYYAN, R. M.; DESAUTELS, J. E. L. Gradient and texture analysis for the classification of mammographic masses. IEEE Trans. Med. Imaging, v. 19, n. 10, p. 1032-1043, 2000. 
NASCIMENTO, M. Z. D. et al. Classification of masses in mammographic image using wavelet domain features and polynomial classifier. Expert Systems with Applications, v. 40, p. 6213-6221, 2013.

NATIONAL ELECTRICAL MANUFACTURERS ASSOCIATION. Digital Imaging and Communications in Medicine (DICOM). Rosslyn, Virginia: National Electrical Manufacturers Association, 2009.

NISHIKAWA, R. M. et al. Computer-aided detection of clustered microcacifications. Proceedings of IEEE International Conference on Systems, Man and Cybernetics. Chicago: [s.n.]. 1992. p. 1375-1378.

NISHIKAWA, R. M. et al. Computer-aided detection of clustered microcalcifications: An improved method for grouping detected signals. Medical Physics, v. 20, p. 1661, 1993.

NISHIKAWA, R. M. . E. A. Effect of case selection of the performance of computer-aided detection schemes. Medical Physics, n. 21, p. 265-270, 1994.

NUNES, F. L. S.; SCHIABEL, H.; BENNATI, R. H. Contrast enchancement in dense breast images using the modulation transfer function. Medical Physics, v. 29, n. 12, p. 2925-2936, 2002.

NUNES, F. L. S.; SCHIABEL, H.; GOES, C. E. Contrast enhancement in dense breasts images to aid clustered microcalcifications detection. Journal of Digital Imaging, v. 20, p. 53-66, 2007.

ORACLE. Oracle Technology NetWork > Java. Oracle Technology NetWork > Java, 2014. Disponivel em: <http://www.oracle.com/technetwork/java/index.html $>$. Acesso em: 08 agosto 2014.

OSHER, S.; SETHIAN, A. Fronts propagating with curvature dependent speed: algorithms based on Hamilton-Jacobi formulations. Journal of Computational Physics, v. 79, p. 12-49, 1988.

OTSU, N. A threshold selection method from gray-level histogram. IEEE Trans. on System, Man and Cybernetics, v. 9, n. 1, p. 62-66, 1979.

PEIXOTO, J. E.; CANELlA, E.; AZEVEDO, A. C. Mamografia: da prática ao controle. Rio de Janeiro: Gráfica Esdeva, 2007.

PRESSMAN, R. S. Software Engineering A practitioner's Approach. 7th. ed. New York, NY: McFraw-Hill, 2010. 
PUN, T. Entropic thresholding, the new approach. Computer graphics and Image Processing, v. 16, p. 210-239, jul 1981.

QIAN, W. E. A. Computer assisted diagnosis for digital mammography. IEEE Engineering in Medicineand Biology, v. 14, n. 5, p. 561-569, 1995.

RANGAYYAN, R. M.; MUDIGONDA, N. R.; DESAUTELS, J. E. L. Boundary modelling and shape analysis methods for classification of mammographic masses. Med. Biol. Eng. Comput., n. 38, p. 487-496, 2000.

RANGAYYAN, R. M.; AYRES, F. J.; DESAUTELS, J. E. L. A review of computer-aided diagnosis of breast cancer: Toward the detection of subtle signs. Journal of the Franklin Institute, n. 344, p. 312-348, 2007.

RASBAND, W. ImageJ. ImageJ, 2011. Disponivel em: $<$ http://rsb.info.nih.gov/ij/index.html $>$. Acesso em: 2015.

RIBEIRO, P. B. Classificação por análise de contornos de nódulos mamários utilizando redes neurais artificiais (MESTRADO). EESC - USP. São Carlos, p. 152. 2006.

RIBEIRO, P. B. Esquema CADx para classificação de nódulos em imagens mamográficas digitais baseado na segmentação pelo modelo EICAMM (doutorado). EESC. São Carlos. 2013.

RIBEIRO, P. B. et al. Automatic segmentation of breast masses using enhanced ICA mixture model. Neurocomputing, v. 120, p. 61-71, 2013.

ROSE, C. et al. Web services for the DDSM and digital mammography research, 2003. Disponivel em: <http://marathon.csee.usf.edu/ ddsm/search.html $>$. Acesso em: 2010.

SAHINER, B. S. et al. Improvement of mammographic mass characterization using spiculation measures and morphological features. Med. Phys. , v. 7, n. 28, p. 14551465, 2001.

SAMPAT, M. P.; MARKEY, M. K.; BOVIK, A. C. Computer-Aided detection and diagnosis in mammography. In: BOVIK, A. C. Handbook of image and video processing. [S.1.]: Elsevier academic press, 2005. p. 1195-1217.

SCHIABEL, H. et al. Performance of a processing scheme for clustered microcalcifications detection with different images database. World Congress Physics and Biomedical Engineering 2000. Chicago: IEEE. 2000. p. 1199-1202. 
SCHIABEL, H. et al. Investigations on a CADx scheme in mammography: evaluating the influence of the nodules contour classifier on radiologists analysis. Inter. Journal of Computer As-sisted Radiology and Surgery, v. 7, n. 1, p. 258-259, 2012.

SCHIABEL, H.; MENECHELLI, R. C. Automated characterization of secondary signals of breast cancer to compose a module from a CADx scheme. 27 th International Congress on Computer Assisted Radiology and Surgery (CARS2013) in 15th International Workshop on Computer-Aided Diagnosis. Heidelberg, Germany: [s.n.]. 2013. p. 404-404.

SCHIABEL, H. Esquemas CAD: uma análise dos seus aspectos e aplicações como ferramenta de auxílio ao diagnóstico em mamografia. In: CBEB14. [S.1.]: Sociedade Brasileira de Engenharia Biomédica, 2014.

SIEGEL, E. et al. Digital mammography image quality: image display. Journal of the American College of Radiology: JACR, v. 3, n. 8, p. 615-27, 2006.

STRICKLAND, R. N. Wavelet transforms for detecting microcalcifications in mammograms. IEEE Trans. Med. Imaging, v. 2, n. 15, p. 218-229, 1996.

STROUSTRUP, B. The C++ Programming Language. 3. ed. [S.l.]: AddisonWesley Professional, 1997.

U. S. FOOD AND DRUG ADMINISTRATION. Summary and safety of Effectiveness Data: R2 Technologies. [S.1.]. 1998. (P970058).

U. S. FOOD AND DRUGS ADMINISTRATION. Sumary and safety of Effectiveness Data: CADx Medical Systems. [S.1.]. 2002. (P010034).

U. S. FOOD AND DRUGS ADMINISTRATION. Sumary and safety of Effectiveness Data: ISSI. [S.1.]. 2002. (P010038).

VYBORNY, C. J.; GIGER, M. L.; NISHIKAWA, R. M. Computer-aided detection and diagnosis of breast cancer. Radiologic Clinics of North America, v. 38, n. 4, p. 725-740, 2000.

WEI, L. et al. Relevance vector machine for automatic detection of clustered microcalcifications. IEEE Trans. Med. Imaging, v. 10, n. 24, p. 1278-1285, 2005.

WINSBERG, G. F. et al. Detection od radiographic abnormality in mammograms by means of optcal scanning and conputer analysis. Radiology, v. 89, p. 211-215, 1967.

YU, S.; GUAN, L. A CAD system for the automatic detection of clustered microcalcifications in digitized mammogram films. IEEE Trans. Med. Imaging, n. 19, p. 115-126, 2000. 
YU, S.-N.; LI, K.-Y.; HUANG, Y.-K. Detection of microcalcifications in digital mammograms using wavelet filter and Markov random field model. Comput. Med. Imaging Graphics, n. 30, p. 163-173, 2006. 